\title{
A REVIEW OF LIMNOCORIS STÅL (HETEROPTERA: NAUCORIDAE) IN SOUTHERN SOUTH AMERICA
}

\author{
EAST OF THE ANDES
}

\begin{abstract}
Nieser, N. \& M. Lopez-Ruf, 2001. A review of Limnocoris Stål (Heteroptera: Naucoridae) in southern South America east of the Andes. - Tijdschrift voor Entomologie 144: 261-328, figs. 1- 202. [ISSN 0040-7496]. Published 1 December 2001.

Revision of the species the genus Limnocoris Stål occurring in the area Southeast Bolivia, Southeast and South Brazil, Paraguay, Uruguay and Argentina with a key to the species occurring in this area. Ten new species are described: L. asper, L. caraceae, L. decarloi, L. espinolai, L. intermedius, L. lanemeloi, L. machrisi, L. porphyros, L. saphis and L. subpauper all from southern Brazil. Lectotypes are designated for four species: L. maculiceps Mont., L. ovatulus Mont., $L$. pectoralis Mont. and L. pusillus Mont.

The following synonymies are established, junior synonyms between brackets: L. borellii Mont. [L. manco-capasi Poiss., L. stali Mont.]; L. burmeisteri De C. [L. bachmanni De C.]; L. insignis Stål [ L. ubleri Mont., L. admontandoni La R.] L. nigropunctatus Mont. [L. sattleri La R.]; $L$. pauper Mont. [L. plaumanni La R.]; L. pusillus Mont. [L. mansosotoi De C., L. vianai De C.]. A checklist for the entire genus Limnocoris, with synonymies and location of holotypes has been added.

Dr. N. Nieser, Htg. Eduardstr. 16, 4001 RG, Tiel, The Netherlands. E-mail: iftang.01@ net.HCC.nl

Key words. - Naucoridae, Limnocoris, new species, new synonymies, lectotypes, Argentina, S. Brazil, key, checklist.
\end{abstract}

Spanish and Portuguese summaries on page 328.

Within the infraorder Nepomorpha (true aquatic bugs), the family Naucoridae contains the largest number of taxa which are adapted to living in running waters. Many of these are benthic and unable to fly. The majority of benthic species prefer small streams where they regularly appear to be (one of) the species at the top of the food chain in the benthic microhabitat (Sites \& Willig 1991). Thus, they are not only interesting for entomologists, but also for ecologists and environmentalists for evaluation of ecological conditions in streams.

The main adaptation of these forms is the development of efficient respiration which enables them to stay permanently submerged. This type of respiration was most intensively studied in the related family Aphelocheiridae (Thorpe \& Crisp 1947). They found a very dense layer of very short and fine hairs, called a plastron, which ensures a permanent film of gas on the ventral side and large parts of the dorsal side. In this thin layer gas exchange takes place. A simple experiment with Limnocoris maculiceps Montandon showed that they can stay submerged for a week or more (Nieser \& Lane de Melo 1997), which suggests that this genus might have plastron respiration too. However, so far no morphological study has been made to verify the existence of a plastron.

In South America the predominant genus of benthic Naucoridae is Limnocoris Stål (1860) which constitutes the monotypic subfamily Limnocorinae. An interesting second is Cryphocricos Signoret (1850) the type genus of the subfamily Cryphocricinae, which has some species living in conditions of very strong current, whereas several of the South American species of Ambrysus Stål (1862) the largest genus of the Cryphocricinae, which are also inhabitants of streams, are not really benthic (La Rivers \& Nieser 1972). Species of Ambrysus occur mainly in Mexico and the Southwest of the U.S.A. (La Rivers 1971). The Ambrysini (Cryphocricinae) of the area under consideration are treated by Nieser et al. (1999). Cryphocricos 
has been revised by Usinger (1947) and the Argentinean species by Lopez Ruf (1991). Both subfamilies are restricted to the Americas. Taking into account the proposed synonymies and descriptions of new species proposed in this paper, Limnocoris contains 71 species mainly occurring in South America and seems to be especially richly represented in Southeast Brazil and North Argentina although this may be partly due to higher intensity of collecting. The fauna of the Andes is probably quite rich too (Nieser et al. 1993, Sites in litt.) but consists mainly of different species. A few species such as $L$. borelli and $L$. pectoralis have a wide distribution in the eastern foothills of the Andes. The fauna of the Amazon Region and the Guyanas is comparatively poorer and has been summarized by Nieser (1975). De Carlo (1951) summarized the species of the southern part of South America essentially on the base of the collections of Museo Argentino de Ciencias Naturales. He overlooked a few species and a fair number have been described in subsequent publications. As the senior author encountered a number of new species and identification problems while studying the fauna of Minas Gerais and since the second author has been studying Naucoridae of Argentina for many years, we decided to join efforts and sort out the taxonomy of the genus Limnocoris in the area from the Brazilian states of Espírito Santo, Minas Gerais, Goiás and Mato Grosso south to Argentina. The choice of area is somewhat artificial but there was no material from Northeast Brazil and Bahia available, the Amazon-basin with the Guyanas has apparently a different fauna (De Carlo 1967, Nieser 1975).

\section{MATERIAL AND METHODS}

\section{Material}

Studies in this genus were prompted by fresh material collected in Minas Gerais in connection with the preparation of a guide to the water bugs of Minas Gerais and a box of specimens from Brazil obtained from F. Plaumann, Nova Teutonia, Santa Catarina, Brazil. Soon it became clear that a revision of the genus for the southern part of South America was needed.

\section{Measurements}

General. - Measurements are in $\mathrm{mm}$, when sufficient material is available, based on five specimens of each sex. In case of descriptions of new species the specimens measured are preferably taken from the sample containing the holotype. They are presented as the observed range with sample mean in italics, or as the mean value only. In new species the dimensions of the holotype are given in brackets after the range of specimens of the same sex, marked HT thus $\{\mathrm{HT} \# \#$. If only two specimens of a sex were available for measurements only the range is given. In this case an eventual holo- type is indicated as being the larger or smaller specimen. Length and width without specification refer to the maximum values of body length and width.

Larvae. - With larvae V, only the mean of measurements of five specimens (if available) is given. Mature instar V larvae can be kept quite well in dry condition glued on a card but the measurements of various dimensions will be slightly lower in dry specimens compared to alcohol specimens.

Head. - The head may be at an angle with the rest of the body. Measurements of the head were taken with the longitudinal axis of the head in a horizontal plane, which might, in some species, result in a different value of the length of the head when it is measured with the main longitudinal body axis in a horizontal plane. However, the combined length of head+pronotum was taken with the main longitudinal body axis horizontal so this measurement usually differs from the sum of the separate measurements of length of head and pronotum. Length of an eye is measured along its inner margin again with the axis of the head horizontal (fig. 3, le). The width of an eye is measured perpendicular to the inner margin of the eye (fig. 3, we).

Legs. - Length and width of anterior femur are measured according to fig. 4. The length of mesoand meta-tibia is without the terminal comb of spines.

In a few cases measurements are estimates based on a single damaged specimen, such estimates are presented between $<>$.

\section{Drawings}

Drawings were mostly made with a camera lucida on a stereo microscope, the pseudoparameres were in many cases made from temporary microscopic slides. Because the general form of the legs gave no clues to specific identification, they usually were omitted in the drawings of the general habitus.

\section{Synonymy}

The catalogue of the Naucoridae by La Rivers (1971, 1974, 1976) contains extensive synonymies and references. So in this paper only essential synonymies are given. In addition references published after the catalogue by La Rivers have been incorporated.

\section{Terminology}

The anterior width of vertex is the width between the eyes anteriorly in dorsal view (fig. 3, v); the synthlipsis is the shortest distance between the eyes posteriorly (fig. 3, s). The eyes have antero-laterally a chitinous extension, the hyperoche, its function is probably to prevent small grains of sand or silt from entering between head and anterior margin of pronotum. Although there some interspecific variation in the development of this structure exists, it does not 
seem to be useful for separating species. The anteclypeus is a sclerite forming the anterior part of the head, just posterior of the rostrum. It is not recognizable as a separate sclerite in Naucoridae. The extent of the frontal projection of the anteclypeus in front of the labrum is measured in ventral view: the distance between the suture between head and labrum and the anterior margin of the head. The gular carina is the median projection posteriorly on the ventral side of the head, just in front of the prothoracic carina.

The anterior width of pronotum is the width between anterolateral angles, roughly equal to width of head across eyes; lateral length of pronotum is measured from the anterolateral angle perpendicular to the hind margin of pronotum (fig. 3, 11). The scutellum is anteriorly demarcated by a transverse groove (in which the posterior margin of the pronotum rests), length of scutellum is measured from this groove to the tip. The claval commissure is the groove between hemielytra (when closed) from apex of scutellum to beginning of membrane (fig. 3, cc), the claval suture is the suture between clavus and corium (fig. 2, cs), it may be indistinct or absent in brachypterous specimens. There are essentially two types of reduction of the wings in brachypterous specimens. The first exhibits little reduction of the hemielytra except for the left membrane and (usually) the claval suture and has been designated the $L$. maculiceps-group. The second exhibits considerable reduction of the hemielytra and usually also dimorphy of the pronotum (figs. 1,2) and has been designated the L. insignis-group. These groups are based on a single characteristic and will be dissolved into smaller units when cladistic analysis is carried out.

The first abdominal segment is reduced and difficult to recognize, so the first visible fully developed abdominal segment is actually segment 2 (Sites 1991, Sites \& Nichols 1990). The term connexival segments without further specification refers to the connexiva of the unmodified segments, $2-5$ in males, $2-6$ in females. Thus the term last connexival segment refers to segment 5 in males and segment 6 in females. The lateral margins of connexiva are serrate, this has been represented in the drawings only when the serration is coarse. The ventral carinae are described relative to the surface of the venter, so strongly elevated means strongly projected ventrally. Sloping or slanting means showing an inclination towards the sternum. The gular carina is usually poorly developed, the metasternal carina is rather uniform, ventrally flat with an indistinct fossa, their form is mentioned only in descriptions and redescriptions when they show diagnostic features. The size of the metasternal carina relative to the width of the metaxiphus is usually given.

The mesosternal carina is, however, diagnostic. In order to give an accurate impression of its structure, we present Scanning Electronic Micrographs of a lateral and a ventral view of the mesosternal carina when sufficient material was available. Due to conditions of preservation the best view for a SEM may be from different angles, which explains the different orientation in the figs. 157-202.

The pilosity of the abdomen is rather uniform: in a few cases we have depicted it on the genital segments to give an impression of its appearance, but because it does not provide diagnostic characteristics, it has been usually left out in the drawings.

The male abdominal apex is modified and very diagnostic. Drawings in dorsal view of tergites 6-8 are presented. The right lobe of tergite 6 bears medially a variable basal projection, which we term proximal projection (fig. 5 pp). Tergite 7 is somewhat reduced, the relative width of the lateral lobes is different in some related species. Tergite 8 is divided into two lobes which bear medio-basally a small flap, named secondary clasper by Nieser (1975), however, here, we adopt the name pseudoparamere (fig. 5, ps). The pseudoparameres are usually not diagnostic at the species level but might be so at the species-group level. They have been drawn in dorsal view with the corresponding tergite lobe horizontally, unless otherwise indicated. The aedeagus (fig. 5, a, fig. 6) and parameres (fig. 5, p) are very uniform and of little use in the taxonomy of this genus.

Polhemus (1994) noted a stridulatory device in both sexes consisting of a short ridge or carina apically on the dorsal surface of the hind femur (fig. 4a). This ridge is rubbed against the margin of ventrites 2 and or 3 which have a sharp edge. As this stridulatory device has apparently no diagnostic value at the species level it has been ignored in the (re)descriptions.

Larva $\mathrm{V}$ is recognizable by the anterior wing pads which, reach the abdominal base and cover the lateral part of the metanotum entirely (figs. 47, 123). In larvae IV and earlier instars, most of the lateral margin of metanotum is exposed. In all species for which larvae $\mathrm{V}$ were available, the pronotum has the posterolateral angles acute and level with the posterior margin of the pronotum.

\section{Abbreviations}

Standard abbreviations for the states of Brazil have been used: AM Amazonas, GO Goiás, MG Minas Gerais, MT Mato Grosso, PA Pará, PR Paraná, RS Rio Grande do Sul, RJ Rio de Janeiro, SC Santa Catarina, SP São Paulo. Other abbreviations used are: AT allotype, HT holotype, LT lectotype, ST, syntype(s); brach. brachypterous, macr. macropterous, Syn. n., new synonymy. 

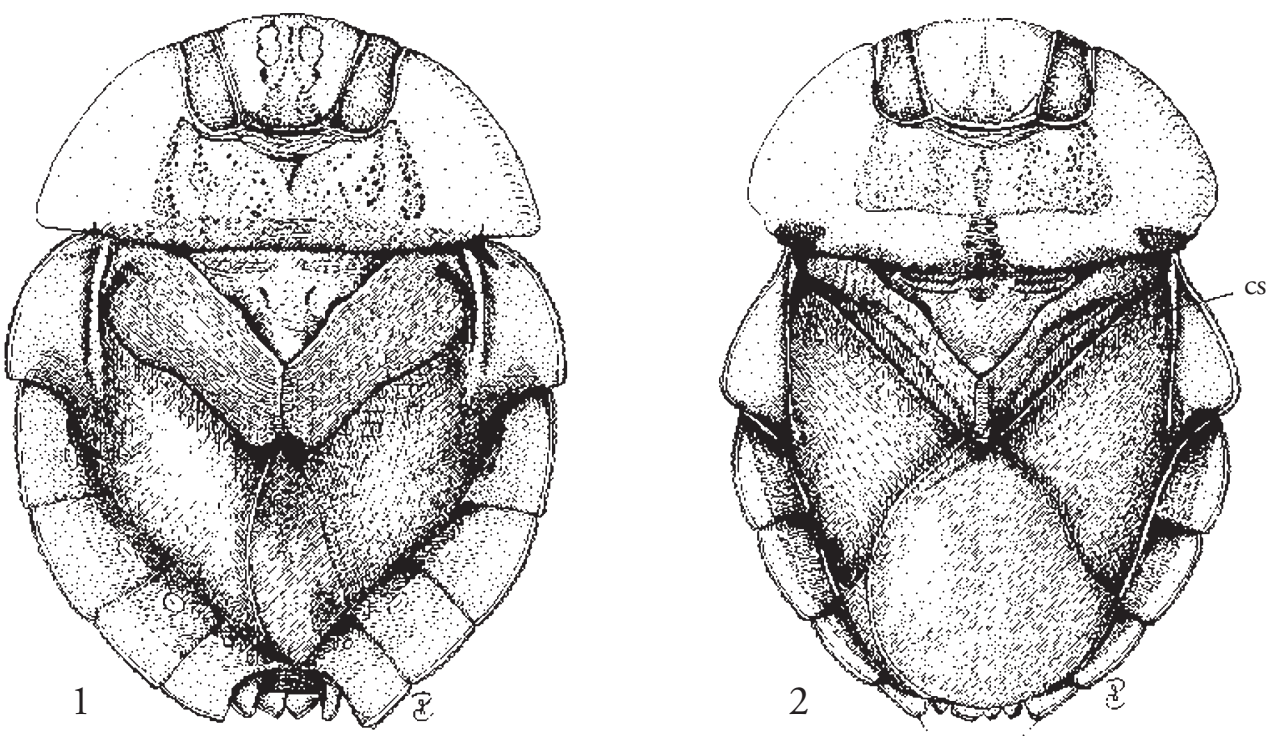

Figs. 1-2. Limnocoris submontandoni habitus. - 1, brachypterous female; 2 , macropterous female, body length $9.4 \mathrm{~mm}$. cs = claval suture.

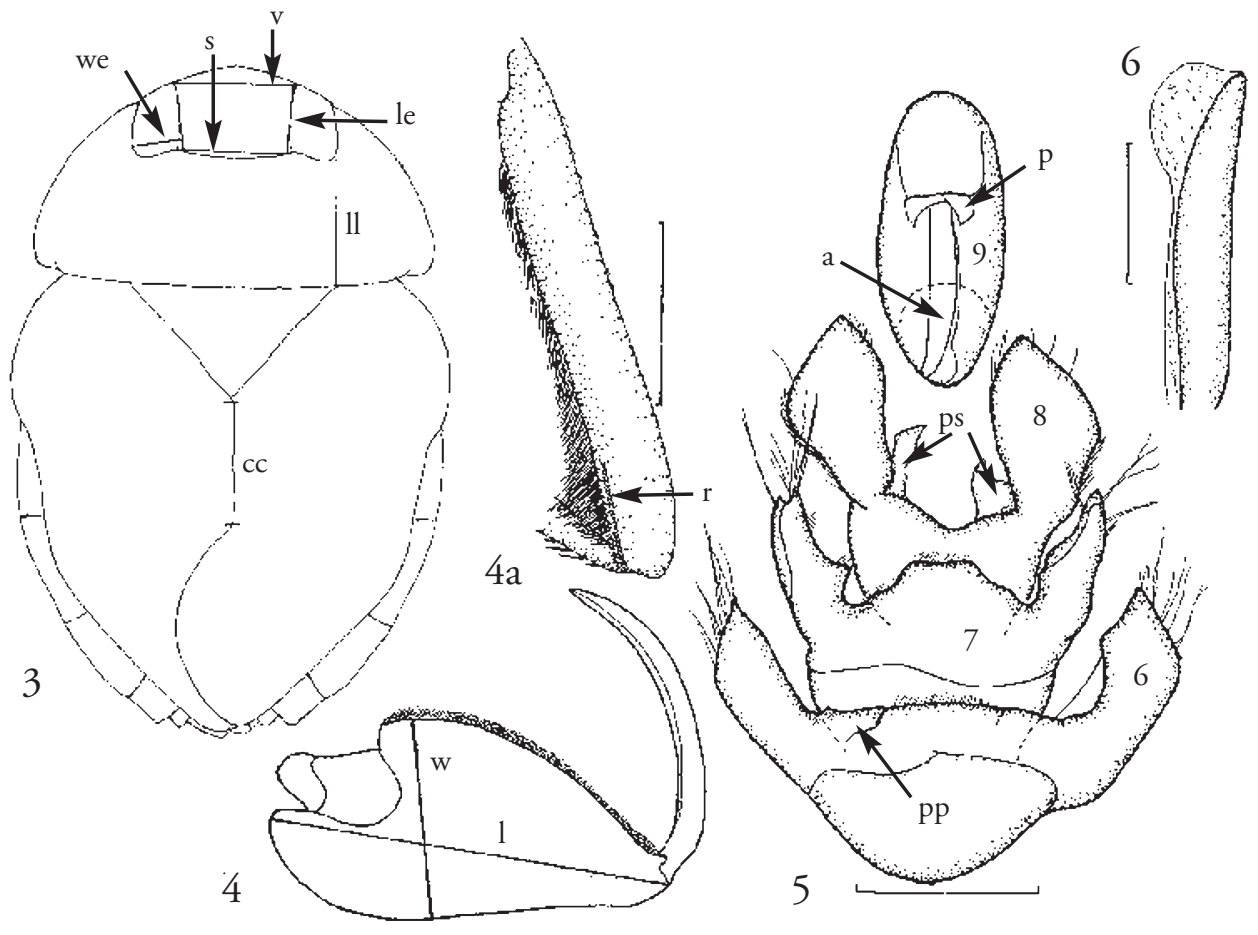

Figs. 3-6. Limnocoris morphology. - 3, Outline of Limnocoris sp. showing various measurements and structures. $\mathrm{cc}=\mathrm{claval}$ commissure, le = length of eye, 11 = lateral length of pronotum, $s=$ synthlipsis, $\mathrm{v}=$ anterior width of vertex, we = width of eye; 4, Outline of fore leg of $L$. sp. showing measurement of length (l) and width (w); 4a. Hind tibia of L. maculiceps, dorsal view. $\mathrm{r}=$ stridulatory ridge. Scale $1 \mathrm{~mm} ; 5$, L. maculiceps male, apex of abdomen with segments expanded and genital capsule, dorsal view. 6-8 = tergites $6-8,9=$ segment 9 or genital capsule, $\mathrm{a}=$ aedeagus, $\mathrm{p}=$ paramere, $\mathrm{pp}=$ proximal projection, $\mathrm{ps}=$ pseudoparamere. Scale $1 \mathrm{~mm}$; 6, Apical part of aedeagus of L. maculiceps. Scale $0.5 \mathrm{~mm}$. 


\section{Depositories}

Mentioned in Arnett et al. (1993, more precise addresses of the collections and some abbreviations occurring only in the checklist can be found in this book): BMNH (British Museum of Natural History, London, England); CASC (California Academy of Sciences, San Francisco, U.S.A.); DPIC (Departamento de Parasitologia, Instituto de Ciencias Biologicas, Belo Horizonte, MG, Brazil); DZUP (Museu de Entomologia, Dept. de Zoologia, UFPR, Curitiba, Paraná, Brazil); JTPC (J. T. Polhemus Collection, Englewood Colorado); MACN (Museo de Ciencias Naturales, Buenos Aires, Argentina); MLPA (Museo de la Plata, La Plata, Argentina); MNHN (Musée National d'Histoire Naturelle, Paris, France); NHMW (Naturhistorisches Museum, Wien, Austria); RMNH (Nationaal Natuurhistorisch Museum, Naturalis, Leiden, The Netherlands); SEMC (Snow Entomological Collection, Lawrence, Kansas, USA); USNM (Smithsonian Institution, United States National Museum, Washington, USA); ZMAN (Zoölogisch Museum, Universiteit van Amsterdam, Amsterdam, The Netherlands); ZMHв (Zoologisches Museum der Humboldt Universität, Berlin, Germany); ZSMC (Zoologische Staatssammlung, München, Germany).

Not mentioned in Arnett et al (1993): LCPU (Lutz Collection, Philadelphia, PA., U.S.A.) NCTN (Nieser Collection, Tiel, The Netherlands); PCMG (A. Pelli Collection, Uberaba, MG, Brazil); UMUN (Universiteits Museum, Heidelberglaan 8, Utrecht, The Netherlands).

\section{ACKNOWLEDGEMENTS}

This work was supported by a grant from the Uyttenboogaart-Eliasen Stichting for the promotion of entomological research (Amsterdam, Netherlands) to the senior author. Dr. P. P. Chen prepared most of the habitus drawings. In addition, thanks are due to Dr. A. Lane de Melo of DPIC and Dr. A. Pelli and colleagues of CEMIG for logistical support during collecting trips in Minas Gerais and Dr. A. O. Bachmann of MACN for help during a visit to the Museum. In addition the following persons helped with loans of material in their care: Dr. R. W. Brooks (SEMC, Lawrence, Kansas, U.S.A.); Dr. E. G. Burmeister (ZSMC), Dr. J. Deckert (ZMHB, Berlin, Germany); Dr. E. Guilbert (MNHN) Dr. S. Malkowski (DZUP); Dr. N. Penny \& Mr. K. Ribardo (CASC); Dr. D. A. Polhemus (USNM); Dr. J. T. Polhemus (JTPC) Dr. M. Webb (BMNH); Dr. H. Zettel (NHMW).

Finally Dr. R. W. Sites (University of Missouri) and Dr. E. J. van Nieukerken (RMNH) gave extensive commentaries on an earlier draft of the manuscript, contributing considerably to its improvement.

\section{SystematiCS}

The genus Limnocoris was erected by Stål (1860) based on L. insignis Stål from Rio de Janeiro. One year later he erected a closely related genus Borborocoris Stål (1861) based on the Venezuelan species $B$. pallescens Stål. Montandon (1897) in the first revision of the genus pointed out that these genera were inseparable when more species were taken into account and synonymized Borborocoris with Limnocoris, which also has been the opinion of subsequent workers. La Rivers (1950) erected the genus Usingerina on an aberrant limnocorid living in warm springs in Nevada (U. S. A.), U. moapensis La Rivers. De Carlo (1951) correctly pointed out that Usingerina was not more than an aberrant Limnocoris. This synonymy was formalized by Sites and Willig (1994). However, 15 years later De Carlo erected the genus Sattleriella (De Carlo 1966) on the species S. siolii De Carlo, which in our opinion, already expressed earlier (Nieser 1975), is simply a Limnocoris with more strongly reduced hemielytra. We propose the synonymy of Sattleriella as a junior synonym of Limnocoris. Taking into account the synonymies proposed and new species described in this paper, the subfamily Limnocorinae Stål (1876) contains only one genus Limnocoris Stål with 71 species and one subspecies endemic to the Americas.

\section{Limnocoris Stål}

Limnocoris Stål, 1860: 83.

Borborocoris Stål, 1861: 202 (synonymized by Montandon 1897).

Usingerina La Rivers, 1950: 368 (synonymized by Sites and Willig 1994).

Sattleriella De Carlo, 1966: 111. Syn. n.

\section{Diagnosis}

The genus Limnocoris is, within the American fauna, recognized by the eyes which are diverging anteriorly (figs. 1-2), whereas in other genera they are parallel or converging anteriorly.

\section{Redescription}

Small to medium sized Naucoridae. Body strongly flattened, broadly oval to nearly circular, many species with pronounced brachypterism. Dorsum covered with fine granulations, set in irregular punctation, most distinctly on scutellum and hemielytra. Head embraced by pronotum up to the anterolateral angles of the eyes. Anteclypeus projecting anteriorly of labrum to a variable extent, labrum covered with short appressed somewhat scale-like bristles. Head anterolaterally of eyes produced forming the hyperoche (La Rivers 1973). Eyes diverging anteriorly. 
Pronotum not incised behind the synthlipsis. Scutellum anteriorly with a transverse groove, the basal width of scutellum is measured over this groove which tends to project slightly anteriad centrally. Posterior embolar suture (nodal furrow) absent in brachypterous specimens. Claval suture usually absent in brachypterous specimens, sometimes indicated. Right membrane coriaceous but thinner and more flexible than corium; true membranal sutures absent but due to difference in texture or colour the membrane may be well delimited from corium. Lateral margins of pronotum, embolium and connexiva serrate, best visible in ventral view. Gula and thoracic venter with well developed carinae especially on proand meso- sternum. Meso- and meta- sternal carina ventrally with a groove (fossa). Propleurae separated by the prosternal carina. Abdominal venter covered with thick pilosity with on sternite 2 one and sternites 3-5 two small holes in the pilosity on each side. Fore femur strongly swollen, fore tibia, tarsus and claw fused to a single elongate hook. Middle and hind tibiae with a distal comb of peg-like bristles, middle tibia with a second smaller one proximally of the distal. Middle femur and hind leg with a fringe of long hairs.

\section{Key to species}

Based on adults and in dimorphic species on brachypterous specimens.

1. Hemielytra short, not reaching abdominal tergite IV (3rd visible), length $8 \mathrm{~mm}$ (fig. 102).... L. siolii

- Hemielytra reaching at least abdominal tergite V

2. Hemielytra posteriorly of embolium curving considerably inward, exposing a broad lateral connexival margin, in brachypterous specimens 0.10 or more of the maximal width of abdomen (across abdominal dorsum, not across embolia) uncovered, in macropterous specimens the exposed margin may be somewhat less than 0.10 of abdominal width (L. insignis-group) ....................... 3

- Hemielytra leaving a much narrower strip of connexiva exposed, 0.08 or less of the maximal width of abdomen across connexiva ( $L$. maculicepsgroup).

3. Large species, length $9.2 \mathrm{~mm}$ or more, maximum width $6.9 \mathrm{~mm}$ or more.

- Smaller species, length $9.1 \mathrm{~mm}$ or less, width 6.7 $\mathrm{mm}$ or less .......................................................... 5

4. Anteclypeus projecting $0.4 \mathrm{~mm}$ anteriorly of labrum; labrum relatively small, its basal width/median length as $0.45 / 0.35 \mathrm{~mm}$................ L. abbreviatus

- Anteclypeal projecting $0.2 \mathrm{~mm}$ or less; labrum larger, its basal width/median length as $0.6 / 0.5$ $\mathrm{mm}$ L. intermedius

5. Lateral margin of embolium in anterior half straight, strongly diverging posteriorly, embolium triangular with tip pointing outward (fig. 21), rather small species, length $7.4 \mathrm{~mm}$ .L. acutalis

- Lateral margin of embolium in anterior half convex, embolium not triangular.

6. Greatest width of pronotum in brachypterous form well anterior of its posterior margin, lateral margin of pronotum broadly rounded, lateral angle ill defined (fig. 103).

- Greatest width of pronotum in brachypterous form near the posterior margin of pronotum, lateral margin of pronotum with a more or less acute, well defined posterolateral angle (figs. 1, 45).

7. A medium brown species, dark pattern on interoculus reduced, consisting of some rows of points, length $7.2-7.6 \mathrm{~mm}$, width $5.0-5.4 \mathrm{~mm}$ (fig. 103) L. asper

- Dark brown species with a purplish hue, interocular pattern well developed (figs. 123, 143), length 7.6-8.6 mm, width 5.6-6.0 mm .............8

8. Interocular pattern usually softly constricted halfway (fig. 143), length 7.6-8.4 mm, width 5.7$5.9 \mathrm{~mm}$. L. porphyros

- Interocular pattern sharply constricted halfway, anterior part in form of an arrow-head (fig. 123), length 8.2-8.6 mm, width 5.9-6.4 mm

L. espinolai

9. Small species, length $8.1 \mathrm{~mm}$ or less, maximal width of pronotum 3.5 times its median length, posterolateral angles moderately sharp (fig. 45) to sharp...................................................... insignis

- Larger species, length over $8.1 \mathrm{~mm}$, shape of pronotum variable ............................................10

10. Hind margin of embolium nearly perpendicular to body axis (fig. 1); ratio anterior width of vertex/synthlipsis 1.48 (1.97/1.31); ratio body length to width 1.28 (8.7/6.8); mesosternal fossa elongate ...................................... submontandoni

- Hind margin of embolium pointing obliquely posteriad in relation to median body axis (figs. $68,141)$ .11

11. Ratio of width of pronotum/median length of head+pronotum in brachypterous form 2.00 or slightly more ...................................................12

- Ratio of width of pronotum/median length of head+pronotum slightly to distinctly less than 2.00 (1.97 or less) .13

12. Mesosternal carina with a distinct anterior tooth (fig. 131), posterolateral angles of pronotum relatively acute (fig. 141), female operculum posteriorly narrowly rounded (fig. 133) ....... L. lanemeloi

- Mesosternal carina virtually without anterior 
tooth (fig. 163), posterolateral angles of pronotum rounded (fig. 104), female operculum broadly rounded posteriorly (fig. 110)

L. caraceae

13. Posterolateral angle of embolium relatively acute, well defined (fig. 68) L. nigropunctatus

- Posterolateral angle of embolium broadly rounded, ill defined (figs. 101, 122) .......................14

14. Right membrane broadly rounded, its length over one third the total length of the hemielytron ..... L. rotundatus

- Right membrane narrowly rounded, small, its length about one sixth the total length of the hemielytron . L. decarloi

15. Large and broad species, length over $10 \mathrm{~mm}$, width over $8 \mathrm{~mm}$. L. borellii

- Smaller species, if length reaches over $10 \mathrm{~mm}$ then width not over $7.1 \mathrm{~mm}$..........................16

16. Small species length $6.5 \mathrm{~mm}$ or less.................17

- Length over $6.5 \mathrm{~mm}$ 18

17. Length under $5.5 \mathrm{~mm}$, fossa of mesosternal carina continuing as a narrow groove downward on anterior side of central part (figs. 169, 170) .....

L. illiesi

- Length 5.5-6.5 mm, mesosternal carina without a narrow groove on anterior face of central body, anteriorly with a deep indentation covered by hairs and two teeth in front of the indentation (figs. 193, 194) L. pusillus

18. Length 6.5-7.1 $\mathrm{mm}$. 19

- Length $7.3 \mathrm{~mm}$ or more.. 20

19. Hemielytra solid dark with a purple hue, central disk of pronotum solid dark, sharply contrasting with the yellow lateral parts (fig. 144); fossa of mesosternal carina small and narrow, extending about one sixth the total length of the carina (figs. 197, 198) L. saphis

- Colour pattern rather uniformly brownish yellow; fossa of mesosternal carina well developed and extending about one third or more the total length of the carina (figs. 181, 182)....L. minutus

20. Length 10.3-11.2 mm; males with a large sharply contrasting black spot ventrally on anterior femur, usually occupying most of its surface (fig. 34). L. brasiliensis

- Length $10.1 \mathrm{~mm}$ or less; males without distinct black spot on ventral face of fore femur... 21

21. Central part of mesosternal carina thin walled due to a very wide and very deep (reaching nearly to the level of the mesosternum) fossa (fig. 189, 190); length $9-10 \mathrm{~mm}$....................... pectoralis

- Central part of mesosternal carina more solid, fossa distinctly less deep; length 7.3-10.1 mm.22

22. Length 7.3-7.5 mm, width 4.9-5.0 $\mathrm{mm}$, ratio length/width 1.49-1.50; serration of connexiva coarse $(20$ teeth $/ \mathrm{mm})$
- Length 8.2-10.1 mm; serration of connexiva distinct but not coarse $(25$ teeth/mm) or, if coarse, then ratio length/width 1.42 or less................23

23. Elongate species, length 8.2-10.1 mm, width 5.5$6.7 \mathrm{~mm}$, ratio length/width $1.43-1.55$; serration of connexiva distinct but not coarse (25 teeth $/ \mathrm{mm}$ ).

- Broadly oval species, length 8.3-9.4 mm, width 6.3-6.6, ratio length/width $1.31-1.42$, but nearly always under 1.40 ; serration of connexiva coarse (17-18 teeth/mm)

. .27

24. Posterolateral angles of connexiva prominent, spinose (fig. 69) ............................... ovatulus

- Posterolateral angles of connexiva rounded, not prominent, non-spinose..............................25

25. Larger species, length over $8.9 \mathrm{~mm}$, mesosternal carina variable .26

- Smaller species, length $8.2 \mathrm{~mm}$ or less, central part of mesosternal carina small (figs. 201, 202), see comparative notes ..................... subpauper

26. Central part of the mesosternal carina small, about one third the total length of the carina (figs. 187, 188) ................................... pauper

- Central part of the mesosternal carina large, slightly over one half the total length of the carina (figs. 179, 180) ........................ melloleitao

27. Labrum with concave lateral margins (fig. 14), see comparative notes ................... . aculabrum

- Labrum with straight lateral margins (fig. 51) ..... L. maculiceps

\section{Limnocoris abbreviatus La Rivers}

(figs. 7-11, 20)

Limnocoris abbreviatus La Rivers, 1974: 5-6. Holotype, brachypterous ô, BRAZIL: SC, Corupa (Hansa Humboldt), V.1940, coll. A. Maller, Frank Johnson donor (CASC) [examined].

Limnocoris montandoni La Rivers, 1974: 9. Holotype brachypterous + , BRAzIL: RJ, Theresopolis, Jul. Michaelis (ZMHB) [examined] Syn. n.

Material examined. - Holotypes (see above). L. montandoni, same data as holotype, 30 brach. (including allotype), 1 o macr. paratypes, in addition $5 \mathrm{lvV}$ (ZMHB).

Remark: The label on the holotype of $L$. abbreviatus is different from the locality and collector cited by La Rivers (1974) in the description.

\section{Redescription}

Brachypterous form. - Generally a large elongate oval species (fig. 20). Dimensions: length ô 9.2-9.610.1 우 10.3 , width of 6.9-7.2-7.5 $\$ 7.7$, anterior width of vertex $\delta 1.95-2.10-2.29+2.22$, width of pronotum of 6.32-6.59-6.81 +7.12 , median length pronotum ot 1.68-1.69-1.70 +1.70 , lateral length of pronotum ơ 2.79-2.87-2.93 +2.92 , median length 

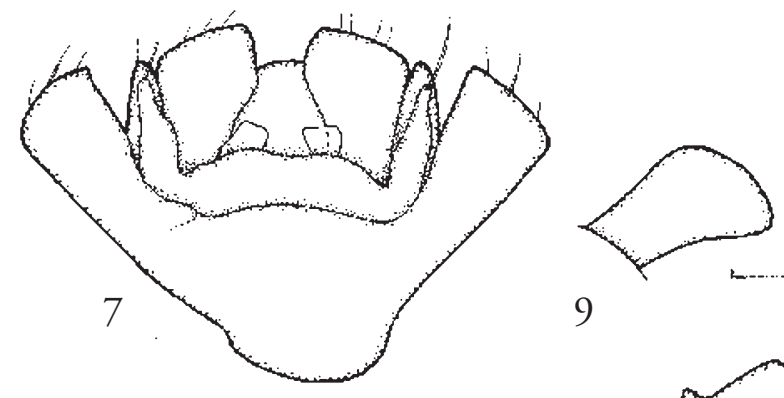

9

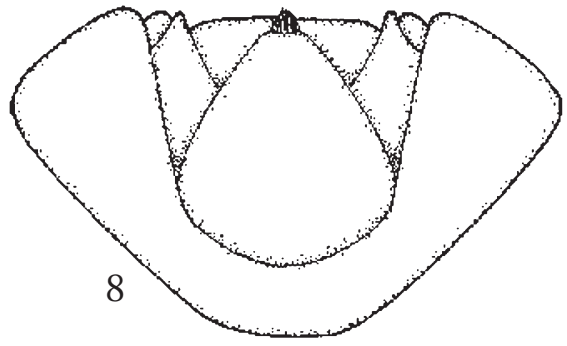

of head+pronotum ot 3.23-3.34-3.52 9.41 .

Colour. - Quite uniformly brownish yellow with scattered brown dots, eyes light grey brown, interocular dots arranged in a pattern, semicircular posteriorly, extending anteriorly in a narrow band but in several species indistinct to virtually absent. Connexiva with vague darker marks at sutures. Venter medially with a greyish tinge.

Structural characteristics. - Anterior margin of head (including eyes) very slightly protruding relative to the curvature of pronotum. Anterior width of vertex 1.5 times the synthlipsis (2.29/1.55), head longer than median length of pronotum (2.01/1.70), length of an eye over twice its width (1.48/0.62). Anteclypeus projecting 0.4-0.5 anteriorly of labrum. Labrum small, with slightly apically convergent sides in basal part, apical half broadly rounded, basal width larger than median length $(0.5 / 0.4)$. Pronotum posterolaterally acutely rounded, angles well defined, 0.1-0.3 anteriorly of posterior margin, maximal width distinctly more than twice anterior width $(6.72 / 3.10)$ and 2.3 times the lateral length (6.72/2.93), lateral margin nearly straight in posterior half, weakly serrate ventrally, about 30 teeth $/ \mathrm{mm}$. Scutellum over twice as wide at base than its median length (3.20/1.45) and 1.3 times as long as claval commissure (1.45/1.10). Granulations on dorsum of body numerous but very fine and little pronounced except along the margins of hemielytra, apparently lying on top of the surface. Hemielytra leaving a broad (0.8-1.2) strip of abdomen exposed, embolium convex, posteriorly strongly curving inward, posterolateral angles obtuse but well defined; lateral margin weakly serrate (posteriorly more distinctly than anteri-
Figs. 7-11.

Limnocoris abbreviatus. - 7 , apex of abdomen of male holotype, dorsal view; 8, female, apex of abdomen, ventral view; 9, apex of right pseudoparamere; 10, apex of left pseudoparamere; 11 mesosternal carina, upper: lateral view, lower: ventral view. Scales 7, 8, 10 11: $1 \mathrm{~mm}$; 9, 10: $0.25 \mathrm{~mm}$.

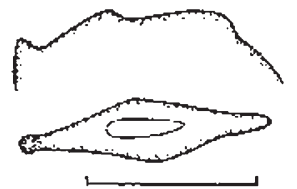

11

orly), about 30 teeth/mm, maximal width across embolium distinctly larger than maximal width across connexiva (7.35/7.02). Claval and membranal sutures absent, membranes moderately to strongly reduced, posteriorly broadly rounded to obtusely pointed, right membrane only slightly different in texture from corium, left membrane with medial band covered by right membrane brown to blackish. Connexival segments not or hardly (less than 0.05 deep) indented, posterolateral angle of last connexival segment bluntly rounded. Connexiva laterally indistinctly serrate, segment 4 with about 35 teeth $/ \mathrm{mm}$. Prosternal carina medium elevated, distinctly sloping posteriorly, anterior tip distinct. Mesosternal carina with a well elevated comparatively narrow central part with a distinct narrow but comparatively deep fossa (fig. 11), posterior part short, strongly sloping, anterior part with a small blunt tooth at anterior margin of fossa a well developed distinctly sloping part ending in a distinct blunt tooth. Metasternal carina small but comparatively well developed, a tubercle with a distinct ventral fossa, covering central quarter on metaxiphus. Fore femur twice as long as wide $(2.30 / 1.16)$. Middle femur nearly 5 times as long as wide $(2.41 / 0.50)$ and 1.4 times longer than middle tibia (2.41/1.72). Hind femur 6.8 times as long as wide $(3.42 / 0.50)$ and as long as hind tibia (3.42/3.42).

Male. - Apex of abdomen as in fig. 7, proximal projection of right lobe of tergite 6 forming a poorly defined tooth at base. Pseudoparameres wide apically (fig. 9, 10).

Female. - Genital operculum posteriorly truncate, slightly indented (fig. 8).

Macropterous form. - In most respects except for 


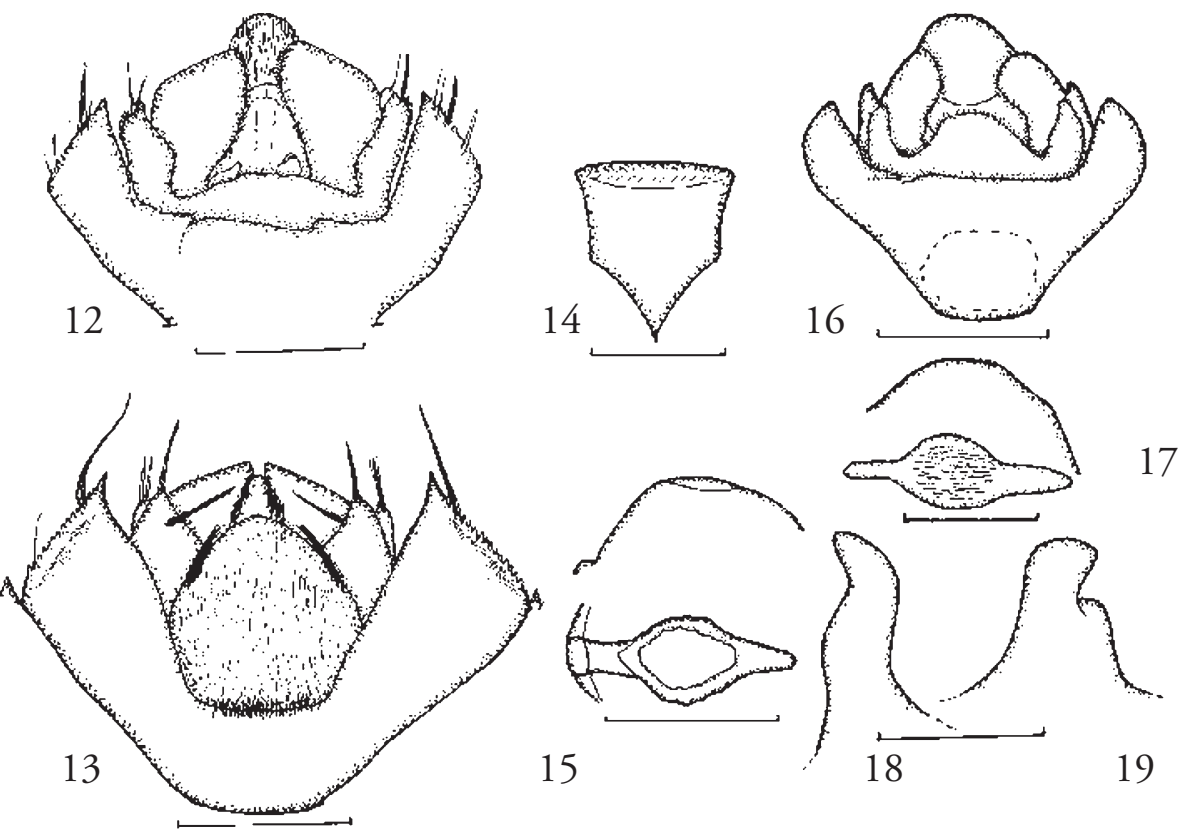

Figs. 12-15. Limnocoris aculabrum. - 12, apex of abdomen of allotype male, dorsal view; 13, apex of abdomen of paratype female, ventral view; 14, labrum; 15, mesosternal carina, upper lateral, lower ventral view. Scales 12, 13, 15: $1 \mathrm{~mm} ; 14: 0.5 \mathrm{~mm}$. Figs. 16-19. Limnocoris acutalis holotype male. - 16, apex of abdomen, dorsal view; 17, mesosternal carina, upper lateral view, lower ventral view; 18, right pseudoparamere; 19, left pseudoparamere. Scales 16: $1 \mathrm{~mm}, 17: 0.5 \mathrm{~mm}, 18,19: 0.25 \mathrm{~mm}$.

development of pronotum and wings as brachypterous form. - Dimensions: length 9.95, width 7.0, anterior width of vertex 1.97, width of pronotum 6.29, median length pronotum 1.90, lateral length of pronotum 3.10, median length of head+pronotum 2.56. Anterior width of vertex 1.3 times the synthlipsis (1.97/1.48), length of head less than median length of pronotum (1.76/1.90). Pronotum posterolaterally rounded, angles ill defined, about 0.9 anteriorly of posterior margin, maximal width 2.1 times the lateral length (6.29/3.01). Scutellum over twice as long as claval commissure (1.55/0.70). Hemielytra leaving a strip of connexiva exposed (the hemielytra are not closed and somewhat deformed, an estimate of the width of the exposed strip is 0.6). Claval suture well developed, right membranal suture absent, membrane membranaceous, broadly rounded, covering left membrane. Left membrane membranaceous, brownish opaque, broadly rounded, membranal suture present. Hind wings fully developed, brownish opaque. Dorsum of abdomen velvety yellowish to orange. Hind tibia longer than hind femur (3.73/3.43).

Larva V. - Dimensions: length 8.8, width 6.9, anterior width of vertex 1.80 , width of pronotum 6.12 , median length pronotum 1.12, lateral length of pronotum 2.34, median length of head+pronotum
2.67. Colour light brown with few, usually little contrasting darker brown dots. Eyes grey, abdomen dorsally and in some specimens exposed part of metanotum and pronotal disk with a reddish tinge. Lateral margin of connexiva serrate with about 37 teeth $/ \mathrm{mm}$. Central part of mesosternal carina strongly elevated, without fossa.

\section{Distribution}

Brazil: RJ, SC.

\section{Comparative notes}

L. submontandoni and other species of the L. insignis-group with similar hemielytral reduction are smaller and have less clypeal overhang.

\section{Limnocoris aculabrum La Rivers}

(figs. 12-15)

Limnocoris aculabrum La Rivers, 1973: 1-4.

Material examined. - BRAZIL: SC, Nova Teutônia, 1.IV. 1935, leg. F. Plaumann, 1 ô (allotype) 2 ㅇ brach., 1 ô macr. paratypes (CASC). BRAZIL, SC, Nova Teutônia, Passo dos Indios, $27^{\circ} 07^{\prime} \mathrm{W}, 52^{\circ} 36$ 'S, 16.XII.1935, leg. F. Plaumann, 1 우 brach. (JTPC). 

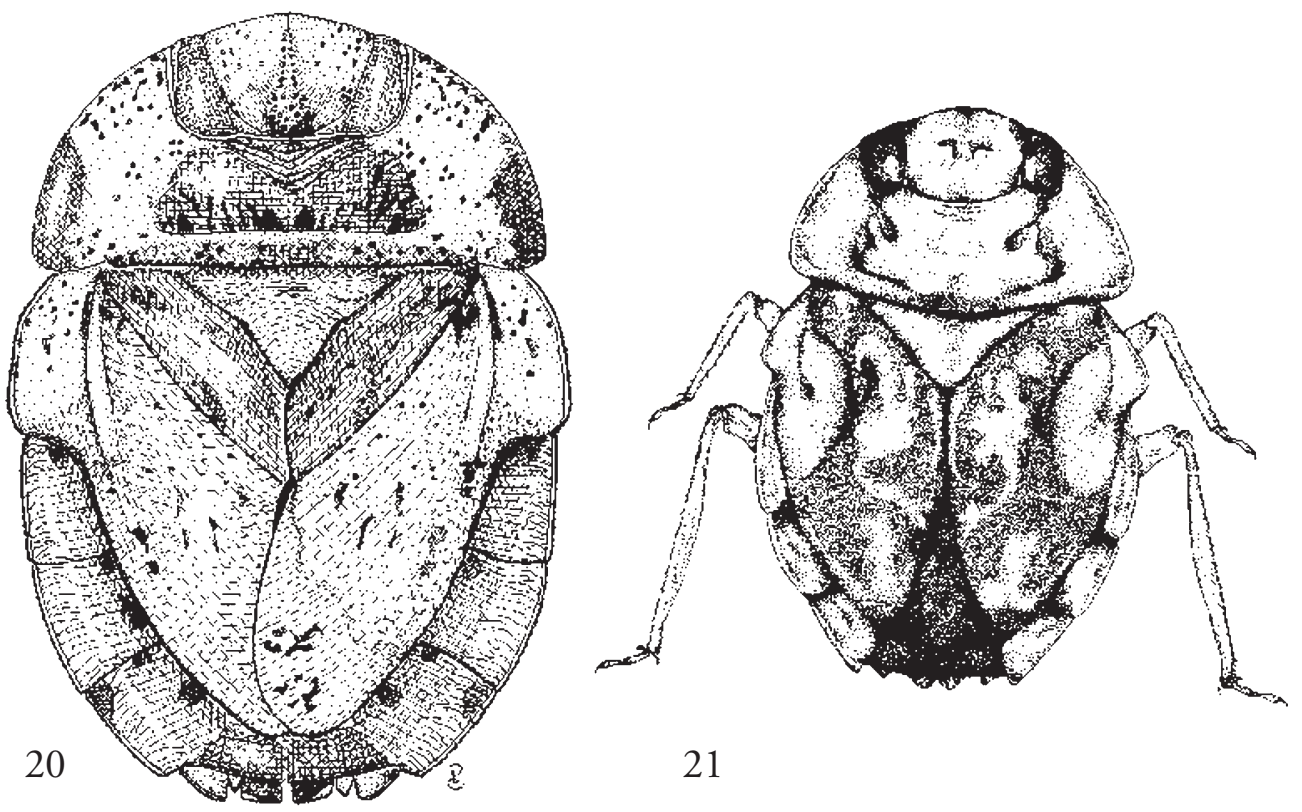

21
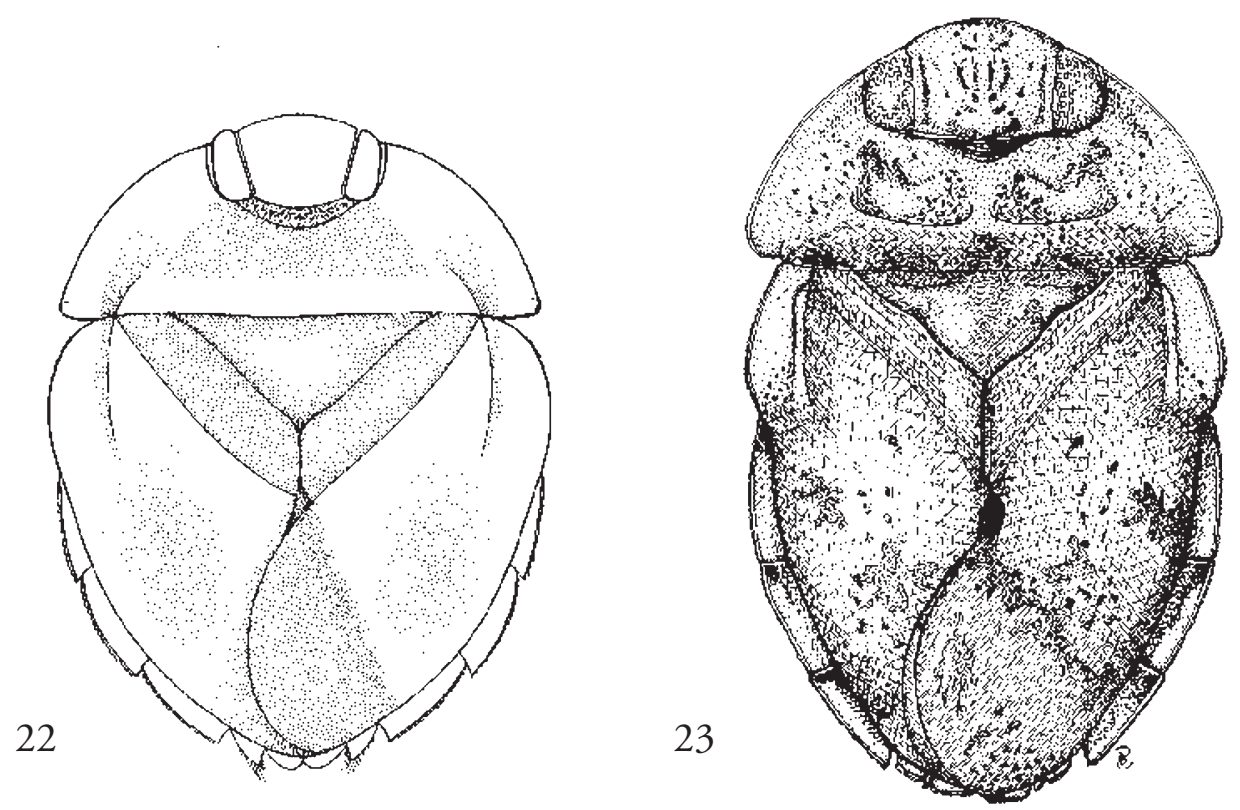

Figs. 20-23. Habitus of Limnocoris. - 20, L. abbreviatus holotype brachypterous male, body length 10.1 mm; 21, L. acutalis holotype brachypterous male, body length $7.4 \mathrm{~mm}$ (from La Rivers 1974); fig. 22, L. borellii outline of body, brachypterous male, body length $11.5 \mathrm{~mm}$; fig. 23, L. brasiliensis brachypterous male, body length $10.6 \mathrm{~mm}$. 


\section{Redescription}

Brachypterous form (based on $102 q$ paratypes). - Generally a medium sized broadly oval medium brown species. Dimensions: length ot 8.9 क 8.9-9.0, width 06.36 \% $6.46-6.70$, anterior width of vertex of 1.75 ㅇ $1.70-1.75$, width of pronotum 0 \$ 5.30 우 5.33-5.39, median length pronotum o 1.67 o 1.70 1.75 , lateral length of pronotum 0 क 2.32 क 2.18 2.25 , median length of head+pronotum $₫ 2.95$, $q$ 2.90-2.97.

Colour. - Light to medium brown with extensive but not strongly contrasting darker mottling, specifically the interocular mark dissolved in small isolated dots, broad posteriorly, narrowing anteriorly, broad again halfway between eyes and narrowing anteriorly (fig. 46); eyes dark brownish-grey. Embolium and lateral areas of pronotum yellowish with a few indistinct brownish spots. Membrane concolorous with to somewhat more densely mottled than corium. Exposed part of connexival segments in dorsal view yellow with a dark patch in anterior half. Venter yellowish to light brownish, a pair of small dark patches anterolaterally on propleurae, connexival segments with dark patches anteriorly. Legs yellow.

Structural characteristics. - Anterior margin of vertex following the curvature of pronotum and eyes, not protruding. Head distinctly declining anteriorly, anterior width of vertex 1.3 times the synthlipsis $(1.73 / 1.38)$, length of head distinctly less than median length of pronotum (1.56/1.71), length of an eye slightly less than twice its width (1.28/0.68). Anteclypeus projecting 0.08 anteriorly of labrum. Labrum parallel-sided in basal part, apical half triangular with a very sharp tip, lateral margins concave (fig. 14), basal width slightly less than median length $(0.52 / 0.59)$. Pronotum posterolaterally rounded, angles hardly anterior of posterior margin (0.15-0.20), maximal width distinctly less than twice anterior width $(5.34 / 2.91)$ and 2.4 times the lateral length (5.34/2.25), lateral margin nearly straight in posterior half, weakly serrate ventrally, about 33 teeth $/ \mathrm{mm}$. Granulations on dorsum of body rather fine, lying on top of the surface. Scutellum distinctly over twice as wide at base than its median length (2.82/1.38) and much less than twice as long as claval commissure $(1.38 / 0.96)$. Hemielytra leaving only a narrow strip (0.3 of connexiva exposed. Embolium convex dorsally (see comparative notes), with lateral margins weakly curved, diverging posteriorly in anterior half, posteriorly smoothly sinuate, lateral margin serrate, approximately 25 teeth $/ \mathrm{mm}$. Maximal width across embolium larger than maximal width across connexiva $(6.51 / 6.11)$. Claval suture indistinctly indicated, right membranal suture absent, membrane coriaceous, broadly rounded, covering most of left membrane. Part of left membrane covered by right mem- brane, light brown, broadly rounded, membranal suture absent; the lateral exposed part 0.5 or less wide at base, coriaceous and concolorous with corium. Hind wings reduced. Connexival segments not indented, forming a smooth outer edge of abdomen, posterolateral angle of last connexival segment with a short spine. Connexiva laterally coarsely serrate, segment 4 with about 18 teeth $/ \mathrm{mm}$. Prosternal carina of average elevation, distinctly sloping posteriorly, the elevated part short bifid, gular carina with an acute tip which points further ventrad than the prosternal carina. Mesosternal carina with a well developed elevated central part with a distinct, broadly oval fossa (fig. 15), posterior part well developed, distinctly sloping, anterior part short and steep with a small tooth anteriorly. Metasternal carina distinctly elevated, a well developed tubercle with an indication of a ventral fossa covering about half the metaxiphus $(0.40 / 0.85)$. Fore femur 1.8 times as long as wide (1.90/1.06). Middle femur 6.2 times as long as wide (2.23/0.36) and 1.4 times longer than middle tibia (2.23/1.58). Hind femur 6.5 times as long as wide $(3.05 / 0.47)$ and about 1.1 times as long as hind tibia (3.05/2.85).

Male. - Genital segments as in fig. 12, right lobe of tergite 6 with a distinct proximal projection.

Female. - Genital operculum with distinct lateral tufts of bristles (fig. 13).

Macropterous form (1 teneral and shrivelled paratype $\widehat{\delta})$. - Very similar to brachypterous form, hind wings fully developed, opaque. Hemielytra with claval suture and nodal furrow well developed, right membrane only slightly larger compared to brachypterous form, left membrane distinctly more developed. Median length of scutellum twice the length of claval commissure (1.30/0.65); body length 8.1, width of 6.3 .

\section{Distribution}

Brazil: SC.

\section{Comparative notes}

$L$. aculabrum belongs to the $L$. maculiceps-group. Its general habitus and colour pattern are virtually identical with lightly pigmented specimens of $L . m a-$ culiceps, so much so that we refrained from figuring the habitus of L. aculabrum. Differences are found in the labrum which has distinctly concave sides in $L$. aculabrum (figs. 14, 51). The fossa on the mesosternal keel is wide with blunt anterior and posterior edges in L. aculabrum, in L. maculiceps it is usually narrow (fig. 178) but quite variable and in some specimens the fossa may be nearly as broad as in L. aculabrum but then the anterior and posterior edges are more acute. The metasternal carina of $L$. aculabrum is much more clearly developed and elevated and the edge of abdominal segment 6 more distinctly serrate than in $L$. 
maculiceps. The pronotum of L. aculabrum is relatively shorter, the ratio body length to lateral length of pronotum is 3.8-4.0 in L. aculabrum and 3.5-3.6 in L. maculiceps. Finally the hind femur is 1.07 times as long as the tibia in L. aculabrum, whereas in L. maculiceps, this ratio is 1.04. Several other ratios differ slightly, but are not diagnostic in small samples. La Rivers (1973) mentioned that the embolia are 'recurved or flared upward to the dorsal plane'. This means that the embolia in more mature specimens are somewhat convex dorsally (from the median suture curving slightly up and laterally curving down again). In the teneral specimens they do not curve down much laterally. This characteristic is shared with most specimens of $L$. maculiceps, and is not so striking as the original description of La Rivers might suggest.

\section{Limnocoris acutalis La Rivers}

(figs. 16-19, 21)

Limnocoris acutalis La Rivers, 1974: 6-7. Holotype brachypterous $\hat{\sigma}$, BRAZIL, leg. Osten-Sacken, (ZMHB) [examined].

Limnocoris acutalis; La Rivers 1976: 14, fig. 5.

\section{Material examined. - Holotype (see above).}

\section{Redescription}

Brachypterous form (based on the unique holotype §). - Generally a rather small, elongate oval, medium brown species (fig. 21). Dimensions: length 7.40, body width 4.98 , anterior width of vertex 1.48 , synthlipsis 1.32 , width of pronotum 4.40 , median length pronotum 1.32 , lateral length pronotum 1.98, median length of head+pronotum 2.58 .

Colour. - Dorsally medium brown with head, pronotum and scutellum somewhat lighter than hemielytra. Vague darker marks on head and pronotum apparently not formed by confluence of small dots. Eyes dark grey, interocular mark ill-defined, triangular pointing anteriorly. Disk of pronotum with indistinct central and a pair of lateral marks. Embolium and patch posteriorly of it lighter than remaining hemielytron, membranes torn off, exposed part of abdomen lighter than hemielytra. Exposed parts of connexiva light brown, indistinctly infuscated anteriorly. Venter orange-yellow, legs yellowish. Abdominal stigmata marked by a small round tuft of yellow hairs. Abdominal venter sparsely covered with shiny yellow hairs somewhat more dense along median line.

Structural characteristics. - Eyes distinctly elevated above head surface, anterior margin of head protruding relative to the curvature of pronotum and eyes. Anterior width of vertex 1.1 times the synthlipsis (1.48/1.32), head longer than median length of pronotum (1.50/1.32), length of an eye less than twice its width (0.94/0.53). Anteclypeus projecting 0.12 anteriorly of labrum, labrum slightly wider at base than its median length $(0.47 / 0.40)$, lateral margins of labrum in basal half slightly converging apically, apical half triangular with an obtuse point. Lateral margin of pronotum only slightly convex, pronotum together with head subtriangular. Posterolateral angles of pronotum rounded, posterior margin in middle five sixth distinctly posteriorly of level of lateral angles (0.2); maximal width less than twice anterior width (4.4/2.4) and 2.2 times the lateral length (4.4/2.0); lateral margin indistinctly serrate, about 32 teeth $/ \mathrm{mm}$. Dorsal granulations small, whitish, lying in small pits. Scutellum over twice as wide as long $(2.20 / 1.02)$ and only a little longer than length of claval commissure (1.02/0.91). Hemielytra leaving most of connexiva (a 0.7 wide strip) exposed. Embolium in the form of an outward pointing triangle (fig. 21), posteriorly curving strongly inward, lateral margin apparently not serrate; maximal width across embolium larger than maximal width across connexiva (4.98/4.88). Membranes torn off, distinctly thinner than corium and apparently broadly rounded. Hind wings strongly reduced. Dorsum of abdomen light brown, posterior margin dark. Connexival segments 3-6 slightly indented (0.05), distinctly serrate in ventral view, segment 4 with about 28 teeth $/ \mathrm{mm}$, posterolateral angle of segment 5 bluntly angulate. Prosternal carina slightly sloping, anteriorly with indistinct tip, closely pressed to the gular carina. Mesosternal carina damaged somewhat by pin (fig. 17) anteriorly strongly sloping with a blunt tooth at anterior edge, central part short, without fossa but covered with yellowish bristles, posterior part short, distinctly sloping. Metasternal carina poorly developed, a simple swelling covering central quarter of metaxiphus. Anterior femur 1.75 times as long as wide (1.98/1.08). Middle femur 4.3 times as long as wide $(1.95 / 0.45)$, both middle tibiae lacking. Hind femur 5.7 times as long as wide (2.58/0.45), shorter than the tibia $(2.58 / 2.81)$.

Male. - Proximal projection on right lobe of tergite 6 acute, appressed against the posterior margin of the tergite (fig. 16). Right pseudoparamere with narrow apex in dorsal view (fig. 18).

Female and macropterous form unknown.

\section{Distribution}

Brazil, only known by the unique holotype without more precise data.

\section{Comparative notes}

L. acutalis belongs to the L.insignis-group. Its rather small size in combination with the triangularly shaped embolia distinguish this species from all other species of Limnocoris. 

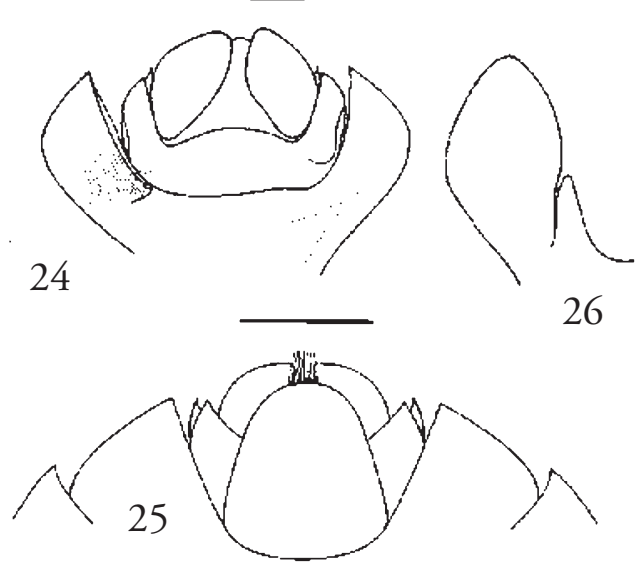

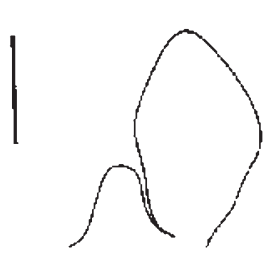

27
Figs. 24-28.

Limnocoris borellii - 24, male, apex of abdomen, dorsal view; 25, female, apex of abdomen, ventral view; 26, right lobe of segment 8 with pseudoparamere; 27 , left lobe of segment 8 with pseudoparamere; 28 , mesocarina of larva V. Scales 24, 25, 28: $1 \mathrm{~mm} ; 26,27: 0.5 \mathrm{~mm}$.
Limnocoris borellii Montandon (figs 22, 24-28, 159-160)

Limnocoris borellii Montandon, 1897: 3. Syntype: BOLIVIA: Caiza, A. Borelli col., Limnocoris borellii Montandon type 1897 with additional labels 'type' and Montandon coll. 1901-233 (BMNH). [examined]

Limnocoris stali Montandon, 1897: 4. Syn. n.

Limnocoris borellii; De Carlo 1951: 43.

Limnocoris stali; De Carlo 1951: 43.

Limnocoris manco-capaci Poisson, 1954: 75-76. Syn. n.

Material examined. - ARgENTINA: Province of Salta, Río Las Cañas, 45994, 1 ô 2 ㅇ 1lvV; Tartagal 7606, 1.III.1961, col. A.O Bachmann, 2 ơ; Santa María, Urundel, XII.1947, leg. Giai, 1 ô brach., 2 ô 1 ㅇ macr. 1lvV (MACN). - BOLIVIA: Sta. Cruz, leg. Steinbach 9ð 2q; Buena Vista, Ichilo,

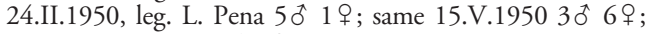
same 10.VIII.1950 4ô 1 웅 Bolivia 30.VI.1949, leg. L. Pena, $1 \mathrm{lvV}$ (SEMC). - PERU, in Rio Negro, 790m asl. 5.IX.1935, leg. F. Woytkowski, 1 o (det. J. T. Polhemus); same XI.1935, 1 ơ macr. (NCTN). Brachypterous unless otherwise indicated.

\section{Redescription}

Brachypterous form (based on dry pinned specimens). - Generally a large oval light brown species (fig. 22). Dimensions: length: of 10.8-11.7-12.2 우 12.4-12.8-13.3, width: of 8.20-8.66-8.95 क 9.319.45-9.77, anterior width of vertex: ot 1.92-2.192.41 1 1.90-2.23-2.50, width of pronotum: 0 7.658.24-8.68 $+9.68-8.79-8.95$, median length of pronotum: 0 1.76-1.90-2.03 $+1.91-2.05-2.17$, lateral length of pronotum: 0 3.02-3.23-3.39 +3.39 3.58-3.93, median length of head+pronotum to 3.39-3.63-3.80 क 3.52-3.13-3.93.

Colour. - Quite uniformly brownish yellow, with scattered diffused dark spots, eyes dark brown, head without interocular dots. Membrane and a lateral strip posteriorly of embolium infuscated. Connexiva with vague dark marks at sutures. Ventral pilosity golden brownish.

Structural characteristics. - Anterior margin of head (including eyes) slightly protruding relative to the curvature of pronotum, length of head: $\delta 1.90$ 우 2.09 . Anterior width of vertex 1.1 times the synthlipsis ( ô 1.92 \& $2.03 /$ o 1.65 ㅇ 1.71 ), length of head approximately the same as median length of pronotum (o 1.90 ㅇ 2.09/ क 1.92 o 2.17). Length of an eye over twice its width ( 0 \% $q 1.65 /$ to $q$ 0.67). Anteclypeus projecting 0.31 anteriorly of labrum. Labrum small with slightly apically convergent sides in basal part, apical half triangular with a sharp point; basal width only slightly larger than median length ( 0 0.54 o $0.65 /$ o 0.59 q 0.70 ).

Pronotum posterolaterally acute, angles defined about 0.13 behind of posterior margin, maximal width over two and a half times anterior width (8.59/3.21) and 2.5 times the lateral length (8.59/3.38), lateral margin slightly convex, weakly serrate ventrally, about 20 teeth $/ \mathrm{mm}$. Scutellum 2.3 times as wide at base than its median length ( $\delta$ 4.52/1.97) and 1.3 times as long as claval commissure (1.97/1.53). Granulations on hemielytra fine, bright, little pronounced, lying on top of the surface. Hemielytra leaving a narrow strip of abdomen exposed (0.5-0.8). Embolium convex, posteriorly curving inward, posterolateral angles acuminate, lateral margin coarsely serrate about 22 teeth/mm, maximal width across embolium slightly larger than maximal width across connexiva (9.04/8.80). Claval suture present but thin, right membranal suture absent, right membrane membranaceous, of different texture as the corium, broadly rounded, covering the left membrane, brownish opaque. Hind wings short, reaching to the base of third abdominal tergite. Connexival segments acuminate, posterolateral angle of last connexival segment bluntly rounded. Connexiva laterally distinctly serrate, with about 20 teeth $/ \mathrm{mm}$. Prosternal carina medium elevated, with two small tips anteriorly. Mesosternal carina with a well developed but rather shallow fossa and the anterior tooth halfway the ante- 

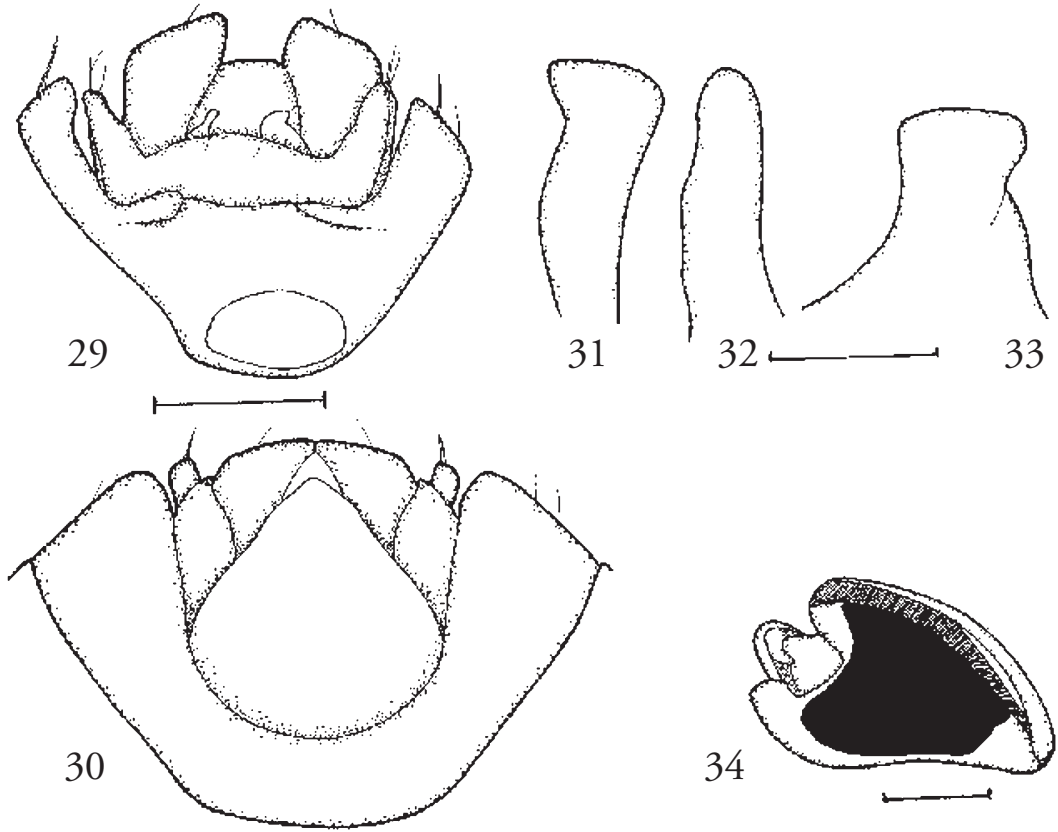

Figs. 29-34. Limnocoris brasiliensis. - 29, male, apex of abdomen, dorsal view; 30, female, apex of abdomen, ventral view; 31, right pseudoparamere medial view; 32, right pseudoparamere dorsal view; 33, left pseudoparamere; 34, left foreleg of male, ventral view. Scales 29, 30, 34: $1 \mathrm{~mm}$; 31-33: $0.25 \mathrm{~mm}$.

rior slope (figs. 159, 160). Metasternal carina small but well developed, a tubercle with a ventral fossa. Fore femur 1.9 times as long as wide (2.65/1.39). Middle femur 5.3 times as long as wide $(3.19 / 0.60)$ and 1.5 times longer than middle tibia $(3.19 / 2.16)$. Hind femur 6.4 times as long as wide ( 0 4.63/0.72) and only slightly longer than hind tibia (4.63/4.31).

Male. - Proximal projection of right lobe of tergite 6, short, poorly developed (fig. 24). Pseudoparameres figs. 26, 27.

Female. - Genital operculum sinuate at the tip, only slightly longer than wide (1.6/1.4) (fig. 25).

Macropterous form. - As brachypterous form except for the development of the opaque hind wings and hemielytra with claval suture present, and membranes fully developed. In addition the posterolateral angles of pronotum rounded, ill-defined, 0.7-1.0 anteriorly of the posterior margin and the claval commissure relatively shorter, median length of scutellum nearly twice the claval commissure (2.1/1.1). Other dimensions do not show significant differences although macropterous males seem to be slightly larger than brachypterous ones; length: 0 11.8-12.4-12.8 + 13.0, width: ot 8.68-8.88-9.02 क 9.09, width of pronotum: of 7.60-7.74-7.90 +7.87 , median length of pronotum: ô 2.20-2.28-2.34 ㅇ 2.44, lateral length of pronotum: $\delta$ 3.60-3.69-3.80 $q 3.80$, anterior width of vertex: of $2.17-2.26-2.32$ क 2.17 , synthlipsis: 0 1.49-1.58-1.62 우 1.62 .

Larva V. (three dry specimens) - Dimensions length 10.7 , width 8.4, anterior width of vertex 2.07, width of pronotum 7.31 , median length pronotum 1.30 , lateral length of pronotum 2.74, median length of head+pronotum 3.18. Colour yellowish brown to reddish brown with sparse rather evenly dispersed small dark brown to blackish dots. Venter somewhat lighter than dorsum, without blackish dots. Lateral margin of connexiva distinctly serrate with about 19 teeth $/ \mathrm{mm}$. Mesosternal carina smaller and of simpler structure with central part relatively longer but narrower than in adult, without fossa (fig. 28) strongly elevated, ending in a point posteriorly.

\section{Distribution}

From N. Argentina (province of Salta) through the eastern foothills of the Andes up to Venezuela.

\section{Comparative notes}

The largest Limnocoris species, it belongs to the $L$. maculiceps-group. Smaller specimens are of the same size as larger specimens of L. robustus Roback \& Nieser from Colombia, but this species has in the 
brachypterous form the posterolateral angles of the pronotum rounded and the membrane is also more broadly rounded.

Limnocoris stali is at least partly the macropterous form of $L$. borellii, the specimens from Guatemala mentioned in the description will belong to another species. We have not been able to check an original Montandon specimen of $L$. stali so we follow the interpretation of De Carlo (1951) who had specimens for comparison and identification sent to various museums. Likewise, we were not able to trace the specimen of $L$. mancocapaci Poisson, but the figures and description leave little doubt that he had a brachypterous (not macropterous as stated in the text) specimen of $L$. borellii before him.

\section{Limnocoris brasiliensis De Carlo}

(figs. 23, 29-34, 161-162)

Limnocoris brasiliensis De Carlo, 1941: 37-38.

Limnocoris bergi De Carlo, 1941: 39-40.

Limnocoris brasiliensis; De Carlo 1954: 13; Nieser \& Lane de Melo 1999: 1235-1236 (synonymy).

Limnocoris bergi; De Carlo 1954: 13-14.

Material examined. - BRAZIL: MG, Rio Caparaó (in N.P. Caparaó) 28.VI.1995, ALM 95007 (approx. 21³0'S/ $\left.41^{\circ} 52^{\prime} \mathrm{W}\right), 1400 \mathrm{~m}$ asl., temp. water $8^{\circ} \mathrm{C}$, $90^{\star} 7$ brach., 10 macr., 17 larvae of various instars, leg. A. Lane de Melo.

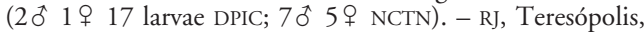
30.VIII.1957, R. Usinger coll., 2 đ 2 q brach. det. J.T. Polhemus $(1 \hat{0} 1$ 우 NCTN, $1 \hat{\sigma} 1$ SEMC); RJ, Teresópolis $1 \hat{\sigma}$ macr. 19 brach., (incorrectly designated allotypes of $L$. bergi and L. brasiliensis by De Carlo, 1954, MACN). - SP, Parque Nacional Bocaina, Rio Mamcubaba, 1650m, 26.II. 1977, leg. N.D. Santos, 1 \% macr. (JTPC).

\section{Redescription}

Brachypterous form, (based on dry pinned specimens from R. Caparaó). - Generally a large medium brown elongate ellipsoid species, with ill-defined dark grey to blackish markings (fig. 23). Dimensions: length के 10.3-10.5-10.8, क 10.3-10.7-11.2; body width of 6.49-6.53-6.60, + 6.58-6.79-7.03; anterior width of vertex 0 2.12-2.18-2.22, क 2.21-2.22-2.24; synthlipsis of 1.78-1.80-1.83, of 1.80-1.83-1.87; width of pronotum of 6.19-6.33-6.51, o 6.20-6.31-6.52; median length pronotum $\hat{o} 1.80-1.81-1.82$, 우 1.83 1.86-1.92; lateral length pronotum of 2.80-2.81-2.82, क 2.82-2.87-2.93; median length of head+pronotum of 3.36-3.47-3.60, q 3.43-3.48-3.57.

Colour. - Dorsally medium brown with head, pronotum and scutellum somewhat lighter than hemielytra. The more or less distinct dark marks are a narrow transverse band at anterior and a broad transverse band at posterior margin of pronotum, posterior third of embolium and membrane. Eyes brown to black, interocular mark ill-defined, dissolved in small spots. Disk of pronotum somewhat darker than lateral parts. Anterior two thirds of embolium lighter than corium in most specimens, membrane usually concolorous with corium. Exposed parts of connexiva light brown, slightly infuscated anteriorly. Venter light to medium brown, thoracic venter with a bluegrey pruinose hue which is more faintly present on abdomen too. Legs yellowish, anterior femur in males largely shiny black ventrally (fig. 34), this profemoral black mark is much smaller to only faintly indicated in female specimens. Abdominal stigmata marked by a small round tuft of yellow hairs. Abdomen with a median band of shiny yellow hairs widening posteriorly, densely covering the genital segments.

Structural characteristics. - Eyes distinctly elevated above head surface, anterior margin of head distinctly protruding relative to the curvature of pronotum and eyes. Anterior width of vertex 1.2 times the synthlipsis $(2.2 / 1.8)$, head longer than median length of pronotum (2.05/1.83), length of an eye less than twice its width (1.35/0.74). Anteclypeus projecting 0.30-0.40 anteriorly of labrum, labrum slightly wider at base than its median length $(0.6 / 0.5)$, lateral margins of labrum in basal half slightly converging apically, apical half triangular with an obtuse point. Gular carina posteriorly with a distinct point which reaches over the anterior part of the prosternal carina. Lateral margin of pronotum only slightly convex, nearly straight in its central portion, pronotum together with head subtriangular. Posterolateral angles of pronotum rounded, posterior margin in middle five sixth distinctly posteriorly of level of lateral angles (0.2-0.3); maximal width twice anterior width $(6.3 / 3.1)$ and 2.2 times the lateral length (6.3/2.8); lateral margin moderately serrate, about 25 teeth $/ \mathrm{mm}$. Dorsal granulations lying on top of dorsal surface. Scutellum slightly over twice as wide as long (3.17/1.53) and only a little longer than length of claval commissure (1.53/1.34). Hemielytra leaving most of connexiva (a 0.4-0.5 wide strip) exposed. Embolium only moderately convex, posteriorly gradually curving inward, hardly sinuate, lateral margin moderately serrate, approximately 25 teeth $/ \mathrm{mm}$; maximal width across embolium larger than maximal width across connexiva (6.7/6.6). Right membranal suture absent, membrane coriaceous, slightly to distinctly darker than corium, broadly rounded, covering left membrane. Left membrane reduced, inner margin diverging laterally in relation to median body axis, membranaceous, dark smoky brown, broadly rounded, membranal suture distinct. Hind wings strongly reduced, reaching base of abdomen. Dorsum of abdomen velvety yellowish brown. Connexival segments 3-6 not indented, forming a smooth outer margin of abdomen, distinctly serrate, segment 4 with about 20 teeth $/ \mathrm{mm}$, posterolateral angle of segment 6 bluntly 


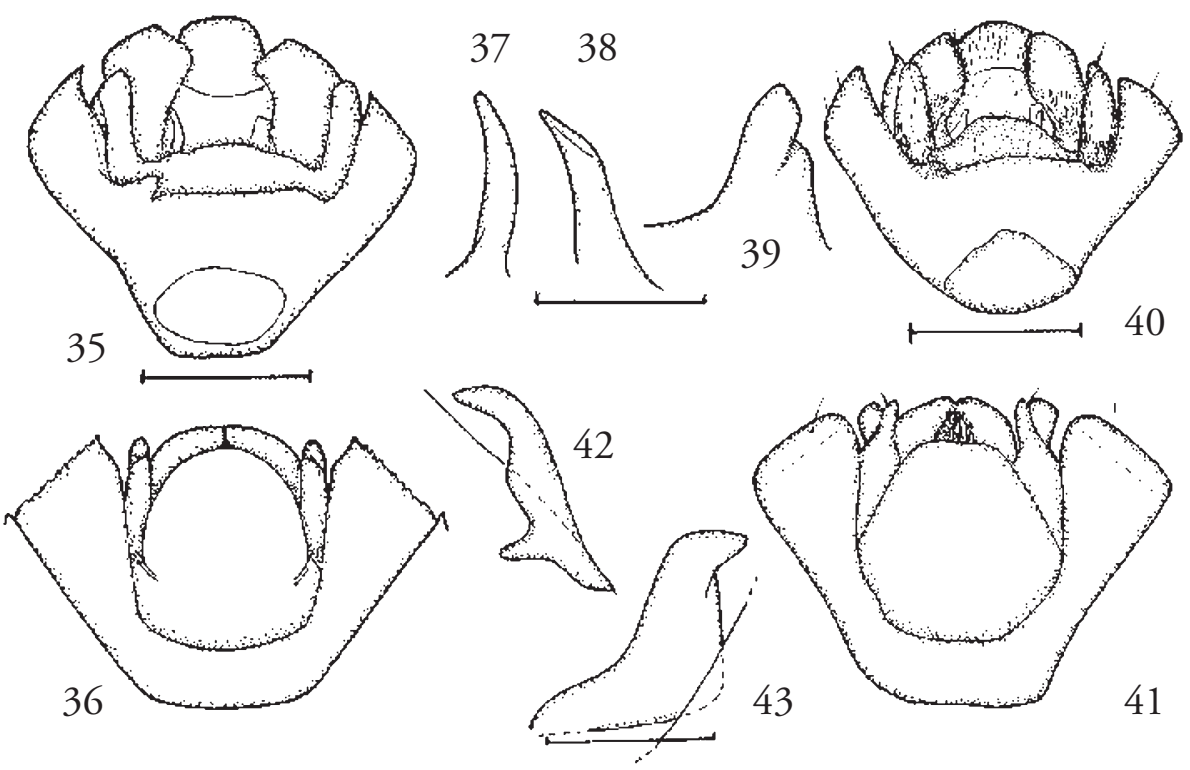

Figs. 35-39. Limnocoris illiesi. - 35, male, apex of abdomen, dorsal view; 36, allotype female, apex of abdomen, ventral view; 37 , right pseudoparamere medial view, 38, right pseudoparamere dorsal view; 39 left pseudoparamere. Scales 35, 36: $1 \mathrm{~mm}$; 37-39: $0.25 \mathrm{~mm}$.

Figs. 40-43. Limnocoris insignis. - 40, male, apex of abdomen, dorsal view; 41, female, apex of abdomen, ventral view; 42, right pseudoparamere; 43, left pseudoparamere. Scales 40, 41: $1 \mathrm{~mm} ; 42,43: 0.25 \mathrm{~mm}$.

angulate. Prosternal carina in the form of an elevated narrow strip, hardly sloping in anterior two thirds, fitting anteriorly in a posterior excavation of the gular carina. Mesosternal carina (figs. 161, 162) anteriorly virtually vertical with a blunt tooth, central part narrow, with a shallow furrow in posterior half, posterior part short, distinctly sloping. Metasternal carina low and simple. Anterior femur about 1.5 times as long as wide (2.7/1.7). Middle femur five times as long as wide $(2.5 / 0.5)$, longer than tibia (2.5/2.0). Hind femur seven times as long as wide (3.5/0.5), slightly shorter than the tibia $(3.5 / 3.7)$.

Male. - Proximal projection on left lobe of tergite 6 acute, projection of right lobe truncate (fig. 29). Right pseudoparamere narrow (figs. 31, 32).

Female. - Genital operculum with slightly sinuate lateral margins (fig. 30).

Macropterous male. - As brachypterous form except for the development of the opaque hind wings and hemielytra with claval suture and nodal furrow present, and membranes fully developed. Pronotum relatively somewhat larger but only slightly different in shape, scutellum relatively larger and more convex, claval commissure relatively shorter, median length of scutellum nearly twice the claval commissure (1.7/0.9). Other dimensions do not show significant differences; length 10.1 , width 6.6 , width of pronotum 6.48 , median length of pronotum 2.00 , lateral length of pronotum 3.95, anterior width of vertex 2.15, synthlipsis 1.78 .

\section{Distribution}

Brazil: RJ, MG.

\section{Comparative notes}

$L$. brasiliensis belongs to the $L$. maculiceps-group. Nieser \& Lane de Melo (1999) studied the 'allotypes' (see above) of L. bergi and L. brasiliensis De Carlo (1941, 1954) and found that $L$. bergi is the macropterous form of $L$. brasiliensis. The males are at once recognizable by the large black patch ventrally on the fore femur. In addition, among similar species from $S$. Brazil, L. pauper and L. subpauper, which are of similar shape are smaller. L. abbreviatus which is roughly of the same length is relatively broader and has the hemielytra more strongly reduced in the brachypterous form (figs. 20, 23). 
Limnocoris illiesi De Carlo

(figs. 35-39, 44, 169-170)

Limnocoris illiesi De Carlo, 1967: 192-193. Holotype brachypterous ơ, BRAZIL: AM, Rio Marauía, 3.II.1963, A508, leg. E. J. Fittkau (ZSMC) [examined].

Limnocoris illiesi; Nieser \& Lane de Melo 1997: 56.

Material examined. - Holotype, see above. BRAZIL: AM, Rio Marauía, $1+$ paratype (allotype), 28.I.1963, leg. E.J. Fittkau, A501, (ZSMC) - PA, Rio Xingo, Rio Setembro, 28.VIII.1965, leg. E.J.Fittkau, A597, 2 ㅇ (NCTN, ZSMC) MG, Uberaba-Delta, Ribeirão Conquistinha, 1958'15”S/ 4751'07”W, 13.III.1996, leg. N. Nieser \& A. Pelli, N9620; stream in agricultural fields (meadows), due to rain water carrying a lot of silt, sampled on overflown banks, 20 (NCTN). All brachypterous.

Discussion. - The type specimens are much smaller than the specimens from MG. However, the holotype and the MG specimens share the same structure of the mesosternal carina with the peculiar fossa. Since other characteristics, not related to size, also agree well we decided to identify the two MG males as L. illiesi. On the other hand, the specimens from Colombia identified as $L$. illiesi by Roback \& Nieser (1974) are now considered to be very small specimens of $L$. pusillus, see under that species.

\section{Redescription}

Brachypterous form (based on two males from MG, alcohol specimens). - Generally a small to very small, light brown, oval species (fig. 44). Dimensions: length $\delta$ 5.72-5.78, width $\delta$ 4.00-4.10, anterior width of vertex 0 1.25-1.28, width of pronotum to 3.40-3.45, median length pronotum of 1.10-1.12, lateral length of pronotum $\hat{\delta} 1.40-1.50$, median length of head+pronotum ot 2.00-2.03.

Colour. - Sordid yellow to light brown with variable brownish mottling, eyes black. Exposed part of connexival segments in dorsal view medium brown in anterior half. Venter and legs yellowish to light brown.

Structural characteristics. - Anterior margin of head following the curvature of pronotum and eyes, but slightly projecting relative to the anterolateral angles of pronotum, head distinctly declining anteriorly. Anterior width of vertex 1.2 times the synthlipsis (1.26/1.04), length of head slightly longer than median length of pronotum (1.17/1.11), eyes relatively broad, length of an eye 1.5 times its width $(0.75 /$ 0.49 ). Anteclypeus projecting 0.10 anteriorly of labrum. Labrum parallel-sided in basal part, apical half triangular with rounded tip, relatively large with basal width larger than median length $(0.4 / 0.3)$. Pronotum with posterolateral angles broadly rounded, ill defined, about 0.3 anteriorly of its posterior margin, maximal width 1.7 times anterior width $(3.43 / 2.05)$ and 2.4 times the lateral length (3.43/1.45), lateral margin indistinctly serrate ventrally with about 45 teeth/mm. Granulations on dorsum of body pale, placed in small pits, on membranal area finer and more dense. Scutellum twice as wide at base as its median length (1.77/0.88), subequal to claval commissure $(0.88 / 0.87)$. Hemielytra leaving a strip of 0.15 0.20 of connexiva exposed. Embolium only softly convex, nearly straight and parallel to longitudinal body axis in posterior part, posteriorly hardly sinuate, lateral margin indistinctly serrate ventrally with about 33 teeth/mm, maximal width across embolium larger than maximal width across connexiva (4.05/3.93). Claval suture absent, membrane coriaceous, concolorous with corium but of smoother texture, broadly rounded, covering a narrow, membranaceous smoky dark brown median strip of left hemielytron. Lateral part of left membrane coriaceous, concolorous with corium, narrowly rounded to broadly pointed. Hind wings strongly reduced, reaching halfway first abdominal tergite. Connexival segment 4 with a sharp posterolateral angle, forming a short spine, posterolateral angle of segment 5 distinctly, though short and broadly spinose. Segment 4 ventrally serrate with 40 teeth $/ \mathrm{mm}$. Prosternal carina steep, posteriorly with a relatively narrow, shallowly bifid tip anteriorly. Mesosternal carina with a short strongly sloping posterior part, central part heart-shaped with a small fossa which, however, continues downward as a more or less closed channel (due to reflexed sides) on the nearly vertical front slope, central part anteriorly with a vertical margin leading to the low anterior part a well-developed anterior tooth (figs. 169, 170). Metasternal carina well developed, with a wide fossa beset with long coarse pubescence, covering about central half of metaxiphus. Pilosity on abdominal venter fine short and dense with two pairs of small bare patches on each sternite, medially a few larger coarser hairs. Fore femur 1.7 times as long as wide (1.33/0.79). Middle femur slightly over four times as long as wide (1.37/0.33) and 1.25 times longer than middle tibia (1.37/1.10). Hind femur 4.7 times as long as wide $(1.80 / 0.38)$ and nearly as long as hind tibia $(1.80 / 1.86)$.

Male. - Genital segments as in fig. 35, right lobe of tergite 6 with a distinct proximal projection. Right pseudoparamere narrow (figs. 37, 38).

Female. - Genital operculum (in allotype) with a pair of lateral grooves in basal third, posterior margin evenly curved (fig. 36).

Macropterous form unknown.

\section{Distribution}

Brazil: AM, PA, MG.

\section{Comparative notes}

L.illiesi belongs to the L.maculiceps-group. It is the smallest species of the genus, differing from the only slightly larger $L$. minutus and $L$. pusillus in the struc- 


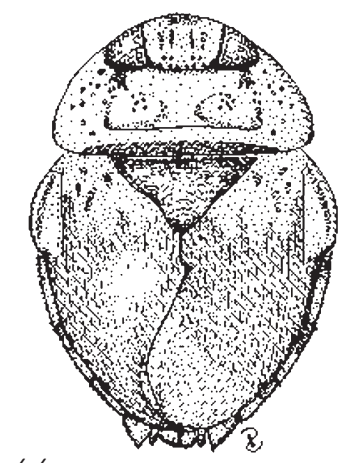

44
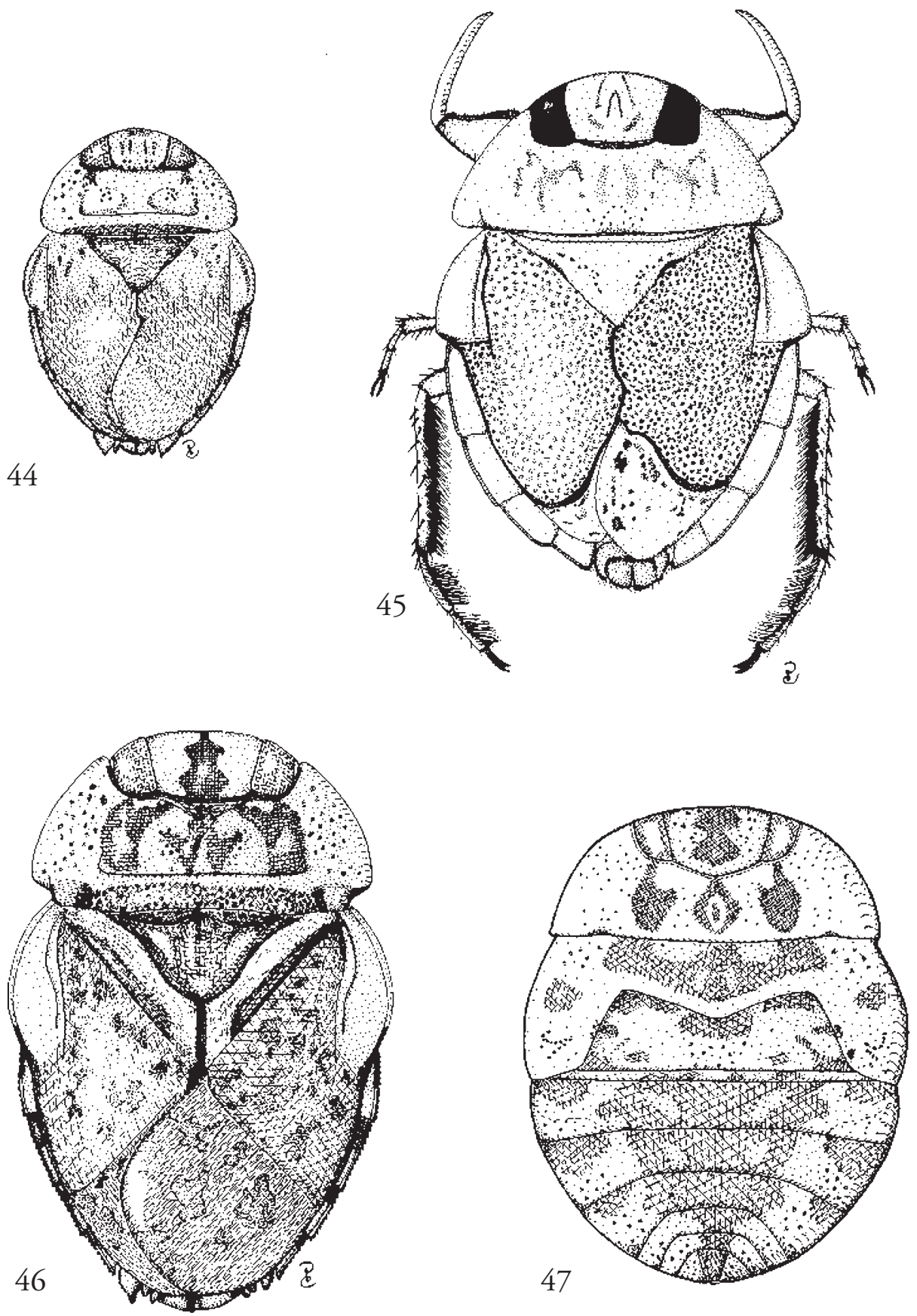

Figs. 44-47. Habitus of Limnocoris. - 44, L. illiesi, allotype brachypterous female, body length $5.5 \mathrm{~mm}$; 45, L. insignis, brachypterous female, (holotype of L. uhleri), length $8.3 \mathrm{~mm}$; 46, L. maculiceps, brachypterous female, body length $9.0 \mathrm{~mm}$; 47, L. maculiceps larvaV, body length $7.7 \mathrm{~mm}$. 
ture of the mesosternal carina (figs. 169, 170, 179, 180, 191 and 192) and the more distinctly spinose posterolateral angles of penultimate and ultimate connexival segments.

\section{Limnocoris insignis Stål}

(figs. 40-43, 45, 171-172)

Limnocoris insignis Stål, 1860: 83.

Limnocoris insignis; Montandon 1897: 7.

Limnocoris uhleri Montandon, 1910: 439-442. Holotype $q$

brach.: BRAZIL: Rio, (USNM) [examined]. Syn. n.

Limnocoris admontandoni La Rivers, 1974: 7-8. Syn. n.

Material examined. - Holotype of L. uhleri see above. BRAZIL: SP, Rio Guaraú, Jacupiranga, $24^{\circ} 45^{\prime} \mathrm{S} 48^{\circ} 02^{\prime} \mathrm{W}, 39 \mathrm{~m}$, XII. 1963, leg. F. Plaumann, 10 brach., 10 (allotype) 2 우 macr., (paratypes L. admontandoni CASC). BRAZIL leg. Schott, det. L. insignis Stål by Montandon 18971 q macr. (NHMW); MG, Viçosa, 28.IX.1998, ALM98008, leg. A. Lane de Melo, 1 to 1 क 2lvV brach. - RJ, Represa dos Ciganos, 30.XII.1976, leg. A.C. Matos, 10 to brach. (det. J. T. Polhemus, ex. JTPC); RJ, Theresopolis, 1887, $2 \hat{0}$ brach. (BMNH) - SP same data as type series of $L$. admontandoni 10 brach.; sP, Pariquera Açú, $24^{\circ} 50^{\prime} \mathrm{S} 47^{\circ} 55^{\prime} \mathrm{W}$, streamlet, 15m, XI.1963, leg. F. Plaumann, $20^{\top}$ brach. - SP, Cananeia, 245' $47^{\circ} 57^{\prime} \mathrm{W}$, streamlet, 10m, XI.1963, leg. F. Plaumann, 19 macr. - RJ, Tijuca, 17.X.1919, Cornell U. lot 569 sub 51, 60 69 brach. (SEMC) - PR, Pirai, Rio Pirai, $24^{\circ} 30^{\prime} \mathrm{S} 50^{\circ} 00^{\prime} \mathrm{W}, 1000 \mathrm{~m}$, X.1959, leg. F. Plaumann, 1 oे 1 क brach. (क MLPA) - SC, Guamirim, Rio Itapocú, XII.1958, leg. F. Plaumann, 1 đิ 1 ㅇ macr. - RS, Rio S. Maria, $31^{\circ} 10^{\prime} \mathrm{S} 54^{\circ} 23^{\prime} \mathrm{W}, 280 \mathrm{~m}$, XII. 1964, F. Plaumann, 10 brach., 1 \% macr. - RS, Arr.(oyo) Granda, 3205’S 5256’ W, 100m, XII.1964, leg. F. Plaumann, 10 brach.; Joinville, Rio Pirany, XII.1958, leg. F. Plaumann, 1 t macr. (det. J.T. Polhemus, JTPC). NCTN unless otherwise indicated.

Discussion. - Unfortunately we have not been able to borrow the holotype of L. insignis from NHRS. However, we have studied the specimen identified by Montandon (1897) from NHMW, which clearly is a macropterous female of the species he later described (Montandon 1910) as L. uhleri. This in combination with the size given by Stål, and the fact that this species is one of the most widespread species in southern Brazil leaves little doubt about the synonymy. The holotype of L. ubleri bears a small red label 'cotype No. 54273 U.S.N.M.', however, according to article 73.1.2 of the Code (ICZN 1999), it is to be considered holotype by monotypy. In addition there are, apart from small collection and number labels, two identification labels: Limnocoris insignis Stål Var. and a label Limnocoris Uhleri Montandon type 1909.

\section{Redescription}

Brachypterous form (based on dry pinned specimens). - Generally a small, very broadly oval to subcircular, light to medium brown species with distinctly reduced hemielytra (fig. 45). Dimensions: length o 7.5-7.7-8.1 क 7.7-8.3, width of 5.72-5.86-6.01 우 5.90-6.03, anterior width of vertex ô 1.61-1.70-1.80 o $1.75-1.80$, synthlipsis ô $1.26-1.32-1.40$ ㅇ 1.28 1.36, width of pronotum of 4.92-5.10-5.20 9 5.255.35, median length pronotum $\delta$ 1.40-1.53-1.70 $q$ 1.50-1.55, lateral length of pronotum ot 2.20-2.29$2.45+2.26-2.30$, median length of head+pronotum ô 2.68-2.80-2.92 क 2.84-2.87-2.89.

Colour. - Yellowish brown, eyes grey, disk of pronotum and hemielytra except embolium medium brown. Interoculus with small little contrasting darker dots posteriorly arranged in a circle segment, anteriorly in four rows. Hemelytra from nearly unmarked to sparse darker mottling most distinct posteriorly. Connexival segments unicolorous pale to anterior fifth to fourth infuscated. Venter laterally yellowish, medially light to medium brown, legs yellowish. The holotype is a pale specimen with vague and reduced marks on head, pronotum scutellum and right membrane, the clavus and corium unmarked so the small hyaline areas around the granules are striking. Structural characteristics. - Anterior margin of vertex following the curvature of eyes, in most specimens distinctly protruding relative the curvature of pronotum. Anterior width of vertex 1.3 times the synthlipsis (1.71/1.33), head longer than median length of pronotum (1.67/1.45), length of an eye twice its width (1.28/0.59). Anteclypeus projecting 0.15 anteriorly of labrum. Lateral margins of labrum slightly converging in basal part, apical half triangular with a broadly rounded tip, basal width larger than median length $(0.59 / 0.45)$. Pronotum posterolaterally acutely rounded, angles 0.2 anteriorly of the level of posterior margin medially, its maximal width twice the anterior width $(5.16 / 2.60)$ and 2.3 times the lateral length (5.16/2.29), lateral margin slightly but evenly convex, indistinctly serrate ventrally, about 33 teeth $/ \mathrm{mm}$. Granulations on dorsum of body distinct on hemielytra only, fine, pale, lying in small pits, somewhat smaller and more densely set on membranal area. Scutellum about twice as wide at base than its median length $(2.30 / 1.08)$ and 1.2 times as long as claval commissure (1.08/0.89). Hemielytra leaving a broad strip of abdominal dorsum (0.6-1.0) exposed. Embolium anteriorly convex, margins posterolaterally nearly straight and parallel, curving abruptly inward posteriorly posterolateral angle obtuse but distinct in most specimens; lateral margin indistinctly serrate ventrally, approximately 32 teeth/mm; maximal width across embolium larger than maximal width across connexiva (5.85/5.65). Claval suture absent, right membrane coriaceous, smoother than corium, reduced, bluntly pointed, right hemielytron covering a median strip of left hemielytron. Apical part of left membrane coriaceous, bluntly pointed, not covered by right hemielytron, inner strip of left hemielytron covered by right hemi- 

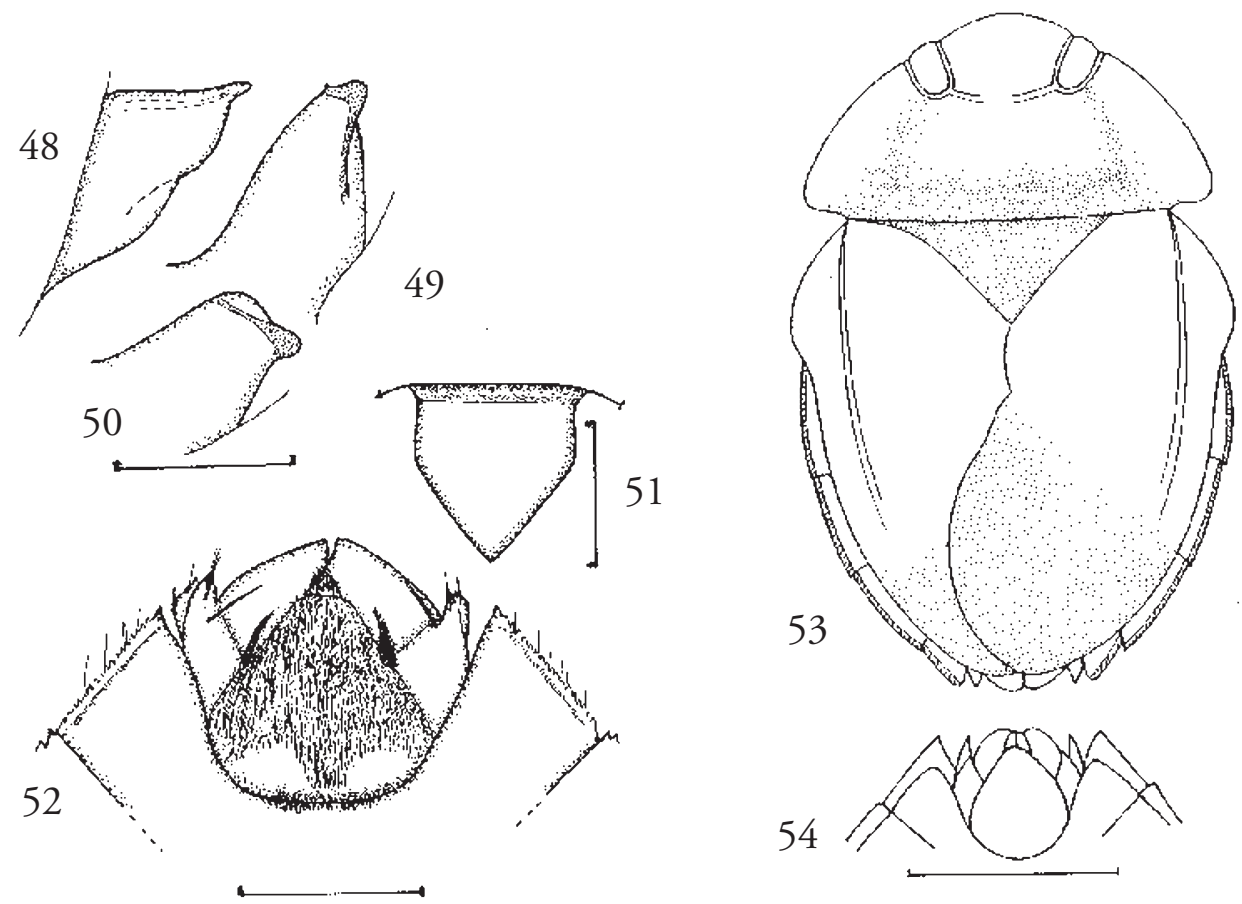

Figs. 48-52. Limnocoris maculiceps. - 48, right pseudoparamere; 49, 50, left pseudoparamere, 49, dorsal view, 50, medial view; 51, labrum; 52, female, apex of abdomen, ventral view. Scales 48-50 0.25mm, $510.5 \mathrm{~mm}, 521 \mathrm{~mm}$.

Figs. 53-54. Limnocoris melloleitaoi. - 53, brachypterous female, outline of body, length $9.7 \mathrm{~mm}$; 54, female apex of abdomen ventral view. Scale $1 \mathrm{~mm}$.

elytron membranaceous, dark velvety brown to blackish, sutured off by the difference in structure between coriaceous and membranaceous part. Hemielytra reaching unto or beyond posterior margin of last abdominal tergite. Hind wings strongly reduced. Dorsum of abdomen velvety yellowish. Connexival segments slightly indented, anterior angles recessing 0.04-0.07 relative to the posterolateral angle of preceding segment, posterolateral angle of last connexival segment pointedly rounded. Connexiva ventrolaterally serrate, segment 4 with about 35 teeth $/ \mathrm{mm}$. Prosternal carina distinctly elevated, gradually slanting posteriorly, broadly truncate, not bifid anteriorly. Mesosternal carina with a well developed elevated central part with a distinct elongate to broadly oval fossa with a somewhat crenulated rim (fig. 172), posterior part short and very steep, anterior part about as long as central part, without tooth at anterior margin of fossa, smoothly sloping to a small, blunt but distinct anterior tooth which tops a vertical edge. Metasternal carina well developed with a wide shallow ventral fossa, covering central quarter to third of metaxiphus. Abdominal venter with distinct but scarce and scattered golden yellow pilosity leaving connexiva exposed, on meta- and meso-sternum only a few isolated hairs. Fore femur 1.7 times as long as wide (2.00/1.18). Middle femur about 5 times as long as wide (2.10/0.44) and 1.4 times longer than middle tibia (2.10/1.55). Hind femur six times as long as wide $(2.73 / 0.46)$ and about as long as hind tibia $(2.73 / 2.79)$.

Male. - Proximal projection short, knob-like, genital segments as in fig. 40. Right pseudoparamere slender (fig. 42).

Female. - Genital operculum only slightly wider than long (1.1/1.0), tapering posteriorly to a broadly truncate to very slightly and shallowly indented posterior margin (fig. 41).

Macropterous form. - Essentially as brachypterous form except for being relatively more slender and the usual differences in pronotum and hemielytra connected with macropterism. Dimensions: length $\delta$ 7.9-8.1 क 8.0-8.3-8.6, width of 5.93-6.15 क 5.806.14-6.40, anterior width of vertex of 1.61-1.67 क 1.63-1.69-1.72, synthlipsis of $1.27-1.30$ \& 1.29 1.31-1.43, width of pronotum of 5.38-5.40 क 5.125.34-5.61, median length of pronotum $\delta$ 1.70-1.72 o 1.62-1.73-1.80, lateral length of pronotum $\delta^{t}$ $2.62-2.70$ क $2.41-2.61-2.81$, median length of 
head+pronotum ot 3.06-3.10-3.15 우 2.98-3.143.25. Colour as in brachypterous form with right membrane greyish, distinctly darker than corium, dorsum velvety medium brown, wings smoky brown. Pronotum with lateral angles broadly rounded, 1.0 anteriorly of its posterior margin, maximal width twice its lateral length (5.36/2.63). Scutellum more strongly developed than in brachypterous form, over twice as wide at base as its median length (2.94/1.32) and 2.5 times as long as claval commissure (1.32/0.53). Hemielytra leaving a broad (0.4-0.6 wide) strip of abdomen exposed. Embolium posteriorly only slightly less abruptly curved inward as in brachypterous form, width across embolium larger than maximal width across connexiva (5.8/5.6), relatively more slender than brachypterous form, claval suture and nodal furrow distinct, membranes fully developed, broadly rounded, right membrane coriaceous, covering membraneous, medium to dark brown left membrane. Hind wings fully developed light brownish opaque, reaching apex of abdomen. Covered part of abdomen medium to dark brown.

Larva V. Dimensions: length 7.0, width (across wing-pads) 5.70 , anterior width of vertex 1.38 , synthlipsis 1.14, width of pronotum 5.18, median length of pronotum 0.89 , lateral length of pronotum 1.89 , median length of head+pronotum 2.15. Colour, dorsally yellowish to in the median part light orangeish-brown with distinct dark dots scattered rather evenly over the median part. Ventrally the same colour as dorsally or somewhat lighter, without dark dots. Legs yellowish, middle and hind legs infuscated at distal tips of segments. Posterolateral angles of pronotum sharp, in line or very slightly posteriorly of median part of posterior margin. Mesosternal carina with a well elevated apically nearly laminar central part, fossa indicated as a narrow groove. Lateral margins of connexiva serrate, nearly 40 teeth/mm on segment 4 .

\section{Distribution}

Brazil: MG, RJ, SP, PR, SC, RS.

\section{Comparative notes}

A member of the species-group with reduced hemielytra in the brachypterous form, named after this species. Within the insignis-group this is the smallest species. The length of the holotype of $L$. uhleri is 8.3 but it has the gonocoxa extended: the length with retracted gonocoxa would be 8.1. Its small size in combination with a triangular head and pronotum are diagnostic.

\section{Limnocoris maculiceps Montandon \\ (figs. 5, 6, 46-52, 177-178)}

Limnocoris maculiceps Montandon, 1898: 424-425.
Limnocoris maculiceps; De Carlo 1951: 44; Nieser \& Lane de Melo 1997: 51, 55.

Lectotype designation. - Montandon (1898) described Limnocoris maculiceps from specimens from Mato Grosso, deposited in MNHN. Through the kindness of Dr. Eric Guilbert we were able to borrow these specimens, a brachypterous female marked type (in Montandon's handwriting) and a macropterous male marked cotype. In order to fix the identity of this species we designate herewith the brachypterous female as lectotype and the macropterous male as paralectotype. The lectotype bears the following labels: a small printed label 'type'; a printed label 'Museum Paris, Matto Grosso, de Castelneau 13-47' and a handwritten label (apparently by Montandon) ' Limnocoris maculiceps Montandon type 1897' we have added a red label 'Lectotype dsg. Nieser \& LopezRuf. The relevant dimensions of the lectotype are length 8.6, width 6.28 , width of pronotum 5.27 , anterior width of vertex 1.78 , median length of pronotum 1.90, lateral length of pronotum 2.58. The paralectotype bears the following labels; a printed label 'Museum Paris, Matto Grosso, de Castelneau 13-47' and a handwritten label 'Limnocoris maculiceps cotype 1897 Montandon', we have added a blue label 'Paralectotype'. It is a very small specimen but structurally agreeing with our material from MG. Dimensions: length 7.8 , width 5.2 , anterior width of vertex 1.38 , width of pronotum 4.03 , median length of pronotum 1.55 , lateral length of pronotum 1.95 .

Material examined. - Lectotype and paralectotype, see above. BRAZIL: MG, São Roque de Minas, Rio do Peixe, 27.III.1996, 20¹4'35” S/ 46²2'13”W, leg. N. Nieser \& A. Pelli, N9636. Mountain stream in gorge with trees, $4-10 \mathrm{~m}$ wide, up to $0.7 \mathrm{~m}$ deep, rapids (Cryphocricos), riffles (Ambrysus, Limnocoris uhleri-group), quiet parts (with Limnocoris maculiceps at margins) water clear to turbid (depending on distance from waste outlets) and enriched (algal growth), bottom small boulders to sand with gravel or sometimes at edges sand only, v.c. very variable, mostly shaded but with sunny patches. Edges with overhanging vegetation and leaf litter, 60 3q; same, 7. XI.1997, leg. Nieser \& Pelli, N9636a, 3 \% . Rio do Peixe $\pm 5 \mathrm{~km}$ upstream of S. Roque, at camping site, 7.XI.1997, N9724, leg. Nieser \& Pelli. River bed very broad (probably artificially as result of search for minerals (diamonds). The (probably) original bed mostly shaded with well developed marginal vegetation, secondary gully mostly exposed to sun, bare margins except for shrubs and trees, bottom pebbles, at edges with leaf litter, most $L$. maculiceps here, $14 \hat{0} 9+1 \mathrm{lvV}(1 \hat{\delta} 19$ macr.). Serra da Canastra, Nasc. R.S. Francisco at bridge, 4.XI.1997, N9713, leg. A. Pelli. $50 \mathrm{~m}$ downstream to $500 \mathrm{~m}$ upstream of bridge 40 c $6911 \mathrm{lvII} / \mathrm{V}$. Sa. Canastra, Córrego do Passageiro, 12.XI.1997, N9734/5, leg. Nieser \& Pelli. Upstream and downstream of bridge, brown clear water in tall grass vegetation mixed with tall herbs and a few shrubs. Most L. maculiceps from stagnant edge with some water plants, 24 đ 28 우․ Sacramento, unnamed Córrego going to Rio Grande, 13.XI. 1997, leg. N. Nieser \& A. Pelli, N9739B. Downstream of 
bridge, virtually stagnant, sand bottom, water colourless, nearly clear, up to $1 \mathrm{~m}$ deep, width $10-20 \mathrm{~m}$, no aquatic vegetation, little shade from marginal trees, 10 . Perdizes, Reserva de Galheiros, $19^{\circ} 12^{\prime} 57^{\prime \prime S} / 47^{\circ} 09^{\prime 2} 27^{\prime W}$, 18.III.1996, leg. N. Nieser; large pond, stagnant (sample taken near exit), bottom muddy, water turbid brown, emergent vegetation, sample site shaded by trees, 29 . Perdizes, stream on fazenda, $19^{\circ} 13^{\prime} 50^{\prime}$ S/4708'48”W, 19.III.1996, leg. N. Nieser \& A. Pelli, N9629, small stream, width $2-5 \mathrm{~m}$, sampled at edge, water clear, hyaline, shaded by gallery forest, $2 \hat{0} 2 \uparrow$. Small stream in open fields just $\mathrm{S}$. of Perdizes-village, leg. N. Nieser \& A. Pelli, N9630. Width 1-1.5m, depth $0.2 \mathrm{~m}$, bottom soft mud, water hyaline, clear, v.c. $4-5 \mathrm{~m} / \mathrm{min}$., exposed to sunshine, $10{ }^{\Uparrow} 4$ ㅇ 1 lv. Serra do Cipó, km 122, 24.II.1996, N9603, leg. N. Nieser. Large pothole in stream, surrounded by a small marsh in small valley, virtually stagnant, water clear, dark brown, plants in margin covered by flocculent ooze, L. maculiceps at margin between plants, $5 \hat{0} 8$ \& $2 \mathrm{lvV}$ 1lvIV; Sa. do Cipó, 5.IX.1998, leg. A. Lane de Melo, ALM 98007, 1 đo 3 ㅇ macr. - PR: Palmas, $26^{\circ} 27^{\prime} \mathrm{S} 52^{\circ} 03^{\prime} \mathrm{W}$, Rio Lontra, 1200m asl., III.1963, leg. F. Plaumann, $1 \delta^{\hat{\sigma}} .-$ SC, Nova Teutonia, Passo dos Indios, $27^{\circ} 07^{\prime} \mathrm{W}, 52^{\circ} 36^{\prime} \mathrm{S}$, 16.XII.1935, leg. F. Plaumann, $40^{\star} 4$ ㅇ (JTPC). All brachypterous and in NCTN unless otherwise stated.

\section{Redescription}

Brachypterous form (based on freshly pinned specimens from the Serra da Canastra and surroundings). - Generally a medium sized broadly oval medium to dark brown species. Dimensions: length 0 8.3-8.6-9.0 क 8.3-8.8-9.4, width of 6.29-6.36-6.50 o 6.10-6.37-6.60, anterior width of vertex ot 1.80 $1.84-1.90$ क $1.78-1.86-1.98$, width of pronotum $0^{t}$ 5.20-5.35-5.50 क 5.15-5.38-5.65, median length of pronotum of $1.75-1.89-1.98$ o $1.80-1.90-2.00$, lateral length of pronotum ô 2.38-2.43-2.50 $\&$ 2.422.47-2.50, median length of head+pronotum $\widehat{0}$ 3.10-3.18-3.28 क 3.20-3.24-3.30.

Colour. - Light to medium brown with variable darker mottling which may become confluent resulting in dark specimens with light patches laterally on interoculus, submedially and laterally on pronotum and laterally on scutellum. Interoculus with a characteristic dark mark, broad posteriorly, narrowing anteriorly, broad again halfway between eyes and narrowing anteriorly (fig. 46); eyes dark brownish-grey. Embolium in lighter specimens usually unmarked,yellow, in dark specimens greyish, little contrasting with corium. Membrane concolorous with, to somewhat more densely mottled than corium. Exposed part of connexival segments in dorsal view yellow with a distinct dark patch in anterior half. Dorsum of abdomen usually velvety yellowish to orange, occasionally black. Venter usually yellowish to light orange-brown in darkest specimens, a pair of dark patches anterolaterally on propleurae, embolium infuscated and connexival segments with dark patches anteriorly, in some specimens larger, forming an ill-defined infuscated lateral band, occasionally venter dark grey. Legs yellow.
Structural characteristics. - Anterior margin of vertex following the curvature of pronotum and eyes, not protruding. Head distinctly declining anteriorly, anterior width of vertex 1.3 times the synthlipsis $(1.85 / 1.44)$, length of head distinctly less than median length of pronotum (1.53/1.89), length of an eye slightly less than twice its width (1.24/0.65). Anteclypeus projecting 0.15-0.20 anteriorly of labrum. Labrum parallel-sided in basal part, apical half triangular with a comparatively sharp tip (fig. 51), basal width larger than median length $(0.60 / 0.55)$. Pronotum posterolaterally rounded, angles hardly anterior of posterior margin (0.15-0.20), maximal width distinctly less than twice anterior width (5.37/3.04) and 2.2 times the lateral length $(5.37 / 2.45)$, lateral margin nearly straight in posterior half, weakly serrate ventrally, about 30 teeth $/ \mathrm{mm}$. Granulations on dorsum of body rather fine, lying on top of the surface. Scutellum distinctly over twice as wide at base than its median length (3.02/1.29) and much less than twice as long as claval commissure (1.29/0.84). Hemielytra leaving only a narrow strip (0.2) of connexiva exposed. Embolium slightly convex dorsally (see comparative notes under L. aculabrum), lateral margins nearly straight but distinctly diverging posteriorly in anterior half, posteriorly smoothly sinuate, lateral margin serrate, approximately 20 teeth $/ \mathrm{mm}$; maximal width across embolium larger than maximal width across connexiva (6.37/5.90). Claval suture indicated, right membranal suture absent, membrane coriaceous, broadly rounded, covering most of left membrane. Part of left membrane covered by right membrane, membranaceous, dark velvety brown to blackish, broadly rounded, membranal suture absent; the lateral exposed part 0.5 or less wide at base, coriaceous and concolorous with corium. Hind wings reduced, reaching halfway the third abdominal tergite, hyaline to whitish opaque. Connexival segments not indented, forming a smooth outer edge of abdomen, posterolateral angle of last connexival segment with a short spine. Connexiva laterally strongly serrate, segment 4 with about 15 teeth $/ \mathrm{mm}$. Prosternal carina of average elevation, distinctly sloping posteriorly, the bifid anterior tip is indistinct in several specimens. Mesosternal carina with a well developed elevated central part with a distinct fossa which usually clothed with hairs (figs. 177, 178), posterior part well developed, distinctly sloping, anterior part without teeth, short and steep. Metasternal carina poorly developed, a hardly elevated tubercle centrally on metaxiphus. Fore femur 1.9 times as long as wide (2.18/1.16). Middle femur 5.2 times as long as wide $(2.22 / 0.40)$ and 1.4 times longer than middle tibia (2.22/1.57). Hind femur 6 times as long as wide (3.07/0.49) and about as long as hind tibia (3.07/2.96).

Male. - Genital segments as in fig. 5, right lobe of tergite 6 with a distinct projection proximally. Aedea- 
gus with the apical widened part partly membranaceous (fig. 6). Pseudoparameres short and stout (fig. 48-50).

Female. - Genital operculum as in fig. 52.

Macropterous form. - Very similar to brachypterous form, hind wings fully developed, light brownish opaque. Hemielytra with claval suture and nodal furrow well developed, right membrane only slightly larger compared to brachypterous form, left membrane and scutellum distinctly more developed, basal width of scutellum 3.20 , median length 1.53 , length of claval commissure 0.67 ; body length of 7.8-8.7 $q$ 8.9, width 0 5.2-6.3 + 6.6, median length of head+pronotum of 3.40 \% 3.30 .

Larva V. - Dimensions: length 8.2, width 6.3, anterior width of vertex 1.43 , width of pronotum 5.40, median length pronotum 1.17, lateral length of pronotum 2.05, median length of head+pronotum 2.45. Colour yellowish with variable, usually extensive brown patches formed by confluence of small dots. In specimens with well developed brown pattern the patch on interoculus is as in adults, pronotum with a median and two lateral longitudinal bands on disk and a large patch laterally at level of posterior half of eyes backward. Mesoalinotum irregularly patched to nearly confluent centrally. Metanotum and dorsum of abdomen with a tendency to become uniformly brown with distinct yellow patches laterally forming a quite regular alternating light and dark pattern laterally on connexiva. Venter medially brown, laterally yellow with the dorsal pattern shining through. Lateral margin of connexiva distinctly serrate with 20 teeth $/ \mathrm{mm}$. Central part of mesosternal carina, relatively much smaller than in adult, strongly elevated.

\section{Distribution}

Brazil: MG, MT, PR. In Minas Gerais this is by far the commonest species, collected in over 15 municipalities (Nieser \& Lane de Melo 1997 and unpublished). Although it is sometimes found at the bottom of small streams, its usual habitat is at the edge of streams between vegetation or leaf litter. Experiments have shown that it can survive a week or more without direct contact with atmospheric air (Nieser \& Lane de Melo 1997).

\section{Comparative notes}

The species after which the L. maculiceps-group is named. This species is variable in size and colour. A female from Sa. do Cipó (N9603) has a dark grey venter and a coal-black dorsum, although, it structurally shows no differences. On average, specimens from higher elevations tend to be darker and slightly larger. It is very similar to $L$. aculabrum La Rivers, see under that species, otherwise the coarse serration of the connexiva, the acute angles of abdominal segments 5 and 6 and the usually well developed characteristic mark on the interoculus will separate this species from others with a similar hemielytral structure.

\section{Limnocoris melloleitaoi De Carlo}

(figs. 53-54, 179-180)

Limnocoris melloleitaoi De Carlo, 1951: 46-47.

Material examined. - BRAZIL: PR, Rio Tacuacal, Morretes, Marumbi, $2 q$ brachypterous paratypes (MACN); Rio Cacatu, Antonina, 1933, leg. O. Leonardos, 19 brachypterous, det. De Carlo (MACN).

\section{Redescription}

Brachypterous form (based on the three dry pinned females mentioned above). - Generally a medium sized elongate light brown species. Dimensions (우 only): length 8.9-9.5-9.8, width: 5.97-6.10-6.24, anterior width of vertex: 1.76-1.85-1.90, width of pronotum: 5.56-5.70-5.83, median length of pronotum: 1.62-1.71-1.76, lateral length of pronotum: 2.30-2.39-2.44, median length of head+pronotum 2.99-3.18-3.30.

Colour. - Interoculus, pronotum and anterior two thirds of embolium brownish yellow, scutellum and rest of dorsum with scattered dark spots. Eyes light to dark brown. Connexiva unicolorous yellowish brown or with vague dark marks at sutures. Venter velvety golden brownish.

Structural characteristics. - Anterior margin of head (including eyes) slightly protruding relative to the curvature of pronotum. Anterior width of vertex 1.2 times the synthlipsis (1.85/1.58). Length of head shorter than median length of pronotum (1.58/1.72). Length of an eye slightly less than twice its width $(1.13 / 0.63)$. Anteclypeus projecting 0.28 anteriorly of labrum. Labrum with parallel sides in basal part, apical half triangular with a blunt tip, basal width 1.3 times the median length $(0.58 / 0.44)$. Pronotum posterolaterally acutely rounded, angles well defined about 0.54 anteriorly of posterior margin of pronotum. Maximal width 1.9 times the anterior width $(5.70 / 2.98)$ and 2.4 times the lateral length (5.70/ 2.39), lateral margin convex, weakly serrate to nearly smooth, teeth difficult to distinguish. Scutellum twice as wide at base than its median length (3.16/1.53) and about one and a half times as long as claval commissure (1.53/1.05). Granulation on dorsum of the body fine, pronounced, lying on top of the surface. Hemielytra leaving only a narrow strip (0.2-0.3) of connexiva exposed, embolium softly convex, posteriorly curving inward, posterolateral angles broadly rounded comparatively well defined, maximal width across embolium little larger than maximal width across the connexiva (6.10/5.80). Claval suture absent. Membranes only slightly reduced, posteriorly 

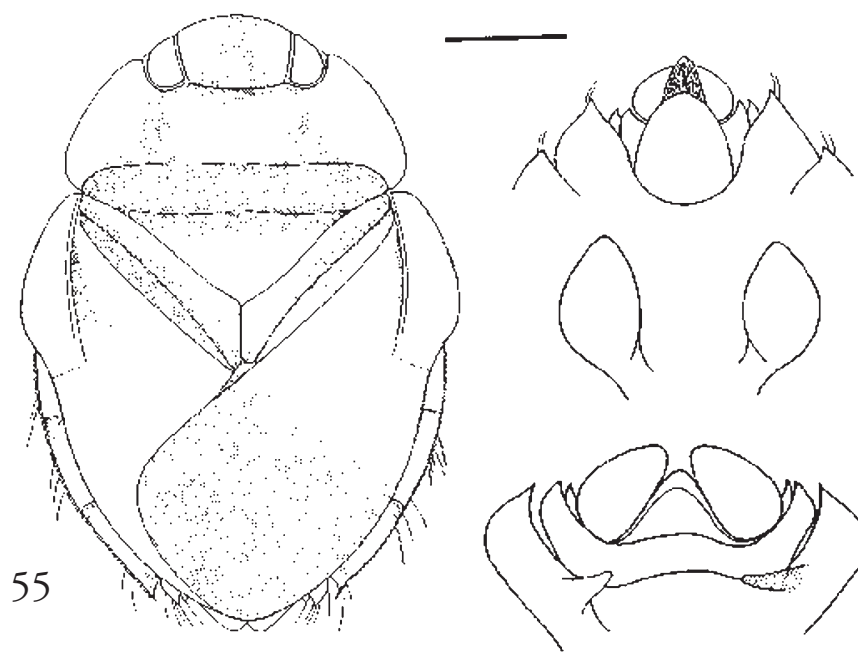

56
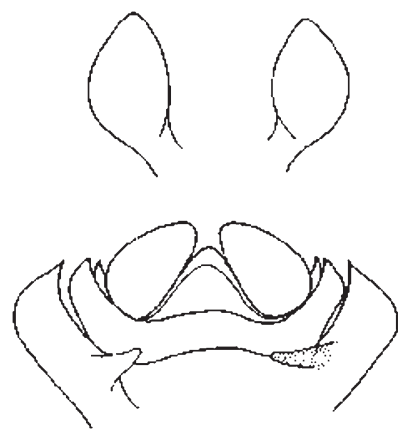

Figs. 55-58.

Limnocoris minutus. - 55 , macropterous male, outline of body, length $7.1 \mathrm{~mm}$; 56, female, apex of abdomen ventral view; 57 , lobes of tergite 8 with pseudoparameres absent; 58, male, apex of abdomen dorsal view. Scales $551 \mathrm{~mm}$; $56-580.5 \mathrm{~mm}$. broadly rounded at the tip, right membrane only slightly different in texture from corium, left membrane mostly covered by right membrane, membranaceous, brownish opaque. Hind wings strongly reduced, transparent, somewhat brownish. Connexival segments weakly serrate laterally, posteriorly more distinctly than anteriorly, 20 teeth $/ \mathrm{mm}$. Posterolateral angles 2-4 obtuse, lateral margin of abdomen continuous, posterolateral angle of last connexival segment pointed. Prosternal carina elevated, softly sloping posteriorly, anterior tip with two points. Mesosternal carina with a large, rather narrow fossa about half as long as the total length of the carina (figs. 179, 180). Metasternal carina small but well developed, a flat tubercle with a ventral fossa covering central part of metaxiphus. Ventral abdominal pilosity yellowish, with short hairs mixed with longer and fine hairs. Fore femur 1.7 times as long as wide (2.31/1.38). Middle femur 4.3 times as long as wide, (2.26/0.52) and 1.3 times longer than middle tibia $(2.26 / 1.80)$. Hind femur 5.6 times as long as wide $(3.12 / 0.56)$ and about as long as hind tibia (3.12/3.25).

Female. - Genital operculum (fig. 54), as long as wide (1.2/1.3).

Male and macropterous form unknown.

\section{Distribution}

Brazil: PR.

\section{Comparative notes}

$L$. melloleitao $i$ belongs to the $L$. maculiceps-group. Its general shape is similar to that of $L$. brasiliensis, $L$. pauper and L. subpauper. Of these L. brasiliensis, is distinctly larger, with a body length of female over 10 $\mathrm{mm}$. In addition, there are differences in the mesosternal carina, the fossa being slightly over one third as long as the carina in L. brasiliensis and half as long in L. melloleitaoi (figs. 161, 162, 179, 180). L. subpauper is distinctly smaller but $L$. pauper is of similar size. However, these two also have a distinctly different mesosternal carina with a small relatively broad central part, whereas the mesosternal carina in L. melloleitaoi has a large elongate central part (figs. 179, 180, 187, $188,201,202)$

\section{Limnocoris minutus De Carlo} (figs. 55-58, 181-182)

Limnocoris minutus De Carlo, 1951: 49-50. Holotype macropterous female: PARAGUAY: Río Paraguay, XII. 1913, 86, Vapor 'Etruria' (MACN, No 2964). [examined] Limnocoris minutus; La Rivers 1971: 76.

Material examined. - Holotype, see above. ARGENTINA, province of Corrientes, Ituzaingó, 8580, 29.VIII.1979, excol. A.O. Bachmann, 10 2 q macropterous (MACN).

\section{Redescription}

Macropterous form (based on the dry pinned specimens cited above). - Generally a small elongate brownish yellow species.

Dimensions: length of 7.05 o 6.78-6.92-7.05, width 04.75 o 4.61-4.75-4.88, anterior width of vertex ô 1.22 \% 1.22-1.30-1.35, width of pronotum o 3.93 \% 3.66-3.89-4.07, median length of pronotum $\delta 1.22$ क $1.35-1.44-1.49$, lateral length of pronotum ô 1.62 우 1.76-1.85-1.90.

Colour. - Quite uniformly brownish yellow with scattered brown spots. Eyes dark brown, interocular spots arranged in a pattern, semicircular posteriorly, extending anteriorly in a narrow band. Connexiva with vague dark marks at sutures. Venter yellowish, medially yellowish brown. 
Structural characteristics. - Anterior margin of head (including eyes) very slightly protruding relative to the curvature of pronotum. Anterior width of vertex 1.2 times the synthlipsis (1.28/1.05). Length of head shorter than median length of pronotum (1.13/1.38). Length of an eye 1.5 times its width $(0.83 / 0.54)$. Anteclypeus projecting 0.11 anteriorly of labrum. Labrum small, with slightly apically convergent sides in basal part, apical half triangular with a sharp tip, basal width 1.2 times the median length $(0.49 / 0.40)$.

Pronotum posterolaterally broadly rounded, angles ill defined about 0.27 anteriorly of posterior margin of pronotum. Maximal width 1.7 times the anterior width $(3.92 / 2.28)$ and 2.3 times the lateral length $(3.92 / 1.73$ oै) 1.62 o 1.85 , median length: ô 1.22 ${ }^{1.44}$, lateral margin nearly straight in median part, ventrally indistinctly serrate, teeth difficult to count.

Scutellum over twice as wide at base than its median length (2.44/1.08) and less than twice as long as claval commissure (1.08/0.76). Granulation on dorsum of the body fine, pronounced lying on top of the surface. Hemielytra leaving only a narrow strip (0.15) of connexiva exposed, embolium softly convex, posteriorly curving inward, posterolateral angles broadly rounded, maximal width across embolium little larger than maximal width across the connexiva (4.75/4.34). Claval suture present. Membranes fully developed, posteriorly round at the top, right membrane only slightly different in texture from corium, left membrane mostly covered by right membrane, brownish opaque. Connexival segments weakly serrate laterally, 14-15 teeth $/ \mathrm{mm}$, with 2 or 3 long hairs by segment. Posterolateral angles 2-4 obtuse, lateral margin of abdomen continuous, posterolateral angle of last connexival segment pointed. Prosternal carina medium elevated, distinctly sloping posteriorly, anterior tip distinct. Mesosternal carina with a shallow but well developed broad fossa about half as long as the carina, anterior tooth low and poorly differentiated (figs. 181, 182). Metasternal carina small but well developed, a tubercle with a distinct ventral fossa covering central part of metaxiphus. Ventral abdominal pilosity yellowish, with short and fine hairs. Fore femur 1.7 times as long as wide (1.44/0.85). Middle femur 5 times as long as wide, (1.76/0.37) and 1.5 times longer than middle tibia (1.76/1.15). Hind femur 6 times as long as wide $(2.30 / 0.39)$ and about as long as hind tibia (2.30/2.23).

Male. - Genital segments as in fig. 56 with a well defined tooth at base of right lobe of tergite 6 . Pseudoparameres absent (fig. 58).

Female. - Genital operculum with posterior margin narrowly rounded (fig. 57), as long as wide (0.90/0.85).

Brachypterous form unknown.

\section{Distribution}

Paraguay, NE Argentina (province of Corrientes).

\section{Comparative notes}

L. minutus belongs to the L. maculiceps-group. It is of similar size as L. pusillus which is, however, predominantly brachypterous and has a very different mesosternal carina with a narrow slit-like fossa, whereas the fossa in L. minutus is very wide (figs. 181, $182,193,194)$.

\section{Limnocoris nigropunctatus Montandon}

(figs. 59-62, 68, 183-184)

Limnocoris nigropunctatus Montandon, 1909: 49-51.

Limnocoris sattleri De Carlo 1966: 113. Holotype brachypterous male: BRAZIL: MG, Levantina, Ibicatu, 13.VIII.1963, leg. W. Sattler, Sa 4971 ơ (ZSMC). Syn. n.

Material examined. - Holotype of $L$. sattleri see above. Same data as holotype of S. sattleri 1 ( ) (allotype + of $L$. sattleri, ZSMC). BRAZIL: MG, Levantina, Rio Can-Can, VIII.1963, leg. W. Sattler, Sa 888, 1 đ (paratype L. sattleri, ZSMC) - RJ, Angra dos Reis, Ariro, 28.III.1948, leg. A. Leitão de Carvalho,

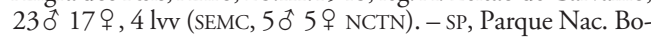
caina, Rio Macumba, 26.II.1977, leg. Santos, 2 우 (det. J.T. Polhemus, JTPC). - PR, Serra do Mar, Rio Pinhal, $25^{\circ} 13^{\prime} \mathrm{S}$ $49^{\circ} 00^{\prime} \mathrm{W}, 850 \mathrm{~m}$ asl., V.1964, leg. F. Plaumann, $70^{\top} 13$ 우 (CASC, 3 o $^{\circ} 1$ JTPC); PR Serra do mar, Rio Mirim, $25^{\circ} 12^{\prime} \mathrm{S}$ $48^{\circ} 59^{\prime} \mathrm{W}, 500 \mathrm{~m}$ asl., V.1964, leg. F. Plaumann, $10^{\text {के }} 2$ ㅇ (CASC). - SC, Rio Cubatão, 26’11S 48'55W, 10m, XI.1964, leg. F. Plaumann 2011 은 (NCTN); SC, Baracão, Aguas Frias Riv. 1942, leg. F. Plaumann, 101 (JTPC, $q$ lacking head and pronotum); SC Baracao, Rio Aguas Frias, 27\% 42 'S $49^{\circ} 19^{\prime} \mathrm{W}, 500 \mathrm{~m}$ asl., XII.1962, leg. F. Plaumann, 31 ơ 18 ㅇ (20 macr., CASC). Brachypterous unless otherwise indicated.

Remark. Part of the series from RJ, Angra dos Reis, has been compared with the holotype from SC, Blumeneau which is in the Zoological Museum, Helsinki, Finland.

\section{Redescription}

Brachypterous form (based on dry pinned specimens). - Generally a medium sized, dorso-ventrally somewhat bulging, broadly oval species, colour dull light brown. Dimensions: length of 8.2-8.5-8.7 of 8.2-8.7-8.9, width of 6.3-6.6-6.8 क 6.3-6.6-6.8, anterior width of vertex 0 1.73-1.80-1.96 \& 1.80 1.84-1.86, width of pronotum 0 5.55-5.75-6.02 + 5.70-5.88-5.94, median length of pronotum ô 1.50 1.67-1.75 $91.53-1.72-1.82$, lateral length of pronotum ot 2.25-2.47-2.60 \& 2.42-2.55-2.63, median length of head+pronotum ô 3.00-3.10-3.23 क 3.003.17-3.30.

Colour. - Light brown, interoculus with medium brown points arranged posteriorly more ore less in a circle continuing anteriorly in two submedial rows. Disk of pronotum and scutellum with medium brown points. Hemielytra variably marked with blackish points, from nearly absent to colouring them 

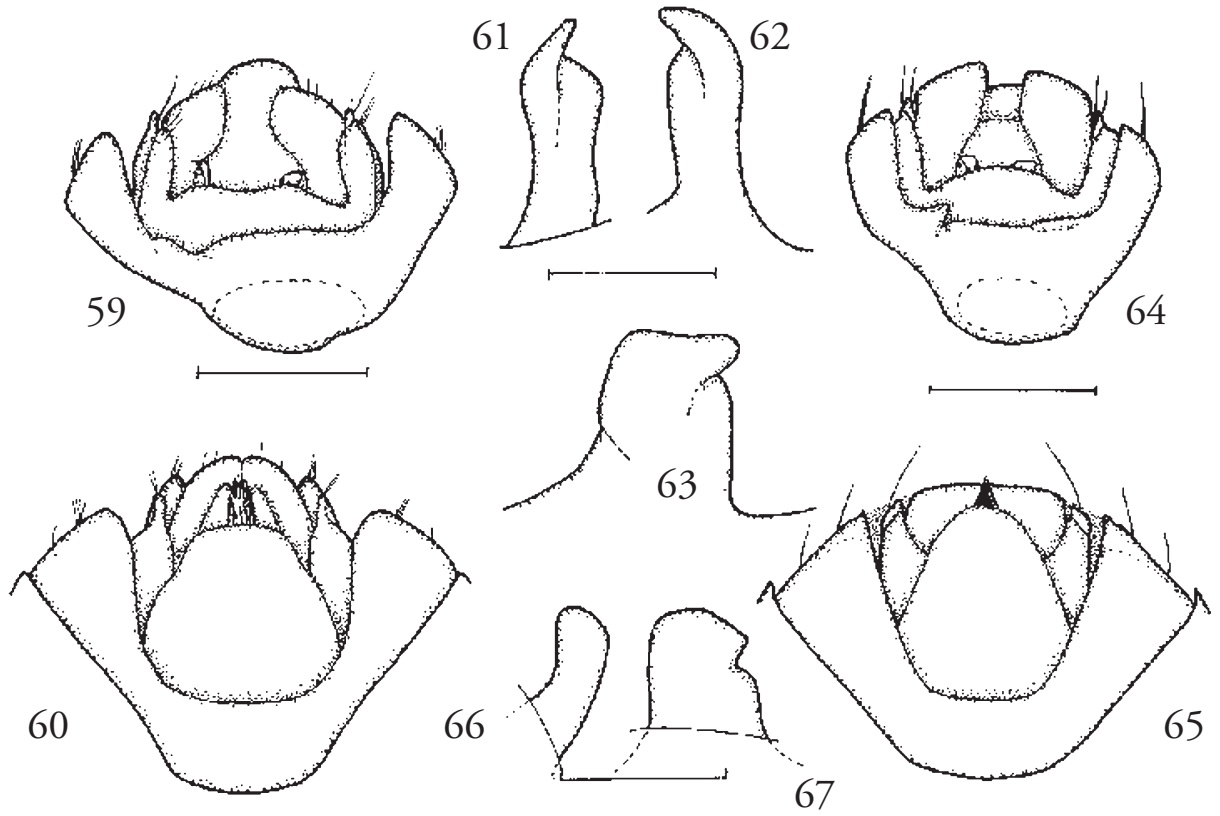

Figs. 59-62. Limnocoris nigropunctatus. - 59, male, apex of abdomen dorsal view; 60, female, apex of abdomen, ventral view; 61, right pseudoparamere, medial view; 62, right pseudoparamere dorsal view; 63, left pseudoparamere. Scales 59, $601 \mathrm{~mm}$; 61-63 $0.25 \mathrm{~mm}$.

Figs. 64-67. Limnocoris ovatulus. - 64, male, apex of abdomen, dorsal view; 65, female lectotype, apex of abdomen, ventral view; 66, right pseudoparamere; 67, left pseudoparamere. Scales 64, $651 \mathrm{~mm}$; 66, $670.25 \mathrm{~mm}$.

greyish brown; membranes with irregular blackish spots. In addition most specimens with two pairs of small but well-defined blackish pots, one at posterior point of inner embolar suture, the other pair anteriorly on connexiva just behind embolium. Anterior margins of connexival segments infuscated. Venter and legs sordid yellow, abdominal venter mostly greyish.

Structural characteristics. - Anterior margin of head somewhat more convex and slightly projecting in relation to the curvature of pronotum. Head distinctly declining anteriorly, anterior width of vertex 1.3 times the synthlipsis (1.82/1.38); length of head subequal to median length of pronotum (1.70/1.73); length of an eye about twice its width (1.37/0.66); anteclypeus projecting $0.10-0.15$ anteriorly of labrum. Lateral margins of labrum very slightly converging in basal half, converging to an obtuse tip in apical half, its basal width 1.2 times the median length $(0.56 / 0.47)$. Pronotum distinctly convex dorsally, lateral angles acutely rounded, 0.2 anteriorly of posterior margin, lateral margin weakly serrate, about 42 indistinct shallow teeth/mm; maximal width slightly over twice anterior width (5.78/2.75) and 2.3 times the lateral length (5.78/2.50). Scutellum over twice as wide at base as its median length (2.64/1.25) and 1.4 times as long as claval commissure (1.25/0.92). Hemielytra leaving a broad (0.6-0.7 wide) strip of abdomen exposed, inner two thirds of this area wrinkled. Embolium laterally slightly convex, posterior part of lateral margin nearly straight and nearly parallel to longitudinal body axis, posterolateral lateral angle obtuse, comparatively well defined (fig. 68), its lateral margin indistinctly serrate in proximal half with about 30 teeth/mm, width across embolium larger than maximal width across connexiva $(6.65 / 6.22)$, claval suture absent, right membrane strongly reduced, coriaceous but thinner and smoother than corium, narrowly rounded, leaving most of left membrane exposed, membranal suture absent. Left membrane more strongly reduced than right membrane, coriaceous, narrowly rounded apically; narrow inner strip of left hemielytron, covered by right hemielytron, membranaceous, smoky dark brown to blackish. The hemielytra end in two separate points. Hind wings vestigial. Covered part of abdomen waxy medium rufous brown. Connexival segments distinctly indented, the margins of connexival segments at their bases originating 0.05-0.10 inward compared with posterolateral angle of preceding segment, last segment obtusely angulate posteriorly. Connexival segment 4 serrate, 
about 35 teeth $/ \mathrm{mm}$. Dorsal granulations, set in small pits, on membrane finer and more densely set than on corium. Prosternal carina distinctly to strongly slanting posteriorly, anteriorly distinctly bifid. Mesosternal carina (figs. 183, 184), strongly elevated, well developed, posterior part about half as long as central part, distinctly sloping, central part wide with a widely oval to rhomboid fossa, anterior part about as long as central part, distinctly sloping, without tooth at anterior edge of fossa and a distinct tooth anteriorly. Metasternal carina well developed ventral fossa distinctly developed, occupying central quarter to third of metaxiphus. Pubescence of venter well developed more sparsely in median area. Fore femur distinctly less than twice as long as wide (2.11/1.17). Middle femur four and a half times as long as wide (2.21/0.49) and about 1.3 times as long as middle tibia (2.21/1.65). Hind femur nearly 6 times as long as wide $(2.98 / 0.51)$ and about as long as hind tibia (2.98/2.99).

Male. - Genital segments as in fig. 59, proximal projection of right lobe of tergite 6 vestigial. Right pseudoparamere with a finger-like tip (fig. 62).

Female. - Genital operculum (fig. 60) lateral margin slightly sinuate, apex broadly rounded nearly truncate, only slightly wider than long (1.3/1.1).

Macropterous form (based on 2 teneral slightly shrivelled males). - Similar to the brachypterous form except for the differences correlated with the development of the wings. Dimensions. Length 8.05-8.3, width 6.496.50, width of pronotum 5.69-5.78. Posterolateral angles of pronotum rounded, ill-defined, about 0.6 in front of its posterior margin. Hemielytra with claval suture and nodal furrow distinct. Membranes fully developed, right membrane covering left, brown with blackish mottling; posterolateral angles of embolium somewhat sharper than in brachypterous specimens. Median length of scutellum three times the claval commissure (1.53/0.48). Connexiva indented (0.05) segments anteriorly with a distinct blackish patch.

Larva V. - Dimensions length 7.2, width 5.8, anterior width of vertex 1.58, width of pronotum 5.07, median length pronotum 1.03, lateral length of pronotum 1.93, median length of head+pronotum 2.28. Colour yellowish with small brown dots. On the median part of interoculus the darker dots are arranged in two longitudinal lines with a wide distance between them posteriorly and a narrow distance anteriorly. On the disk of pronotum the darker dots form a median and two lateral bands. On alinotum and abdomen the darker dots are regularly dispersed leaving broad bands laterally unspotted. Venter yellowish to light, somewhat greyish brown. Lateral margin of connexiva serrate with about 43 teeth $/ \mathrm{mm}$. Mesosternal carina a simple, strongly elevated laminar structure, apex truncate to slightly convex in some specimens with an indication of a fossa.

\section{Distribution}

Brazil: MG, RJ, SP, PR, SC.

\section{Comparative notes}

L.nigropunctatus belongs to the L. insignis-group. Its body shape, notably in being not strongly flattened, is similar to $L$. decarloi sp. n., but it has the pronotum more divergent posteriorly, the posterolateral angle of embolium more distinctly defined and usually a deeper and somewhat smaller fossa on metasternal carina (figs. 165, 166, 183, 184). Other species with similar hemielytral reduction are generally flatter, for further differences see key.

\section{Limnocoris ovatulus Montandon}

(figs. 64-67, 69, 185-186)

Limnocoris ovatulus Montandon, 1897: 4-5.

Limnocoris ovatulus, Montandon 1898: 414; De Carlo 1951: 44; La Rivers 1971: 76; Lopez Ruf 1993: 17-19.

Lectotype designation. - Montandon (1897) described this species from specimens collected by Dr. A. Borelli at Argentina, Salta, Dr A. Borelli. We found among specimens from BMNH 1 macropterous female bearing a label Argentina, Salta, Dr A. Borelli. Additional labels: 1) L. ovatulus Montandon type 1897 2) Montandon coll. 1901-233 3) a small round label with red margin: 'type'. Montandon (1897) did not designated a holotype, this specimen is one of the original series kept initially in his collection and herewith designated lectotype in order to fix the identity of this species. A red label: lectotype desg. Nieser \& L.-Ruf has been added to the above mentioned labels.

Material examined. - Lectotype, see above. ARGENTINA: Catamarca, Río Paclín, 29.V.1990, area with sparse xerophytic vegetation, the specimens were taken in a side channel of the main stream with crystalline well oxygenated water due to high current velocity, depth $0.15-0.20 \mathrm{~m}$, bottom with small to medium sized pebbles, no aquatic vegetation, the habitat was shared with Ambrysus ochraceus Montandon, 30 3 ㅇ leg. M. Lopez Ruf (MACN). - Salta, Rio Valle, 1 우 (det. De Carlo, JTPC); Salta, Juntas de San Antonio, Río Bermejo, 6.XI.1992, the specimens were collected in a tree less area, near the margin of the stream at a depth of $0.2-0.3 \mathrm{~m}$, water turbid, current velocity low, bottom stony with pebbles, no aquatic vegetation, the habitat was shared with Ambrysus bergi Montandon, Limnocoris borellii Montandon) and Cryphocricos sp., leg. M. López Ruf, 50 \% 5 (MACN). - BOLIVIA, Yacuiva, VIII.1917, 1 đิ (SEMC) first record for Bolivia, [Yacuiva is probably Yacuiba on the border with Argentina]. All macropterous.

\section{Redescription}

Macropterous form (based on the lectotype, the male from Bolivia and alcohol specimens from Salta). - Generally a rather small oval medium brown species, with blackish right membrane. Dimensions: length ô 


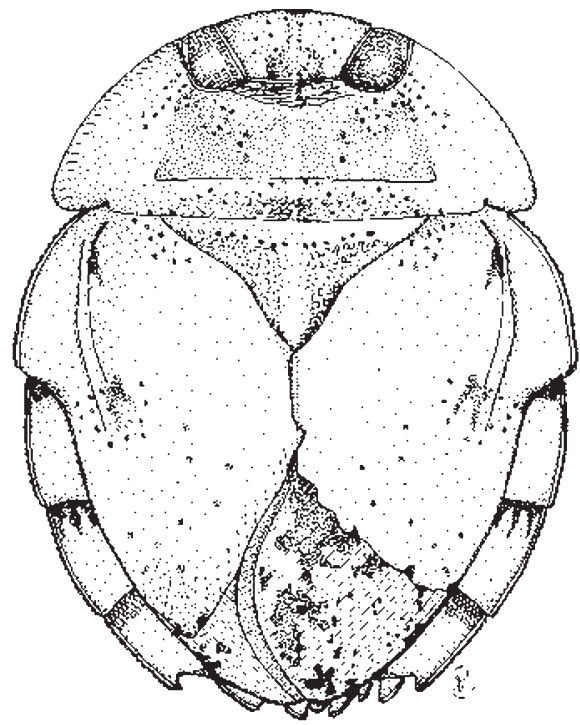

68

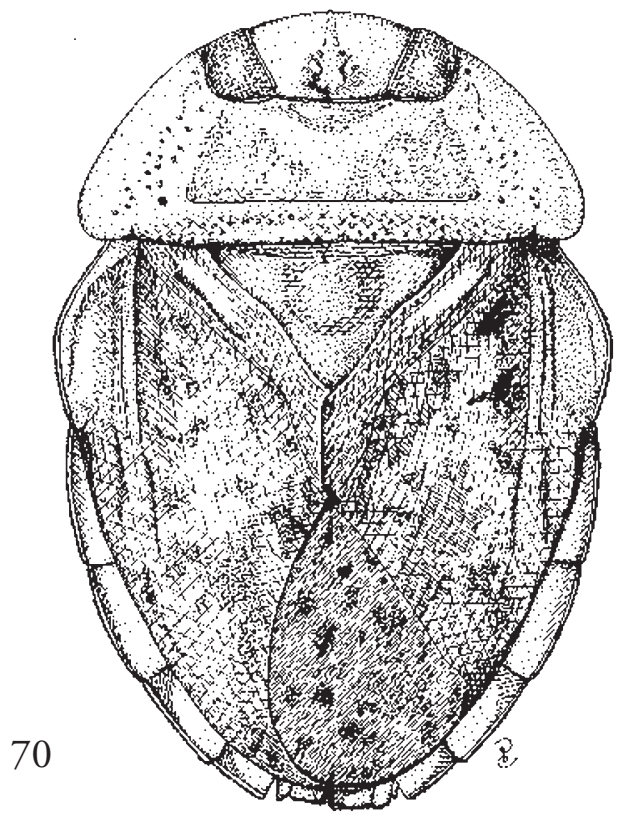

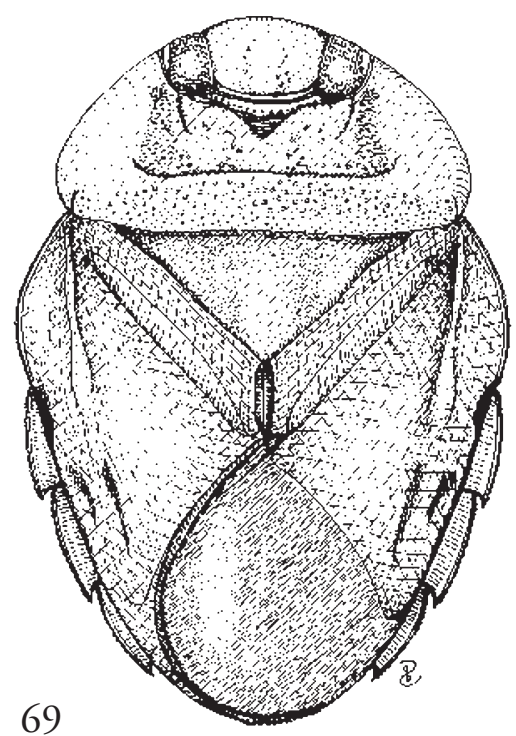

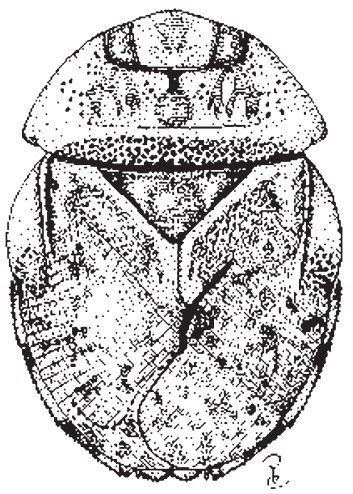

71

Figs. 68-71. Habitus of Limnocoris. - 68, L. nigropunctatus brachypterous male, body length $8.5 \mathrm{~mm}$; 69, L. ovatulus lectotype, macropterous female, body length $8.6 \mathrm{~mm} ; 70, \mathrm{~L}$. pauper, brachypterous female, body length $9.5 \mathrm{~mm} ; 71, L$. pusillus, brachypterous female, body length $6.8 \mathrm{~mm}$. 
7.90-9.12 ㅇ 8.42-9.58, width of 5.40-6.18 क 5.906.37, anterior width of vertex of 1.60-1.73 9 1.621.81 , width of pronotum ot 4.58-5.48 \% 5.02-5.61, median length pronotum of 1.61-1.84 क $1.75-2.00$, lateral length of pronotum of 2.32-2.44 $+2.35-2.52$, median length of head+pronotum 0 2.83 +2.90 .

Colour. - Quite uniformly light brown, interoculus from nearly plain to a triangular dark patch, a narrow row of small black dots at anterior margin of pronotum, posterior third of pronotum also with small but quite dense black dots. Membranes and narrow bands along costal margins from membrane to embolium dark brown to blackish. Eyes dark brownish-grey. Exposed part of connexival segments in dorsal view unicolorous. Venter and legs yellowish, central part of mesosternal carina and lateral patches anteriorly on metasternum dark.

Structural characteristics. - Anterior margin of head in a smooth curve with pronotum and eyes. Anterior width of vertex 1.1 times the synthlipsis (1.69/1.49), length of head less than median length of pronotum (1.48/1.84), length of an eye nearly twice its width (1.07/0.56). Anteclypeus projecting 0.14 anteriorly of labrum. Lateral margins of labrum very slightly convergent in basal part, apical half triangular with a sharp tip, basal width larger than median length $(0.49 / 0.39)$. Pronotum posterolaterally broadly rounded, angles consequently ill-defined, approximately 0.5 anteriorly of posterior margin, maximal width a little less than twice anterior width $(5.28 / 2.74)$ and 2.2 times the lateral length (5.28/2.42), lateral margin weakly serrate about 32 teeth $/ \mathrm{mm}$. Granulations on dorsum of body placed in small pits, due to their whitish colour most distinct on right membrane. Scutellum 2.6 times as wide at base as its median length (3.50/1.37), and 1.6 times as long as claval commissure (1.37/0.84). Embolium convex, posteriorly hardly sinuate, lateral margin weakly serrate (anteriorly more distinctly than posteriorly), approximately 20 teeth $/ \mathrm{mm}$; maximal width across embolium larger than maximal width across connexiva (6.09/5.81). Claval suture distinct, right membranal suture absent, membrane coriaceous but distinctly thinner, smoother and darker than corium, broadly rounded, covering left membrane. Left membrane membranaceous, dark brown to blackish, broadly rounded, membranal suture distinct. Hind wings fully developed, brownish, more or less transparent. Hemielytra leaving a narrow strip (0.15-0.25) of connexiva exposed. Connexival segments strongly dented, posterolateral angles of abdominal segments 3-6 distinctly spinose. Segment 4 ventrally serrate with about 25 teeth $/ \mathrm{mm}$. Prosternal carina low, gradually sloping posteriorly. Mesosternal carina with a large central part, its fossa closed to a narrow slit centrally with opening anteriorly and posteriorly (fig. 185, 186), posterior and anterior parts short. Metasternal carina small but well developed, a flat tubercle with a ventral fossa. Fore femur 1.7 times as long as wide (1.97/ 1.16). Middle femur 4.6 times as long as wide $(2.11 / 0.46)$ and 1.3 times longer than middle tibia $(2.11 / 1.58)$. Hind femur 5.7 times as long as wide (2.84/0.50) and about as long as hind tibia (2.84/2.72).

Male. - Genital segments as in fig. 64, right lobe of tergite 6 with a distinct projection proximally, pseudoparameres as in figs. 66, 67.

Female. - Genital operculum with a comparatively narrowly rounded tip (fig. 65).

Brachypterous form unknown.

\section{Distribution}

Argentina: Catamarca, Salta; Bolivia: Tarija.

\section{Comparative notes}

$L$. ovatulus belongs to the $L$. maculiceps-group. The colour pattern and general shape is similar to the sympatric $L$. pectoralis, which is larger, has a different mesosternal carina with a very large, deep and open fossa (figs. 186, 190) and has the posterolateral angles of the connexiva not spinose. The macropterous form of $L$. pauper is also similar, although it has a larger gap between pronotum and embolium larger and therefore appears slightly different. L. pauper has non-spinose posterolateral angles of connexiva and a small but open fossa on the mesosternal carina (fig. 188).

\section{Limnocoris pauper Montandon}

(figs. 70, 72-76, 187-188)

Limnocoris pauper Montandon, 1897: 5. Holotype brachypterous $q$ : BRAZIL: 'Brésil Nord', Cumbase (BMNH).

Limnocoris plaumanni La Rivers, 1973: 4-7. Syn. n.

Remark. - Apart from the locality label, the holotype bears a label 'Limnocoris pauper Montandon 1897, type'. Judging from the description Montandon (1897) based his description on this single specimen, so it is a holotype by monotypy.

Material examined. - Holotype, see above. BRAZIL: RS, Tainhas, Arroio Corneto $29^{\circ} 45^{\prime} \mathrm{S} / 50^{\circ} 15^{\prime} \mathrm{W}, 800 \mathrm{~m}$ asl., IV.1959, leg. F. Plaumann L. plaumanni 1 ô (allotype) 2 우 paratypes (CASC). Same data as paratypes of L. plaumanni but not used in original description 1 to 39 (NCTN) - SP, S(erra) dos Agudos, Rib(eirão) do Poço, $24^{\circ} 12^{\prime} \mathrm{S} 47^{\circ} 59^{\prime} \mathrm{W}, 1000 \mathrm{~m}$, XI. 1963, leg. F. Plaumann, 2 ㅇ (1 macr.). S(erra) do Descanço, R. Braço da Pedra, 24⒋ $44^{\prime} \mathrm{S} 48^{\circ} 44^{\prime} \mathrm{W}, 1000 \mathrm{~m}$, XI.1963, leg. F. Plaumann, 1 ㅇ - PR, Serra do Mar, R. São João, $25^{\circ} 46^{\prime} \mathrm{S} 49^{\circ} 05^{\prime} \mathrm{W}, 800 \mathrm{~m}$ asl., V. 1964, leg. F. Plaumann, $2 q$ ( 19 CASC, labelled paratype $L$. plaumanni by la Rivers but not mentioned in his description of the species, 1 ㅇ NCTN); Serra do Mar, Rio do Cervo, $25^{\circ} 14^{\prime}$ 'S $49^{\circ} 01^{\prime} \mathrm{W}$, $1200 \mathrm{~m}$, XII.1963, leg. F. Plaumann, 1 ㅇ. - PR, Camp. Palmas, Laj da Taipa, $26^{\circ} 15^{\prime} \mathrm{S} / 52^{\circ} 05^{\prime} \mathrm{W}, 1200 \mathrm{~m}$ asl., leg. F. Plaumann, 1 . PR, Porto da Cima, Rio Ipiranga, XI. 1958, 

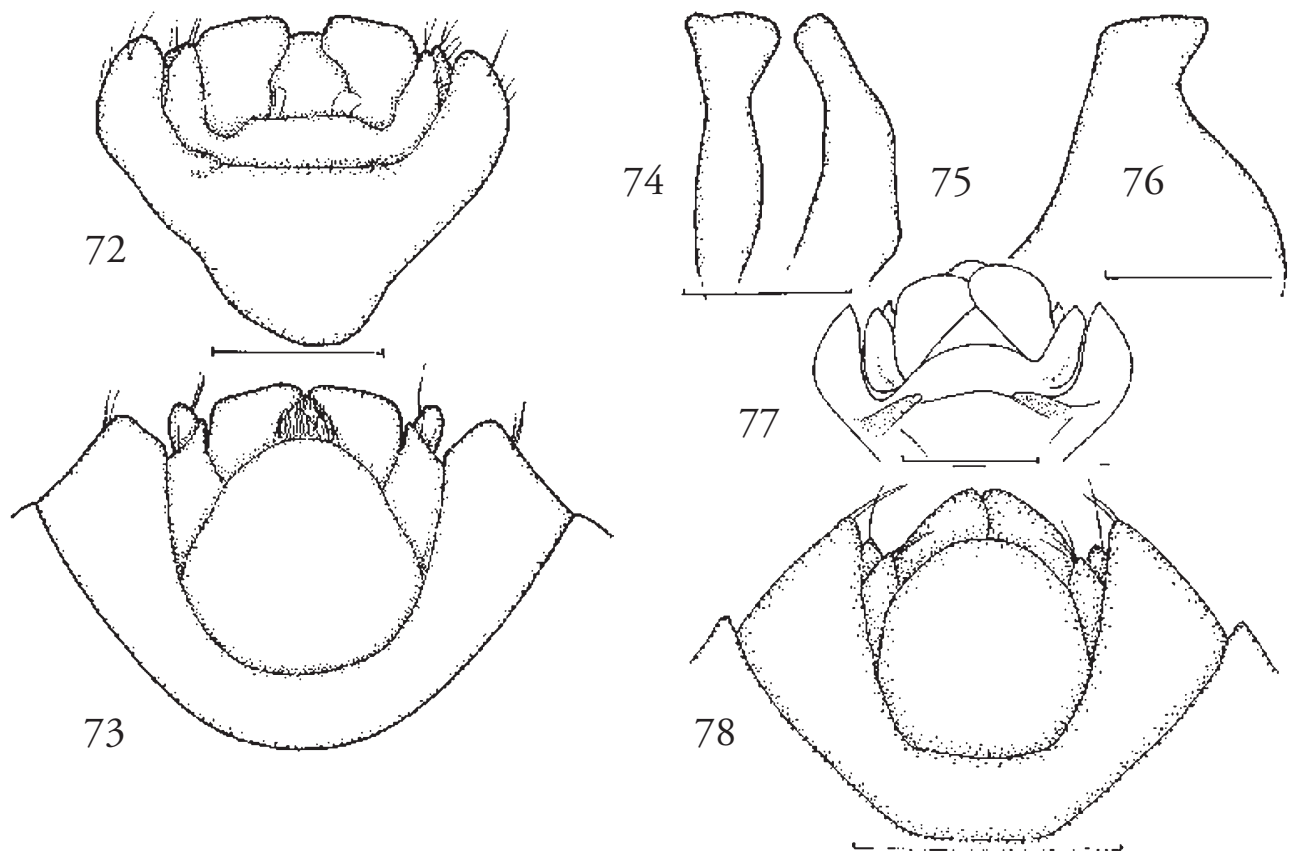

Figs. 72-76. Limnocoris pauper. - 72, male, apex of abdomen, dorsal view; 73, female, apex of abdomen, ventral view; 74, right pseudoparamere medial view; 75, right pseudoparamere, dorsal view; 76, left pseudoparamere. Scales 72, $731 \mathrm{~mm}$; 74 $760.25 \mathrm{~mm}$.

Figs. 77-78. Limnocoris pectoralis. - 77, male, apex of abdomen in dorsal view; 78, female, apex of abdomen in ventral view. Scale $1 \mathrm{~mm}$.

leg. F. Plaumann, $10^{\text {đ. }}$ - SC, Rio Cubatão, $26^{\circ} 11^{\prime}$ S $48^{\circ} 55^{\prime} \mathrm{W}$, $10 \mathrm{~m}$, XI. 1964, leg. F. Plaumann, $1+$ - RS, Pulador, XI. 1959, leg. F. Plaumann, 1 . Brachypterous and NCTN unless otherwise indicated.

Discussion. - The specimens collected by Plaumann and described as L. plaumanni agree very well with the holotype of $L$. pauper both in dimensions, general shape and structural detail, including the female genital operculum. Thus we consider L. plaumanni La Rivers (1973) to be a junior synonym of $L$. pauper Montandon (1897).

\section{Redescription}

Brachypterous form (based on dry pinned specimens). - Generally a medium sized, elongate oval, medium brown species. Dimensions: length ot 8.99.1-9.4 o 9.0-9.4-10.1, width of 5.99-6.07-6.16 우 5.90-6.40-7.00, anterior width of vertex $\delta$ 1.79$1.84-1.92+1.80-1.85-1.93$, width of pronotum $\delta$ 5.38-5.55-5.62 क 5.26-5.77-6.30, median length pronotum of 1.65-1.74-1.87 क 1.64-1.77-2.00, lateral length of pronotum 0 t 2.40-2.45-2.53 +2.42 2.62-2.90, median length of head+pronotum $\delta$ 3.04-3.07-3.12 o 3.12-3.27-3.42.
Colour. - Interoculus, pronotum and scutellum light to medium brown eyes brownish to grey. Hemielytra dark due to dark brown to blackish mottling which may become confluent. Interoculus with a characteristic dark mark, broad posteriorly, narrowing anteriorly, broad again halfway between eyes and narrowing anteriorly (fig. 70); eyes dark brownish-grey. Embolium yellowish, exposed part of connexival segments in dorsal view yellowish, anterior third infuscated. Prosternum yellowish to light brown, median area and a pair of dark stripes along anterolateral margin darker embolium infuscated. Meso- and metasternum variable from yellowish to castaneous, legs yellow. Abdominal venter covered by a thick layer of golden yellow pubescence.

Structural characteristics. - Anterior margin of vertex following the curvature of pronotum and eyes, not protruding. Head distinctly declining anteriorly, anterior width of vertex 1.1 times the synthlipsis (1.84/1.63), length of head subequal to median length of pronotum (1.78/1.73), length of an eye slightly over twice its width $(1.41 / 0.65)$. Anteclypeus projecting 0.10-0.12 anteriorly of labrum. Labrum parallelsided in basal part, apical half triangular with a broad- 
ly rounded tip, basal width larger than median length $(0.62 / 0.48)$. Pronotum posterolaterally rounded, angles ill defined, about 0.5 anterior of posterior margin, maximal width distinctly less than twice anterior width $(5.56 / 2.89)$ and 2.2 times the lateral length (5.56/2.48), lateral margin weakly but evenly convex, serrate ventrally, about 27 teeth $/ \mathrm{mm}$. Granulations on dorsum of body fine, lying in small pits which form a reticulate pattern, granulations on membrane only slightly smaller and denser than on corium. Scutellum distinctly over twice as wide at base than its median length (2.98/1.34) and of subequal length claval commissure (1.36/1.35). Hemielytra leaving only a narrow strip (0.3) of connexiva exposed. Embolium with lateral margins weakly convex, gradually curving inward posteriorly, lateral margin serrate, approximately 20 teeth/mm; maximal width across embolium only a little larger than maximal width across connexiva (6.26/6.11). Claval suture absent, right membrane coriaceous but thinner than corium, about 0.3 times as long as hemielytron, broadly rounded, covering most of left membrane which is medially distinctly reduced. Part of left membrane covered by right membrane, membranaceous, velvety blackish, apically broadly rounded, the lateral exposed part about 1.0 wide at base, coriaceous and concolorous with corium or darker. Hemielytra just not reaching apex of abdomen. Hind wings vestigial. Dorsum of abdomen velvety orange. Connexival segments not to hardly indented (indentations less than 0.03), forming a smooth outer edge of abdomen, posterolateral angle of last connexival segment acutely rounded. Connexiva laterally serrate, segment 4 with about 25 teeth $/ \mathrm{mm}$. Prosternal carina of average elevation, distinctly sloping posteriorly, the bifid anterior tip well developed. Mesosternal carina with a short, steep posterior part about half as long as central part $(0.35 / 0.65)$ strongly elevated but rather short and narrow $(0.65 / 0.35)$ central part with a small, rather narrow, shallow fossa with a somewhat irregular lateral margin (figs. 187, 188), anterior part well developed, about as long as or slightly shorter than central part, distinctly sloping, tooth at anterior edge of fossa poorly defined, anterior tooth blunt. Metasternal carina well developed, occupying central third of metaxiphus, ventral fossa present. Fore femur 1.7 times as long as wide (2.26/1.32). Middle femur 4.2 times as long as wide (2.27/0.54) and 1.2 times longer than middle tibia (2.27/1.85). Hind femur five times as long as wide (3.02/0.60) and distinctly shorter than hind tibia (3.02/3.28).

Male. - Genital segments as in fig. 72, right lobe of tergite 6 with a poorly developed projection proximally. Right pseudoparamere narrow with in inner view a somewhat widened tip (figs. 74,75 ).

Female. - Genital operculum (fig. 73) as long as wide (1.4/1.4) lateral margins basally diverging, api- cally virtually straight, converging to a comparatively narrow truncate tip.

Macropterous form (based on the single $q$ from SP). - Colour and most characteristics as in brachypterous form. Dimensions length 9.68, width 6.10, anterior width of vertex 1.80 , width of pronotum 5.61 , median length pronotum 2.10 , lateral length of pronotum 2.72, median length of head+pronotum 3.43. Pronotum with poorly defined, broadly rounded posterolateral angles which are about $1 \mathrm{~mm}$ in front of its posterior margin median length of scutellum twice the length of claval commissure (1.5/0.70). Claval suture distinct, right membrane well developed, about 0.4 as long as hemielytron (measured along longest axis of hemielytron), blackish and of thinner texture than corium. Left membrane and hind wing not checked because of poor condition of specimen.

\section{Distribution}

Brazil: SP, PR, RS.

We have not been able to locate Cumbase, N. Brazil. Judging from the time the species was described, it could be in the Atlantic NE of Brazil. Probably this species is distributed along the entire Atlantic E. Coast of Brazil but fresh material from NE Brazil is needed to support this assumption.

\section{Comparative notes}

L. pauper belongs to the L.maculiceps-group. Its general shape is similar to that of $L$. brasiliensis, which on average is larger and has a large black patch on the ventral side of fore femur in males. Other species with a similar shape are L. melloleitaoi and L. subpauper, see under those species.

\section{Limnocoris pectoralis Montandon}

(figs. 77-81, 189-190)

Limnocoris pectoralis Montandon, 1897: 6.

Limnocoris pectoralis; De Carlo 1951: 44.

Limnocoris peruvianus Melin, 1930: 194-196. Syn. n.

Lectotype designation. - Montandon (1897) described this species from specimens colleted by A. Borelli at Argentina, Salta. We studied a specimen from the collections of the NHMW labelled: Rep. Argentina, Salta, Dr. A. Borelli, 10 macr., L. pectoralis det. Montandon. This specimen belongs to the original series studied by Montandon (1897) who did not designate a holotype. In order to fix the identity of this species this specimen is herewith designated lectotype. Additional labels: a second identification label: L. pectoralis Mont. with det. Montandon in print and a red label: Lectotype dsg. Nieser \& Lopez-Ruf.

Material examined. - Lectotype see above. - ARGENTINA: Salta, Pocitos, XI. 1960, leg. Prosen, 20 (NCTN); Salta, 


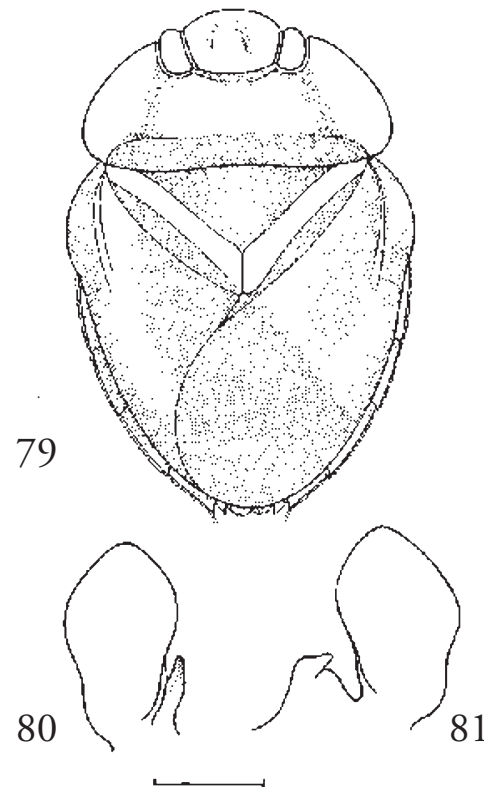

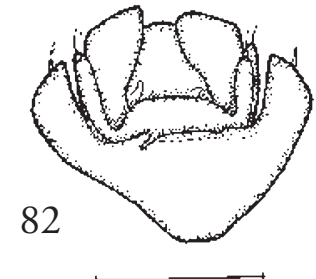

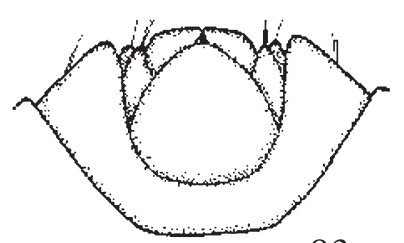

83

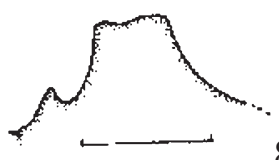

84

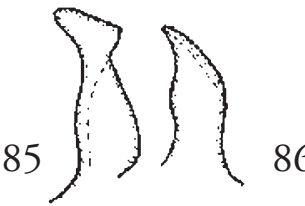

86

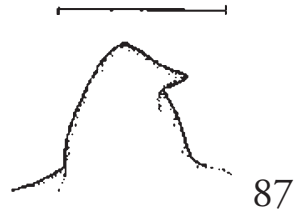

Figs. 79-81. Limnocoris pectoralis. - 79, outline of body, macropterous female, body elngth $10.1 \mathrm{~mm}$; 80 , right lobe of tergite 8 with pseudoparamere; 81 , left lobe of tergite 8 with pseudoparamere. Scales $791 \mathrm{~mm}, 80-810.5 \mathrm{~mm}$.

Figs. 82-87. Limnocoris pusillus. - 82, male, apex of abdomen, dorsal view; 83, female, apex of abdomen, ventral view; 84 , mesosternal carina of larva $\mathrm{V}$, lateral view; 85 , right pseudoparamere, medial view; 86 , right pseudoparamere, dorsal view; 87 , left pseudoparamere. Scales $82-831 \mathrm{~mm}, 840.5 \mathrm{~mm}, 85-870.25 \mathrm{~mm}$.

Route 9, Campo Alegre, 2.I.1997, leg. P. Pérez Goodwyn, 101 ( 9 (MLPA); Province of Salta, leg. Bosq, 10 (MACN) Jujuy, Calilegua National Park, 12.XII.1981, leg. O. Tremouilles, 20 (MACN). - BOLIVIA: La Paz, rocky stream in cloud forest $23 \mathrm{~km} \mathrm{NW}$ of Sapecho bridge, $1280 \mathrm{~m}$, 13.IX.1989, Cl2518, D.A. \& J.T. Polhemus, 20 2우 (JTPC); La Paz, Chulumani, 9.VI.1937, leg. H.E. Hinton, 3 ô 2 \%; La Paz, Yungas valley, 12-13.VI.1937, leg. H.E. Hinton, 19 ; Bolivia S.A., 30.XI.1949, leg. L.E. Pena, $3 \sigma^{\uparrow}$ $1+$ (JTPC). All macropterous.

Discussion. - Judging from its description and the figures, L. peruvianus Melin (1930) is clearly the same species as L. pectoralis Montandon (1897). Unfortunately we did not get a reply on our request for the loan of specimens. Roback \& Nieser (1974) also suggested this synonymy without formalizing it.

\section{Redescription}

Macropterous form, based on dry pinned specimens. - Generally a medium sized broadly oval medium brown species, head and pronotum somewhat lighter than hemielytra, membranes darkest. Dimensions: length of 9.1-10.2-10.9 क 9.2-9.9-10.6, width o 6.30-6.96-7.32 क 5.92-6.67-7.32, anterior width of vertex of 1.76-1.87-1.92 $+1.75-1.87-2.05$, width of pronotum ot 5.64-5.75-5.80 o 5.40-5.97-6.50, median length pronotum of 1.80-2.02-2.17 $q$ 1.811.95-2.08, lateral length of pronotum of 2.55-2.782.98 ? 2.17-2.64-3.00, length of head+pronotum $\delta$ 3.18-3.44-3.51 क 3.03-3.35-3.53.

Colour. - Light to medium brown with variable darker mottling on corium, membrane medium brown to blackish. Interoculus with a pair of small, sometimes hardy visible, elongate curved dots; eyes dark brownish-grey. Disk of pronotum somewhat darker than the rest, anterior margin behind eyes with a narrow black stripe, broad transverse band along posterior margin light but often appearing darker due to underlying parts shining through. Embolium little contrasting with corium except when corial dark mottling is extensive. Membrane nearly black, a dark band running from membrane along costal margin to posterior end of embolium. Exposed part of connexival segments in dorsal view unicolorous or very vaguely darkened anteriorly. Venter of head, lateral part of prothorax and legs yellowish brown, median part of prosternum, meso- and metasternum medium brown, abdominal venter pruinose grey.

Structural characteristics. - Anterior margin of head slightly protruding relative to the curvature of prono- 
tum and eyes. Anterior width of vertex 1.2 times the synthlipsis (1.87/1.61), length of head less than median length of pronotum (1.85/1.64), length of an eye twice its width (1.19/0.57). Anteclypeus projecting $0.20-0.25$ anteriorly of labrum. Labrum parallel-sided in basal part, apical half triangular with obtuse tip, basal width larger than median length (0.5/0.4). Pronotum posterolaterally broadly rounded, angles consequently ill-defined, approximately 0.5 anteriorly of posterior margin, maximal width nearly twice anterior width (5.86/3.02) and 2.2 times the lateral length $(5.86 / 2.71)$, lateral margin very weakly serrate anteriorly, virtually smooth posteriorly. Granulations on dorsum of body placed in small pits, developed most distinctly on scutellum and hemielytra. Scutellum twice as wide at base as its median length (3.47/1.63), twice as long as claval commissure (1.63/0.88). Hemielytra leaving only a narrow strip $(0.2-0.3)$ of connexiva exposed. Embolium only softly convex, posteriorly hardly sinuate, lateral margin weakly serrate, approximately 20 teeth $/ \mathrm{mm}$; nodal furrow present; maximal width across embolium larger than maximal width across connexiva (6.82/6.62). Claval suture distinct, right membranal suture absent, membrane coriaceous but much thinner than corium, broadly rounded, covering left membrane. Left membrane membranaceous, dark smoky brown, broadly rounded, membranal suture distinct. Hind wings fully developed, light brown, opaque. Dorsum of abdomen velvety yellowish brown. Connexival segments 3-6 not or slightly indented ( 0.05 or less), forming a virtually smooth outer edge of abdomen, posterolateral angles of segments 3 and four with a very small spine last abdominal segment posterolaterally acutely angulate but not mucronate. Segment 4 ventrally serrate with about $20 \mathrm{teeth} / \mathrm{mm}$. Prosternal carina low, gradually sloping posteriorly bifid anteriorly. Mesosternal carina with a large thin walled central part enclosing a wide and deep fossa (figs. 189, 190), posterior part short ending halfway (on dorsoventral axis) the central part, anterior part beginning with a small tooth at anterior edge of fossa, and a second sort, blunt one anteriorly. Fore femur 1.8 times as long as wide (2.21/1.21). Middle femur 5.2 times as long as wide (2.38/0.46) and 1.4 times longer than middle tibia (2.38/1.73). Hind femur 6 times as long as wide (3.23/0.54) and about as long as hind tibia (3.23/3.26).

Male. - Genital segments as in fig. 77, right lobe of tergite 6 with a distinct projection proximally.

Female. - Genital operculum apically narrowed with a truncate tip (fig. 78).

Brachypterous form. - Unknown.

\section{Distribution}

Argentina: Salta; Bolivia: La Paz; Peru: San Martin.

\section{Comparative notes}

L. pectoralis belongs to the L. maculiceps-group. It is similar in colour and shape to L. ovatulus, see under that species. L. angulatus from Colombia has a mesosternal carina with a deep and wide fossa as in $L$. pectoralis. As can be seen from fig. 189 in L. pectoralis the rim of the fossa of the mesosternal carina points anteriorly very slightly ventrally suggesting a weakly developed tooth. The anterior tooth of the mesosternal carina is poorly defined and placed near the base of the carina. In L. angulatus, in lateral view with the ventral side up, the rim of the fossa goes down anteriorly and the anterior tooth is more distinctly developed and higher above the base of the carina. In addition all $L$. pectoralis specimens seen are macropterous whereas the specimens of $L$. angulatus are brachypterous. Other structural characteristics not related to wing polymorphism of these two species are very similar.

\section{Limnocoris pusillus Montandon}

(figs. 71, 82-87, 193-194)

Limnocoris pusillus Montandon, 1897: 7-8.

Limnocoris mansosotoi De Carlo, 1951: 45-46 Holotype brachypterous male BOLIVIA: Ichilo, Sta. Cruz, Buenavista, Riacho Tacú, III.1951 (MACN) [examined]. Syn. n.

Limnocoris vianai De Carlo, 1967: 186-187. Syn. n.

[Limnocoris illiesi; Roback \& Nieser 1974: 37. misidentification]

Limnocoris vianai; Nieser \& Lane de Melo 1997: 56.

Lectotype designation. - We studied a macropterous female form the collections of the BMNH with labels: BRAZIL: RJ, Novo Friburgo and Müller, Limnocoris pusillus Montandon type. In addition a small round label with red margin 'type', Montandon Coll. 1901-233 and a label M. R. Belg. Severin. This is the specimen from the type series deposited by Montandon in his own collection. As Montandon (1897) did not designate a holotype we designate this specimen as lectotype in order to fix the identity of this species. A red label 'Lectotype desg. Nieser \& L.-Ruf has been added. We suppose that Novo Friburgo is the same as the mountain town presently named Nova Friburgo.

Material examined. - Lectotype of L. pusillus and holotype of L. mansosotoi, see above. - ARGENTINA: Misiones, Dep. Concep(ción), Sta Maria, XII.1952, leg. M.J. Viana, 10 (NCTN), first record from Argentina. - BOLIVIA: same data as holotype of $L$. mansosotoi, 1 o 1 우 (allo-, and paratype of $L$. mansosotoi De Carlo, MACN); Buena Vista, Ichilo, 20.IV.1950, leg. L. Pena 1 9 ; same, 15.V.1950 3 o (SEMC); Santa Cruz, leg. J. Steinbach, $40 \hat{0} 5 q 1 \mathrm{lvV}(2 q$ macr., SEMC); Beni, $24 \mathrm{~km} \mathrm{~S}$ of Rurrenabaque at Santa Isabel saw mill, sandy river, $275 \mathrm{~m}, 12 . \mathrm{IX} .1989$, leg. D.A. \& J.T. Polhemus $2 \hat{0} 2$ ㅇ (JTPC). - BRAZIL: MG, Sacramento, Ribeirão Rifaninha, just downstream of Gruta das Palhares, 10. XI 1997, leg. N. Nieser, N9728: In gallery forest at right bank restricted to one row of trees, and a much thicker row on the 
other bank. Downstream of a small rapid/waterfall, bottom pebbles and stones, water clear colourless, velocity of current and depth variable (Limnocoris at shallow places with fairly strong current), no aquatic vegetation, $10-20 \mathrm{~m}$ broad, shade only at margins 15 o 19 ㅇ (DPIC, MPLA, NCTN, PCMG); Sacramento, unnamed Córrego going to Rio Grande, 13.XI.1997, leg. N. Nieser \& A. Pelli, N9739: At one side pastures, other side a path through wooded (cerrado) hill side. Upstream of bridge quiet part with sand bottom (A.Pelli) followed by less deep part with stronger current pebbles etc. Naucoridae (Cryphocricos, Limnocoris) from gravelly bottom with some larger pebbles on top, $3 \uparrow$; Sacramento, Córrego Choral, 13.XI.1997, leg. N. Nieser \& A. Pelli, N9740: Open meadows with a few trees on the banks (shaped like pollard-willows) upstream of bridge, rather straight part, 3-5m wide mostly $0.2 \mathrm{~m}$ deep (downstream bridge deeper, swimming pool, not sampled), current medium strong. Limnocoris \& Cryphocricos from bottom with fine pebbles, in coarser pebbles only Cryphocricos., 1 to 1 q brach., 1 lvV.; São Roque de Minas, Rio do Peixe, 27.III.1996, 20¹4’35" S/ $46^{\circ} 22^{\prime} 13^{\prime} \mathrm{W}$, leg. N. Nieser \& A.Pelli, N9636. Mountain stream in gorge with trees, $4-10 \mathrm{~m}$ wide, up to $0.7 \mathrm{~m}$ deep, rapids, riffles (Limnocoris), quiet parts (with L. maculiceps at margins) water clear to turbid (depending on distance from waste outlets) and enriched (algal growth), bottom small boulders to sand with gravel or sometimes at edges sand only, v.c. very variable; mostly shaded (sample taken 9-12h) but with sunny patches, 29 brach., 19 macr.; Conceição das Alagoas, fazenda Sta. Cruz, $19^{\circ} 53^{\prime} 48^{\prime \prime}$ S $48^{\circ} 12^{\prime} 09^{\prime} \mathrm{W}$, small stream in agricultural area, bottom soft sand, width $2-3 \mathrm{~m}$, depth $0.7-0.8 \mathrm{~m}$, current variable, fast except at edges, water turbid light brown (due to silt), no aquatic vegetation, $\mathrm{pH}$

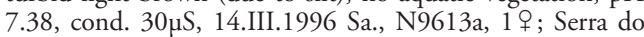
Cipó, Rio Peixe, 16.XII.1992, leg. L. Rocha, 19 . Rio Peruaçu at bridge road Januária-Itacambira, 24.XI.1997, leg. N. Nieser, N9747A. Bottom sample just downstream bridge, exposed to sunshine, pebbles and a few larger stones, silt (Cryphocricos, Limnocoris), 2 đ 2 क $1 \mathrm{lvV}$ 1lvIV; Viçosa, 28.IX.1998, leg. A. Lane de Melo, ALM98008 20 2 웅 Ponte Nova, 29.VIII.1957, leg. R. Usinger, 1 to 1 ㅇ brach., 1 to 1 ㅇ macr. (JTPC) - RJ, Bacia R. Paraiba, Rio Pirai, leg. D.S. Fernandes, $1 \delta^{\widehat{ }} 2$ ㅇ. - SC, Nova Teutônia, $27^{\circ} 11^{\prime}$ S $52^{\circ} 23^{\prime} \mathrm{W}, 300-500 \mathrm{~m}$, II/V various years, leg. F. Plaumann 30 to (NCTN, 20 t 2 det. L. vianai by La Rivers); same, 2 oิ 1 ㅇ $3 \mathrm{lvV}$ (SEMC); same, 1 ô 3 오 (JTPC); Roça Grande, Rio Limeira, $27^{\circ} 05^{\prime} \mathrm{S} 51^{\circ} 31^{\prime} \mathrm{W}, 700 \mathrm{~m}$, XII.1959, $10^{\star}$. - RS, leg. Ribeiro, $1 \delta^{\dagger} 1$ (paratypes L. vianai De Carlo, MACN); Lagoa Vermelha, Rio Santa Rita, $28^{\circ} 20^{\prime} \mathrm{S} 51^{\circ} 18^{\prime} \mathrm{W}, 800 \mathrm{~m}$, leg. F. Plaumann, $30^{\circ} 1$ \% ; R. Ivay, $28^{\circ} 48^{\prime} \mathrm{S} 53^{\circ} 42^{\prime} \mathrm{W}, 350 \mathrm{~m}$, XI.1964 leg F. Plaumann 1 ơ (NCTN); L(agoa) Vermelha, IV. 1959, leg. F. Plaumann, 1 o 3 q , 1 lvV (SEMC). - COLOMBIA: Meta, $32 \mathrm{~km}$ ENE of Puerto Lopez, Caño La Emma at gate to Hacienda el Viento, pH 4.5, temp. $24^{\circ} \mathrm{C}$, 9.III.1971, col. J. Richardson 19 . Brachypterous and in NCTN unless otherwise indicated.

\section{Discussion}

The study of the lectotype made it possible to verify which species Montandon described as L. pusillus. We have compared it with paratypes of $L$. vianai and these are conspecific. One of the problems in identification of this species is that the bristles on the first tooth anterior of the mesosternal fossa may be very dense and cover the indentation between fossa and tooth, suggesting a very different form of the anterior part of the carina. Likewise the specimens of the type series of $L$. mansosoto $i$ we studied show only minute differences with $L$. pusillus e.g. only the male paratype has a few bristles on first tooth of mesosternal carina, but apart from the lack of bristles there is no real difference between the pro- and mesosternal carinae. Specimens of $L$. mansosoto $i$ are slightly larger, relatively slightly flatter, embolium slightly less convex, membrane of brachypterous specimens slightly more developed but all this only recognizable when specimens are compared side by side.

The specimen from Misiones, Sta. Maria differs in the anterior tooth of mesosternal carina being higher, otherwise it fits closely with the L. pusillus/vianai material. Finally the specimen from Colombia is very small (length $4.95 \mathrm{~mm}$ ) which led to an initial identification as L. illiesi De Carlo (Roback \& Nieser 1974). Comparison with the types of L. illiesi and the ample material of L. pusillus at hand confirms that it is a very small brachypterous specimen of $L$. pusillus.

\section{Redescription}

Brachypterous form (mainly based on alcohol specimens from N9728). - Generally a small, light to medium brown broadly oval species. Dimensions: length of 6.4-6.7-7.0 क 6.7-6.9-7.1, width of 4.44.6-4.8 9 4.5-4.7-4.74, anterior width of vertex 0 1.32-1.40-1.46 o 1.30-1.37-1.42, width of pronotum of 3.89-4.01-4.17 क 3.81-3.99-4.14, median length pronotum 0 of $1.20-1.26-1.32$, lateral length of pronotum ôे 1.55-1.65-1.70 우 1.68-1.76-1.82, median length of head+pronotum of 2.03-2.14-2.33 q 2.00-2.13-2.31.

Colour. - Light to medium brown with variable blackish mottling most distinct in lighter specimens. Lateral parts of head and pronotum and most of embolium yellowish, eyes black. Exposed part of connexival segments in dorsal view blackish in anterior two thirds. Venter and legs yellowish, meso- and meta-sternum slightly darker, sternal carinae variably infuscated. The general colour is quite variable between populations.

Structural characteristics. - Anterior margin of head following the curvature of pronotum and eyes, not projecting. Anterior width of vertex 1.2 times the synthlipsis (1.39/1.15), length of head subequal to median length of pronotum, length of an eye 1.8 times its width $(0.85 / 0.46)$. Anteclypeus projecting 0.10-0.15 anteriorly of labrum. Labrum parallel-sided in basal part, apical half triangular with obtuse tip, basal width larger than median length $(0.4 / 0.3)$. Pronotum with posterolateral angles broadly rounded, removed from base of hemielytra, maximal width 1.9 times anterior width $(4.00 / 2.15)$ and 2.4 times the lateral length (4.0/1.7), lateral margin indistinctly serrate 
to nearly smooth.

Granulations on dorsum of body placed in small pits, developed most distinctly on scutellum and hemielytra. Scutellum three times as wide at base as its median length (3.2/1.1), distinctly longer than claval commissure (1.1/0.7). Hemielytra leaving only a narrow strip of connexiva exposed (0.2). Embolium only softly convex, posteriorly hardly sinuate, lateral margin indistinctly serrate with about 48 teeth/mm; maximal width across embolium distinctly larger than maximal width across connexiva (4.65/4.45). Claval suture indistinctly present in some specimens, right membranal suture absent, membrane coriaceous, concolorous with corium, broadly rounded, covering left membrane. Left membrane membranaceous, slightly opaque to distinctly smoky brown, narrowly rounded, membranal suture distinct. Hind wings strongly reduced, reaching basal third of abdominal tergite 2 . Connexival segments 3-6 slightly indented, posterolateral angle of segment 6 forming an acute angle but without spines. Lateral margins of connexiva serrate, best visible in ventral view, segment 4 with 30 teeth $/ \mathrm{mm}$. Prosternal carina steep posteriorly usually bifid anteriorly. Mesosternal carina low and gradually sloping posteriorly, central part short with a narrow shallow fossa with callous margins of variable thickness, anterior part with two teeth, the first one (counted from central part) with a tuft of yellowish bristles which may cover the first indentation so obscuring the form of the anterior part of carina (figs. 193, 194). Fore femur 1.7 times as long as wide (1.61/0.95). Middle femur 5.4 times as long as wide $(1.66 / 0.31)$ and 1.3 times longer than middle tibia $(1.66 / 1.31)$. Hind femur 6.4 times as long as wide $(2.11 / 0.33)$ and as long as hind tibia $(2.11 / 2.12)$.

Male. - Genital segments as in fig. 82, right lobe of tergite 6 with a distinct projection proximally. Right pseudoparamere relatively slender with a widened tip (figs. 74, 75).

Female - Genital operculum with posterior margin sinuate, distinct medioposterior pointed tip (fig. 73).

Macropterous form. - Apart from development of a distinct claval suture and nodal furrow, a relatively larger scutellum, probably larger average size, fully developed membranes and hind wings, identical with brachypterous form. Dimensions (based on $4 q q$ ): length 6.7-7.0-7.9, width 3.66-4.41-4.80, anterior width of vertex 1.30-1.32-1.33, width of pronotum 3.99-4.08-4.15, median length pronotum 1.22-1.301.35 , lateral length of pronotum 1.80-1.83-1.90, median length of head+pronotum 2.30-2.30-2.31. Basal width of scutellum slightly over twice its length (2.47/1.17) and twice the length of claval commissure (1.17/0.57).

Larva $\mathrm{V}$ (based on dry pinned specimens from RS and SC). - Dimensions: length 5.4, width 4.0, anteri- or width of vertex 1.12 , width of pronotum 3.41 , median length pronotum 0.71 , lateral length of pronotum 1.22, median length of head+pronotum 1.54 Colour yellowish brown to greyish brown with small darker dots which do not merge to patches, eyes brown. Venter rather uniformly coloured in a similar but somewhat lighter colour as dorsum. Lateral margin of connexiva serrate with about 35 teeth $/ \mathrm{mm}$. Central part of mesosternal carina, laminate and strongly elevated (fig. 84).

\section{Distribution}

From N. Argentina and S. Brazil through E. Bolivia to central Colombia.

\section{Comparative notes}

L. pusillus belongs to the L. maculiceps-group. The size and the peculiar hair-covered indentation in the mesosternal carina just in front of the central part characterize this species. The larva $\mathrm{V}$ is identifiable by its size and the characteristic mesosternal carina.

\section{Limnocoris rotundatus De Carlo}

(figs. 88-91, 101, 195-196)

Limnocoris rotundatus De Carlo, 1951: 48-49. Holotype brachypterous ơ: M. de Lourdes, No 424 (DZUP) [examined].

Material examined. - Holotype, see above. BRAZIL: PR, Boqueirão, $25^{\circ} 00^{\prime} \mathrm{S} 50^{\circ} 09^{\prime} \mathrm{W}$, stream, $950 \mathrm{~m}$, October 1959 ,

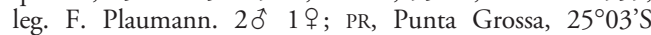
$50^{\circ} 09^{\prime} \mathrm{W}, 950 \mathrm{~m}, \mathrm{X} .1959$, leg. F. Plaumann, 1 \% ; PR, Serra do Purunā, Rio Tibagi (Confl.), $25^{\circ} 15^{\prime}$ S $49^{\circ} 56^{\prime} \mathrm{W}, 1000 \mathrm{~m}$, V. 1964, leg. F. Plaumann $20^{t} 2$ ․ All brachypterous, NCTN.

Remarks. - De Carlo (1951) gave the type locality as 'Rio Guavirosa, Villa Velha, Ponta Grossa', which is an important road and rail junction about $100 \mathrm{~km}$ WNW of Curitiba in Paraná. However, the holotype bears only identification and type labels and the M. de Lourdes label mentioned above which may refer to a collector.

\section{Redescription}

Brachypterous form (based on dry pinned specimens). - Generally a small to medium sized, flat, light to medium brown broadly oval species with strongly reduced hemielytra. Dimensions: length of 7.9-8.18.3 \% 7.8-8.0-8.2, width of 5.62-5.88-6.05 क 5.625.88-6.15, anterior width of vertex o $1.58-1.67-1.75$ क 1.65-1.69-1.76, width of pronotum of 5.03-5.555.56 ㅇ 5.00-5.29-5.43, median length pronotum ơ 1.48-1.53-1.60 ㅇ 1.42-1.51-1.55, lateral length of pronotum of 2.22-2.36-2.50 क 2.20-2.35-2.50, median length of head+pronotum 0 2.81-2.92-3.01 $q$ 2.80-2.81-2.83.

Colour. - Brownish yellow to medium brown, eyes dark grey, triangular patch posteriorly on interoculus, central part of pronotum and an ill defined patch on 

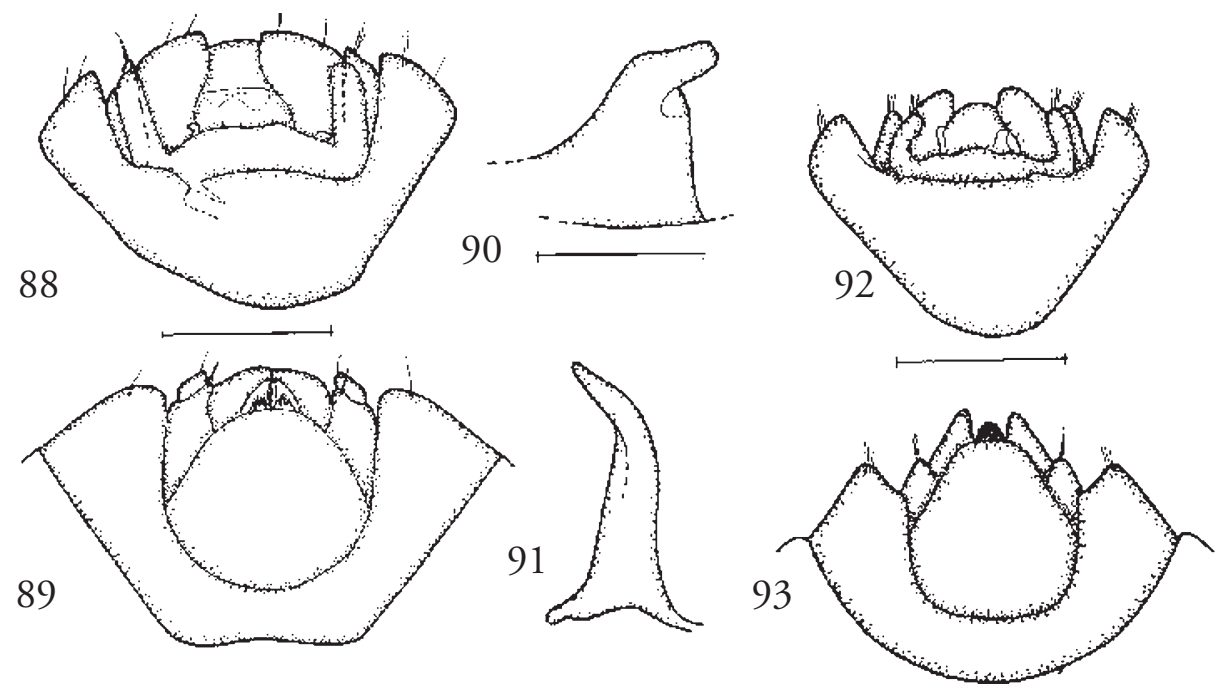

Figs. 88-91. Limnocoris rotundatus. - 88, male holotype, apex of abdomen, dorsal view; 89, female, apex of abdomen, ventral view; 90, left pseudoparamere, 91, right pseudoparamere. Scales 88, $891 \mathrm{~mm}, 90,910.25 \mathrm{~mm}$.

Figs. 92-93. Limnocoris siolii. - 92, male holotype, apex of abdomen in dorsal view; 93, female, apex of abdomen in ventral view. Scale $1 \mathrm{~mm}$.

scutellum darker brown. Hemielytra with greyish or brown mottling on clavus and corium except embolium, right membrane and a narrow band along corium up to the posterior curve of embolium blackish. Interocular mark indefinite, consisting of a double row of regular darker points wide apart enclosing a subcircular area posteriorly, anteriorly subparallel enclosing a narrower strip. Connexival segments yellowish, variably infuscated, exposed part of abdominal dorsum brown, wrinkled. Venter and legs yellowish, venter in several specimens medially light brown.

Structural characteristics. - Anterior margin of vertex following the curvature of pronotum and eyes, not protruding. Anterior width of vertex 1.3 times the synthlipsis (1.68/1.30), length of head subequal to the median length of pronotum (1.55/1.53), length of an eye twice its width (1.27/0.65). Anteclypeus projecting 0.13 anteriorly of labrum. Lateral margins of labrum slightly converging in basal two thirds, apical part with a very broadly rounded tip, basal width larger than median length $(0.54 / 0.42)$. Pronotum with distinctly convex lateral margins, outline of head and pronotum forming a nearly perfect semicircle (fig. 101), posterolateral angles pointing somewhat backward, level with the posterior margin, broadly rounded. Maximal width of pronotum over twice the anterior width $(5.51 / 2.62)$ and 2.3 times the lateral length $(5.51 / 2.40)$, lateral margin weakly serrate ventrally, about 30 teeth $/ \mathrm{mm}$. Granulations on dorsum of body fine and indistinct, except on membrane where they contrast sharply against the blackish background, lying in small pits. Scutellum about twice as wide at base than its median length $(2.44 / 1.20)$ and nearly twice as long as claval commissure (1.30/0.69). Hemielytra leaving a $0.8-1.0$ wide strip of connexiva and abdominal dorsum exposed. Embolium convex, curving distinctly inward posteriorly, posterolateral angle rounded, ill defined; lateral margin weakly serrate, approximately 35 teeth $/ \mathrm{mm}$, visible in ventral view only; maximal width across embolium only slightly larger than maximal width across connexiva (5.99/5.87). Claval suture and right membranal suture absent, right membrane coriaceous, but distinctly thinner than corium, reduced, bluntly pointed, right hemielytron covering a median strip of left hemielytron. Apical part of left membrane coriaceous, bluntly pointed, not covered by right hemielytron, inner strip of hemielytron covered by right hemielytron membranaceous, dark velvety brown to blackish, sutured off by the difference in structure between coriaceous and membranaceous part. Hind wings vestigial. Dorsum of abdomen velvety yellowish to orange. Connexival segments hardly indented, forming a nearly smooth outer edge of abdomen, posterolateral angle of last connexival segment bluntly rounded. Connexiva laterally serrate, segment 4 with about 30 teeth $/ \mathrm{mm}$. Prosternal carina distinctly sloping posteriorly, anteriorly with a short truncate not bifid tip. Mesosternal carina with a short ( 0.4 long) but well developed elevated central part with a distinct broadly 
oval to rhomboid fossa (figs. 195, 196), posterior part shorter than central part $(0.30 / 0.45)$ but well developed, distinctly sloping, posteriorly abruptly vertical; anterior part about one and a half times as long as central part, without tooth at anterior margin of fossa, distinctly sloping to a blunt but distinct anterior tooth which tops a vertical edge. Metasternal carina well developed, consisting of a tubercle with a wide ventral fossa and laminate anterior part on central third of metaxiphus. Abdominal venter with quite dense golden yellow pilosity leaving connexiva exposed and extending onto meta- and mesosternum where it is less dense (venter of holotype less densely pilose than other specimens). Fore femur 1.7 times as long as wide (1.97/1.18). Middle femur 4.3 times as long as wide $(2.04 / 0.47)$ and 1.4 times longer than middle tibia $(2.04 / 1.44)$. Hind femur 5.6 times as long as wide $(2.80 / 0.50)$ and as long as hind tibia $(2.80 / 2.78)$.

Male. - Genital segments as in fig. 88 , right lobe of tergite 6 with a vestigial basal process. Right pseudoparamere slender (fig. 91).

Female. - Genital operculum about as long as wide $(1.1 / 1.1)$, greatest width about midway, apical part of lateral margins converging, slightly convex, apex truncate (fig. 89).

Macropterous form unknown.

\section{Distribution}

Brazil: PR.

\section{Comparative notes}

L. rotundatus belongs to the L.insignis-group. The semicircular head and pronotum are diagnostic. Other species in this group have head and pronotum semi-oval, semi-rhomboid or semi-spindle shaped. $L$. nigropunctatus has usually a relatively shorter, more transverse pronotum, however, some specimens can be quite similar to $L$. rotundatus in this respect. They differ by the more acute lateral angle of the embolium (figs. 68, 101).

\section{Limnocoris siolii (De Carlo)}

(figs. 92-96, 102)

Sattleriella siolii De Carlo, 1966: 111-113. Holotype brachypterous ô BRAZIL: SP, Serra do Mar, Rio das Corujas, Boraccia, 22.VIII.1963, Sa621, leg. Sattler. (ZSMC). [examined]

Material examined. - Holotype, see above. Same data as holotype, 19 paratype (allotype, MACN) - PR, Rio Lago Castro, 15-19.X.1925, leg. W.L. Schmitt, 1 ㅇ (JTPC). All brachypterous.

\section{Redescription}

Brachypterous form (dimensions taken from holoand allotype only). - Generally a dorsally somewhat convex, medium sized, elongate oval, medium brown species with distinctly reduced hemielytra. Dimensions: length of 8.23 o 8.12 , width of 5.18 o 4.80 anterior width of vertex $\hat{\sigma} 1.67 \uparrow 1.50$, width of pronotum $\hat{\delta}$ 4.35 ㅇ 4.30, median length pronotum ot 1.55 \& 1.42 , lateral length of pronotum $\delta 2.20$ क 2.00 , median length of head+pronotum ot 2.87 ? 2.62 .

Colour. - Medium brown with indistinct dark markings on head, pronotum and hemielytra, eyes greyish, venter yellowish to medium brown, legs yellowish. Anterior part of connexival segments of males in dorsal view blackish.

Structural characteristics. - Anterior margin of vertex slightly protruding compared to the curvature of pronotum and eyes. Anterior width of vertex 1.1 times the synthlipsis (1.60/1.44), length of head distinctly more than median length of pronotum $(1.60 / 1.50)$, length of an eye slightly less than twice its width (0.99/0.56). Anteclypeus projecting 0.18-0.21 anteriorly of labrum. Lateral margins of labrum very slightly converging in basal part, apical half triangular with a sharply rounded tip, basal width larger than median length $(0.48 / 0.34)$. Pronotum with ill defined, broadly rounded, posterolateral angles which are $0.5-0.7$ in front of posterior margin, its maximal width 1.7 times the anterior width (4.33/2.52) and 2.1 times the lateral length (4.33/2.10), lateral margin very slightly but evenly convex, weakly serrate ventrally, about 27 teeth/mm. Granulations on dorsum of body lying on top of surface, finer and less distinct on pronotum than on hemielytra, of the same colour as their surroundings. Scutellum about twice as wide at base than its median length (2.50/1.20). Hemielytra leaving apical part of abdomen, posterior of tergite three or four, exposed. Embolium variable, from evenly convex to having a rather well defined lateral point (figs. 94, 102); lateral margin smooth in anterior half, weakly serrate with approximately $22 \mathrm{teeth} / \mathrm{mm}$ ventrally in posterior half; maximal width across embolium equal to slightly less than maximal width across connexiva (4.80/4.80-5.02/5.16). Claval suture and right membranal suture absent, membranes variable from virtually absent to a narrow posterior strip of thinner texture than corium. Hind wings absent. Dorsum of abdomen covered by hemielytra velvety yellowish to orange. Connexival segments hardly indented, forming a nearly smooth outer edge of abdomen, posterolateral angle of last connexival segment bluntly (in male) to acutely (in female) rounded. Connexiva laterally serrate, segment 4 with about 30 teeth $/ \mathrm{mm}$. Prosternal carina only slightly elevated, slightly sloping posteriorly, anterior tip pronounced, not bifid. Mesosternal carina with a well developed elevated central part, one fourth the total length of carina with a small slit like fossa (figs. 95, 96), posterior part short but well developed, distinctly sloping, posteriorly 

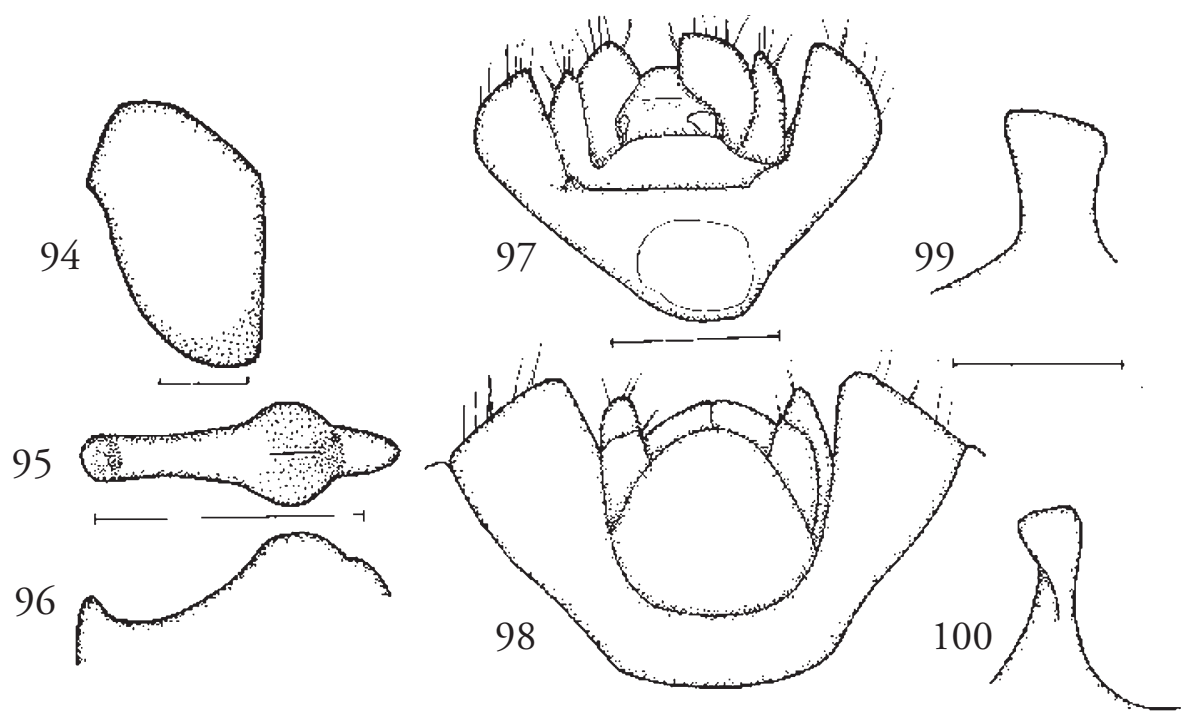

Figs. 94-96. Limnocoris siolii. - 94, left hemielytron; 95, 96, mesosternal carina, 95, ventral view, 96, lateral view. Scales 1 $\mathrm{mm}$.

Figs. 97-100. Limnocoris submontandoni. - 97, male, apex of abdomen, dorsal view; 98, female, apex of abdomen, ventral view; 99, 100, pseudoparameres, 99, left, 100, right. Scales 97, $981 \mathrm{~mm}, 99,1000.25 \mathrm{~mm}$.

abruptly vertical; anterior part deeply concave in lateral view with an well defined blunt anterior tooth which tops a vertical edge. Metasternal carina rather narrow, restricted to anterior two thirds of metaxiphus. Abdominal venter with very sparse golden yellow pilosity somewhat more distinct in midline and near stigmata. Fore femur twice as long as wide $(2.06 / 1.05)$. Middle femur 4 times as long as wide $(2.05 / 0.50)$ and 1.3 times longer than middle tibia (2.05/1.62). Hind femur 5.6 times as long as wide $(2.78 / 0.49)$ and very distinctly shorter than hind tibia (2.78/3.11).

Male. - Genital segments as in fig. 92, right lobe of tergite 6 with a small blunt projection proximally.

Female. - Genital operculum somewhat narrowed in apical half, apex bluntly rounded (fig. 93).

Macropterous form unknown.

\section{Distribution}

Brazil: SP, PR, so far only known by the three specimens cited above.

\section{Comparative notes}

L. siolii does not fit in either one of the two groups we distinguish. It is the only species of Limnocoris in which the hemielytra leave the posterior part of the abdomen exposed (fig. 103).

\section{Limnocoris submontandoni $\mathrm{La}$ Rivers} (figs. 1-2, 97-100, 199-200)

Limnocoris submontandoni La Rivers, 1974: 10-11.

Material examined. - BRAZIL: SP, Rio Guarau, Jacupiranga, $24^{\circ} 45^{\prime} \mathrm{S} 48^{\circ} 02^{\prime} \mathrm{W}, 30 \mathrm{~m}$ asl., Dec. 1963 , leg. F. Plaumann 10 (allotype) 1 q paratype (CASC), both macr. - MG, Sacramento, Ribeirão Rifaninha, just downstream of Gruta dos Palhares, 10.XI.1997, leg. Nieser \& Pelli, N9728. In gallery forest which at right bank (fazenda) is restricted to one row of trees, and a much thicker row on the other bank. Downstream of a small waterfall, bottom stones pebbles, water clear colourless, velocity of current variable, no aquatic vegetation, $10-20 \mathrm{~m}$ wide, depth variable mostly $0.2-0.5 \mathrm{~m}$, some places

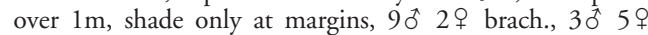
macr. - Sacramento, Ribeirão Rifaninha, at bridge in main road, 8.XI.1997, leg. Nieser \& Pelli, N9727. Mountain stream in agricultural area, little shade, small boulders-large pebbles, edges with overhanging vegetation, at bridge (downstream of N9728), 506 우 brach., 10 macr. - Perdizes, Nature Reserve de Galheiras, $19^{\circ} 13^{\prime} 50^{\prime \prime} \mathrm{S} 47^{\circ} 08^{\prime} 48^{\prime \prime W}$, small stream (width $2-5 \mathrm{~m}$, depth $0.3 \mathrm{~m}$ ) in gallery forest, water current variable, water clear, hyaline, leg. Nieser \& Pelli, N9626 201 i brach. - Perdizes, stream on Recanto do Sr. Jesus, $19^{\circ} 22^{\prime} 57^{\prime}$ S/47 $12^{\prime} 29^{\prime} 48^{\prime}$ W, 20.III.1996, leg. N. Nieser \& A. Pelli, N9629, small stream, width $2-5 \mathrm{~m}$, depth at sampling site $0.1-0.4$, bottom coarse sand (Limnocoris on the sand, blending well with the substrate), velocity of current low, nearly stagnant, water clear, hyaline, shaded by gallery forest, 808 brach., 4lvV, 1lvIV. (DPIC, JTPC, MLPA, NCTN, NHMW, PCMG, RMNH, ZMAN 101 1 each). In NCTN unless otherwise indicated. 


\section{Redescription}

Brachypterous form (based mainly on alcohol specimens from N9728 and some $q+q$ from N9727). Generally a flat medium sized, broadly oval to subcircular species, medium brown with yellowish margins. Dimensions: length of 8.2-8.55-8.9 क 8.70-8.9-9.1, width ot 6.4-6.7-7.0 9 6.9-7.0-7.2, anterior width of vertex of 1.88-1.95-2.02 9 1.97-1.99-2.01, width of pronotum of 6.00-6.22-6.41 + 6.40-6.44-6.48, median length of pronotum ô 1.52-1.56-1.60 \& 1.531.56-1.61, lateral length of pronotum ot 2.50-2.582.72 \& 2.60-2.64-2.70, median length of head+ pronotum ô 2.92-3.01-3.18 9 2.91-2.98-3.02.

Colour. - Head and pronotum yellow, eyes brown to dark grey, central areas of interoculus and pronotum with small brown dots, posterior margin of pronotum dark. Scutellum and hemielytra medium brown, membranes darker, especially in lighter specimens, embolium yellow, connexiva yellowish, anterior margins of segments infuscated, exposed part of abdominal dorsum brownish. Venter and legs yellow, central part of abdominal venter darker varying from brownish dark grey.

Structural characteristics. - Anterior margin of head following the curvature of pronotum and eyes to weakly projecting. Median mark of interoculus ill defined, consisting of not very contrasting isolated dots arranged in a pattern which is broad posteriorly, narrow anteriorly. Anterior width of vertex 1.5 times the synthlipsis (1.97/1.31); length of head distinctly longer than median length of pronotum (1.73/1.56); length of an eye over twice its width (1.38/0.62); anteclypeus projecting $0.20-0.30$ anteriorly of labrum. Labrum parallel-sided to slightly converging apically in basal half, converging to an acutely rounded tip in apical half, its basal width only slightly larger than the median length $(0.49 / 0.46)$. Pronotum with lateral angles acutely rounded, at same level as posterior margin, central area hardly elevated, lateral margin weakly serrate, about 40 teeth $/ \mathrm{mm}$; maximal width over twice anterior width (6.33/2.85) and 2.4 times the lateral length $(6.33 / 2.61)$. Scutellum twice as wide at base as its median length $(2.73 / 1.32)$ and 1.5 times as long as claval commissure (1.32/0.89). Hemielytra leaving a broad (0.8-1.4 wide) strip of abdomen exposed, inner three fourth of this area light to medium brown, wrinkled. Embolium with posterior half of lateral margin nearly straight and parallel to longitudinal body axis, its posterior margin perpendicular on longitudinal axis, posterolateral angle well defined (fig. 1), lateral margin weakly serrate, about 35 teeth $/ \mathrm{mm}$. Width across embolium larger than maximal width across connexiva (6.9/6.7). Claval suture absent, right membrane coriaceous, strongly reduced, acutely rounded, covering narrow, membraneous, velvety black median strip of left hemielytron, membranal suture absent, however, in nearly all specimens membrane clearly delimitated because of darker colour and different texture. Left membrane partly exposed, more strongly reduced and apically more narrowly pointed; hemielytra posteriorly not reaching the hind margin of last abdominal tergite. Hind wings vestigial, reaching base of abdomen. Covered part of abdomen waxy yellowish to light rufous brown. Connexival segments slightly indented, anterolateral edges of connexival segments 0.05-0.10 more medially than posterolateral angle of preceding segment, last segment obtusely angulate posteriorly. Segment 4 serrate with about 35 teeth $/ \mathrm{mm}$. Dorsal granulations most distinct posteriorly on pronotum and on hemielytra, set in small pits, distinctly finer and denser on membranal area. Prosternal carina well developed, very gradually slanting posteriorly to nearly parallel with ventral surface of prosternum, anteriorly broadly rounded, not bifid. Mesosternal carina (figs. 199, 200), well developed, posterior part short, strongly sloping, central part rather slender (about 0.35 wide) with a thin walled, shallow oval fossa, anterior part about two thirds as long as central part, medium sloping, no small tooth at anterior edge of fossa, anterior tooth small but distinct. Metasternal carina, well developed occupying the central third to half of metaxiphus, with a shallow but distinct oval fossa. Pubescence of venter well developed. Fore femur about twice as long as wide $(2.12 / 1.09)$. Middle femur slightly over five times as long as wide (2.28/0.42) and 1.5 times as long as middle tibia (2.28/1.55). Hind femur seven times as long as wide (3.18/0.46) and longer than hind tibia (3.18/2.97).

Male. - Genital segments as in fig. 97, proximal projection of right lobe of tergite 6 poorly developed. Right pseudoparamere slender with a widened apex (fig. 100).

Female. - Genital operculum (fig. 98), basal width only slightly larger than median length (1.2/1.1), lateral margins slightly sinuate, distinctly converging posteriorly over most of their length, apex broadly rounded.

Macropterous form. - Essentially as brachypterous form except for being relatively more slender and differences connected with macropterism (fig. 2). Dimensions: length of 8.7-8.85-8.9 क 8.7-8.8-9.0, width of 6.4-6.6-6.8 $+6.5-6.6-6.7$, anterior width of vertex ô $1.80-1.84-1.89$ \% $1.80-1.84-1.90$, width of pronotum of 5.78-5.83-5.90 o 5.80-5.84-5.92, median length of pronotum ${ }^{\star} 1.70-1.72-1.76+1.70-1.74-1.78$, lateral length of pronotum ${ }^{t} 2.80-2.82-2.85$ ㅇ 2.72 2.75-2.80, median length of head+pronotum ot 3.123.21-3.38 $+3.16-3.25-3.40$. Colour as in brachypterous form but anterior margins of segments more distinctly infuscated. Pronotum with lateral angles broadly rounded, $0.9-1.0$ anteriorly of its posterior 

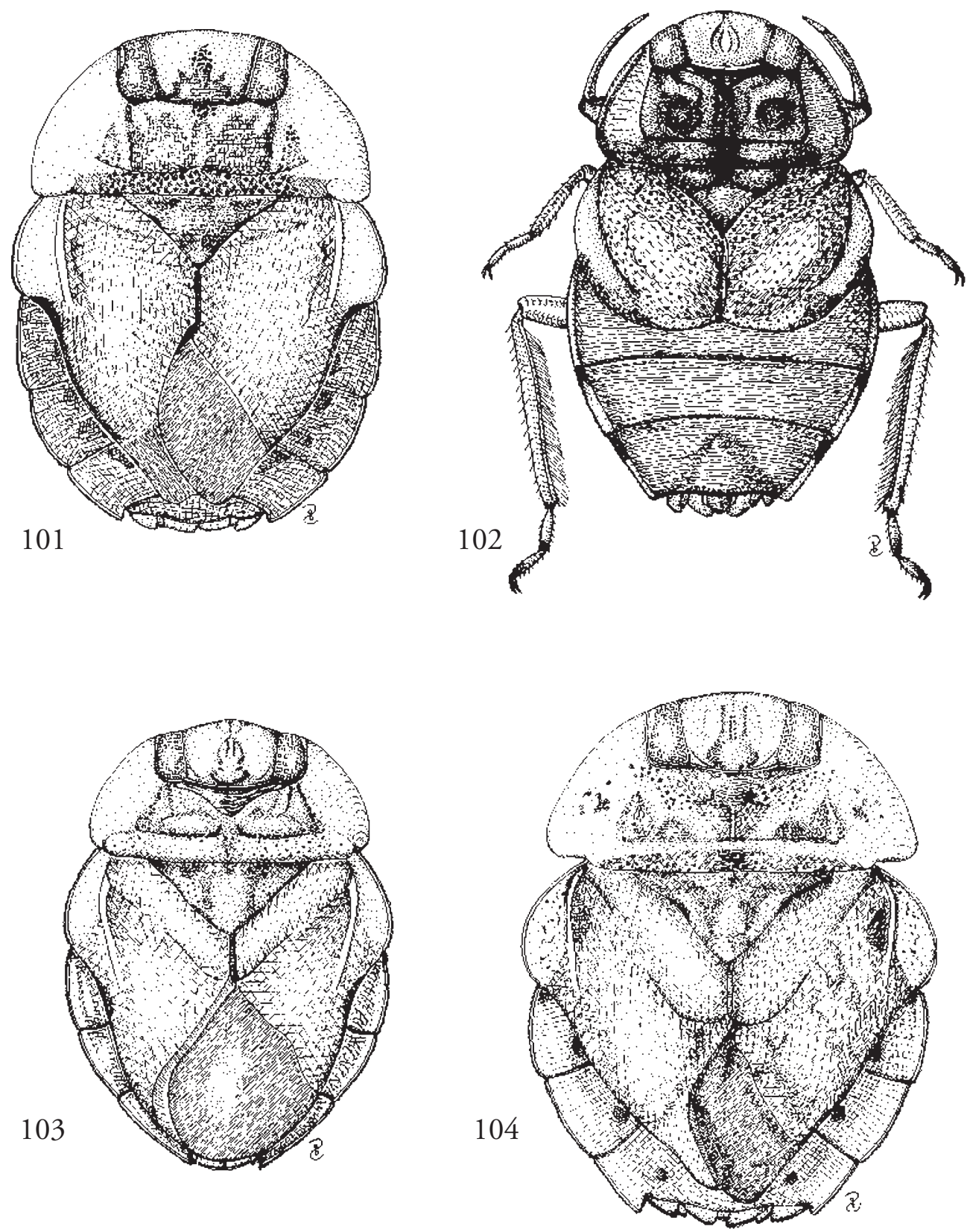

Figs. 101-104. Habitus of Limnocoris. - 101, L. rotundatus, holotype, brachypterous male, body length 8.5 mm; 102, L. siolii, holotype, brachypterous male, body length $8.1 \mathrm{~mm} ; 103$, L. asper, paratype, brachypterous female, body length $7.5 \mathrm{~mm} ; 104$, L. caraceae, holotype, brachypterous male, body length $8.8 \mathrm{~mm}$ (reconstructed). 
margin, maximal width 2.1 times the lateral length (5.83/2.78). Scutellum more strongly developed than in brachypterous form, twice as wide at base as its median length (3.08/1.49) and nearly three times as long as claval commissure (1.49/0.53). Hemielytra leaving a broad ( 0.8 or less wide) strip of abdomen exposed, exposed area yellowish not wrinkled. Embolium posteriorly somewhat less abruptly curved inward as in brachypterous form (fig. 2), its lateral margin weakly serrate, about 45 teeth $/ \mathrm{mm}$, width across embolium larger than maximal width across connexiva (6.6/6.2), on average more slender than brachypterous form, claval suture and nodal furrow distinct, membranes fully developed, broadly rounded, right membrane coriaceous, covering membraneous, velvety black left membrane. Hind wings fully developed light brownish opaque, reaching apex of abdomen. Covered part of abdomen brown to black. Dorsal granulations more prominent than in brachypterous form.

\section{Distribution}

Brazil: MG, SP.

\section{Comparative notes}

L. submontandoni belongs to the L. insignis-group. At first sight this species is very similar to L. nigropunctatus, which is slightly smaller on average, has the posterior margin of embolium less abruptly curving inward, the lateral part of connexiva not covered by hemielytra narrower (figs. 1, 68), and the apex of the female genital operculum narrower (figs. 60, 98).

\section{Limnocoris asper sp. $\mathrm{n}$.}

(figs. 103, 105-108, 157-158)

Material examined. - Holotype brachypterous female (DPIC), BRAZIL: MG, Bacia do Rio Doce, Ribeirão Indaía, 1100m, VIII.1993, leg. L. Rocha. Paratypes 40109 same data as holotype distributed as follows: 10 (allotype) DPIC, 19 JTPC, 2 ㅇ MLPA, $30^{\dagger} 49$ NCTN, 19 NHMW, 19 RMNH, 19 ZMAN. Additional paratypes: Bacia do Rio Doce, $\pm 1100 \mathrm{~m}, 27$.VIII. 1993, leg. L. Rocha, 1 t 1 ㅇ (DPIC). All brachypterous.

\section{Description}

Brachypterous form (based mainly on alcohol specimens). - Generally a small, light to medium brown, broadly oval species. Dimensions. Length of 7.2-7.37.4 9 7.3-7.5-7.6 \{HT 7.4\}, width of 5.0-5.2-5.4 क 5.2-5.3-5.4 \{5.24\}, anterior width of vertex $\delta$ 1.48$1.53-1.57$ क $1.49-1.52-1.57\{1.49\}$, width of pronotum o 4.45-4.58-4.65 क 4.55-4.60-4.70\{4.56\}, median length of pronotum $\delta$ 1.25-1.28-1.30 o 1.241.27-1.30 \{1.24\}, lateral length of pronotum ot 1.982.03-2.10 $+2.03-2.07-2.10\{2.08\}$, median length of head+pronotum ô 2.32-2.37-2.40 9 2.38-2.41-2.46 $\{2.39\}$.
Colour. - Dorsally light brown with a median mark on interoculus, disk and posterior margin of pronotum and scutellum medium brown. Right membrane concolorous with corium or slightly darker, left membrane velvety dark brown to dark grey. Connexival segments unicolorous or anterior part very slightly darker. Exposed strip of abdominal dorsum pruinose grey. Venter of head, pronotum laterally, embolium, connexiva and legs light brown, remainder of venter pruinose grey. Eyes black in wet specimens becoming greyish or brownish in dry pinned specimens.

Structural characteristics. - Anterior margin of head following the curvature of pronotum and eyes, not projecting. Median mark of interoculus diffuse. Anterior width of vertex 1.1 times the synthlipsis (1.53/ 1.37); length of head slightly longer than median length of pronotum (1.38/1.28); length of an eye 1.7 times its width $(0.98 / 0.57)$; anteclypeus projecting 0.10-0.12 anteriorly of labrum. Labrum parallel-sided in basal half, converging to a very obtuse tip in apical half, its basal width 1.4 times the median length $(0.42 / 0.30)$. Pronotum with lateral angles obtusely rounded, maximal width 0.3 removed from posterior margin, central area distinctly elevated, lateral margin distinctly serrate, about 30 teeth $/ \mathrm{mm}$; maximal width less than twice anterior width (4.59/2.41) and 2.2 times the lateral length (4.59/2.05). Scutellum twice as wide at base as its median length $(2.53 / 1.25)$ and twice as long as hemielytral commissure (1.25/0.58). Hemielytra leaving a broad (0.5-0.7 wide) strip of abdomen exposed, inner two thirds of this area dull grey, wrinkled. Embolium with lateral margin only slightly convex in posterior half subparallel to longitudinal body axis, posterolateral lateral angle obtuse (fig. 103), its lateral margin indistinctly serrate in proximal half, more distinctly distally about 20 teeth $/ \mathrm{mm}$, width across embolium distinctly larger than maximal width across connexiva $(5.25 / 5.04)$, claval suture absent, right membrane coriaceous, broadly rounded, covering left membrane, membranal suture absent. Left membrane well developed, membranaceous. Hind wings strongly reduced, reaching base of abdomen. Covered part of abdomen waxy medium rufous brown. Connexival segments not indented, forming a continuous lateral margin of abdomen, last segment obtusely angulate posteriorly. Lateral margin of connexiva distinctly serrate, on segment 4 with 19 teeth/mm. Granulations on top of dorsal surface. Prosternal carina hardly slanting posteriorly, low and weakly bifid anteriorly. Mesosternal carina (figs. 157, 158), relatively small, posterior sloping part small, central part medium wide with a shallow fossa, anterior part strongly sloping, anterior tooth only weakly developed. Pubescence of venter poorly developed. Fore femur slightly less than twice as long as wide $(1.90 / 1.02)$. Middle femur nearly six times as long as wide (1.87/0.33) and about 1.5 times as long as mid- 


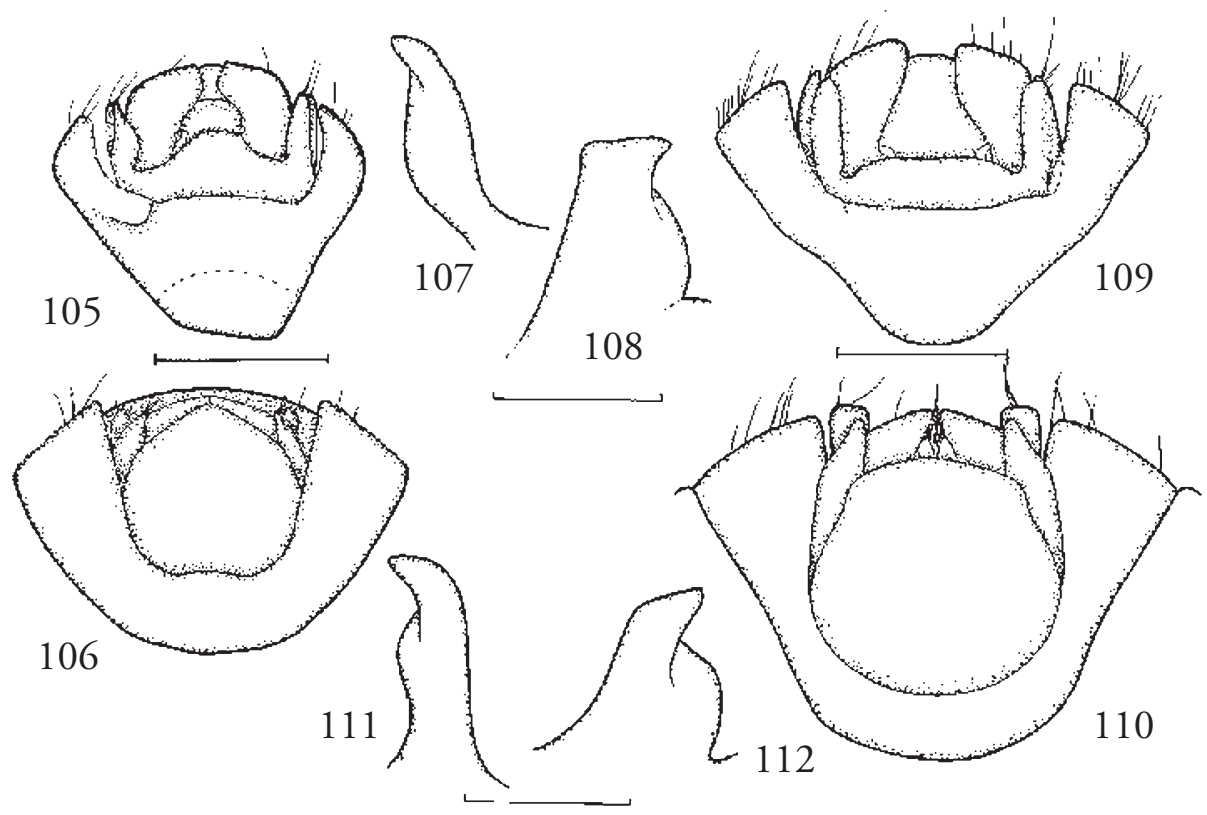

Figs. 105-108. Limnocoris asper. - 105, male paratype, apex of abdomen, dorsal view; 106, female paratype, apex of abdomen, ventral view; 107, 108, pseudoparameres, 107, right, 108, left. Scales 105, $1061 \mathrm{~mm}, 107,1080.25 \mathrm{~mm}$.

Figs. 109-112. Limnocoris caraceae. - 109, male holotype, apex of abdomen, dorsal view; 110, female allotype, apex of abdomen, ventral view; 111, right pseudoparamere; 112, left pseudoparamere. Scales 109, $1101 \mathrm{~mm}, 111,1120.25 \mathrm{~mm}$.

dle tibia (1.87/1.27). Hind femur 6 times as long as wide (2.48/0.41) and as long as hind tibia (2.48/2.45).

Male. - Genital segments as in fig. 105, proximal projection of right lobe of tergite 6 short and broad. Pseudoparameres as in figs. 107, 108.

Female. - Genital operculum (fig. 106) lateral margin strongly converging in apical part, straight to slightly concave, apex obtusely rounded.

Macropterous form unknown.

\section{Etymology}

Asper (Greek adjective: rough) refers to the rough dorsal surface due to granules lying on top of the surface.

\section{Distribution}

Only known by the type series from Brazil: MG.

\section{Comparative notes}

L. asper belongs to the L. insignis-group. Except for size and colour it is at first sight nearly identical with $L$. porphyros with which it has been found together. Structural differences are in the embolia which have a more distinct posterolateral angle in L. porphyros (figs. 103,143 ), the non pruinose margin of the exposed part of abdominal dorsum which is relatively broader in $L$. asper and the lateral serration which is more distinct in $L$. porphyros. The fossa of the mesosternal carina is comparatively larger and wider in L. asper (figs. $158,192)$.

\section{Limnocoris caraceae sp. n.}

(figs. 104, 109-112, 163, 164)

Material examined. - Holotype brachypterous male (DPIC) and paratype (allotype) female (NCTN), BRAZIL: MG, Santa Barbara, Serra do Caraça, 21. X. 1972, leg. H. N. Espinola.

\section{Description}

Brachypterous form (based on damaged dry pinned specimens, ô lacking part of thorax and hemielytron on left side, $q$ lacking head and fore legs). - Generally a medium sized, broadly oval species, colour light to medium brown with lighter lateral margins. Dimensions. Length of 8.8 o -, width $0<<6.8>$ \& 6.68 , anterior width of vertex $\bar{\delta} 1.83$, width of pronotum $\delta$ $6.20+5.95$, median length of pronotum $\delta 1.67$ 우 1.62 , lateral length of pronotum ô 2.72 ? 2.71 , median length of head+pronotum $\delta 3.10$ ㅇ .

Colour. - Lateral parts of interoculus and pronotum, embolium and connexiva yellowish. Disk of 
pronotum and hemielytra medium brown, scutellum yellowish with vague brown markings, right membrane darker than corium. Interoculus with indistinct dots, arranged in the usual pattern broad semicircular posteriorly, narrow band anteriorly, eyes blackish, connexival segments 4 and 5 with small round dark patches near the margin of hemielytra, corresponding with the ventral tracheal openings. Venter and legs orange yellow, central parts of meso and meta sternum and variable marks on abdomen, darker.

Structural characteristics. - Anterior margin of head slightly projecting in relation to the curvature of pronotum. Anterior width of vertex 1.2 times the synthlipsis (1.83/1.49); length of head slightly less than median length of pronotum (1.60/1.67); length of an eye slightly over twice its width (1.40/0.65); anteclypeus projecting 0.10 anteriorly of labrum. Lateral margins of labrum very slightly converging in basal half, converging to an obtuse tip in apical half, its basal width 1.3 times the median length (0.60/0.47). Disk of pronotum indistinctly delimited, lateral angles broadly rounded, 0.4-0.5 anteriorly of posterior margin, lateral margin weakly serrate, about 32 teeth $/ \mathrm{mm}$; maximal width distinctly over twice anterior width $(6.08 / 2.82)$ and 2.2 times the lateral length (6.08/2.72). Scutellum over twice as wide at base as its median length $(2.95 / 1.30)$ and 1.4 times as long as hemielytral commissure (1.30/0.92). Hemielytra leaving a broad (0.8-1.0 wide) strip of abdomen exposed, inner two thirds of this area wrinkled. Embolium laterally slightly convex, posterolateral lateral angle obtuse, ill defined (fig. 104), its lateral margin weakly serrate with about 32 teeth $/ \mathrm{mm}$, width across embolium larger than maximal width across connexiva (6.68/6.55), claval suture absent, right membrane strongly reduced, distinctly thinner than corium, narrowly rounded, leaving most of left membrane exposed, membranal suture absent. Left membrane somewhat more strongly reduced than right membrane, coriaceous, narrowly rounded apically; narrow inner strip of left membrane, covered by right membrane, blackish. The hemielytra end in two separate points. Connexival segments slightly indented, the margins of connexival segments at their bases originating 0.05 inward compared with posterolateral angle of preceding segment, last segment obtusely angulate posteriorly. Segment 4 weakly serrate, about 35 teeth $/ \mathrm{mm}$. Dorsal granulations small, pale, set in small pits due to colour contrast especially distinct on right membrane of holotype. Prosternal carina distinctly slanting posteriorly, anteriorly distinctly bifid. Mesosternal carina (fig. 163, 164), strongly elevated, well developed, posterior part distinctly sloping abruptly ending in a vertical edge, without teeth, central part medium wide with a widely oval, thin walled, shallow fossa, anterior and posterior angles of fossa depressed without teeth, anterior part strongly sloping, without anterior tooth. Metasternal carina well developed, subcircular with a short anterior extension, ventral fossa present, covering central third of metaxiphus. $\mathrm{Pu}$ bescence of venter well developed, leaving a broad lateral margin exposed, pubescence on metasternum sparser but longer. Fore femur distinctly less than twice as long as wide (2.15/1.20). Middle femur four and a half times as long as wide (2.30/0.50) and about 1.4 times as long as middle tibia (2.30/1.65). Hind femur nearly 6 times as long as wide (3.05/0.51) and about as long as hind tibia (3.05/3.00).

Male. - Genital segments as in fig. 109, proximal projection of right lobe of tergite 6 not differentiated.

Female. - Genital operculum (fig. 110) only slightly wider than long $(1.49 / 1.35)$, lateral margin virtually straight, apex convex, nearly truncate.

Macropterous form unknown.

\section{Etymology}

Caraceae (a noun in genitive case) refers to the type locality, Serra do Caraça. Caraça is the Brazilian name for the maned wolf, Chrysocyon brachyurus, which in a semidomesticated way is conserved there.

\section{Distribution}

Only known by the type series from Brazil: MG.

\section{Comparative notes}

$L$. caraceae belongs to the $L$. insignis-group and is similar to L. Lanemeloi and L. nigropunctatus. However, L. nigropunctatus has the lateral angles of pronotum produced more posteriorly, the embolium curving inwards more abruptly posteriorly (figs. 68,104 ) and the metasternal carina wart-like, not semicircular as in $L$. caraceae. L. lanemelo $i$ has the lateral angles of pronotum more acute (figs. 104, 141), the synthlipsis narrower compared to anterior width of vertex, 1.85/1.30 in L. lanemeloi, $1.83 / 1.49$ in L. caraceae; the anterior tooth of mesosternal carina is well developed (figs. 131, $175,176,163,164)$ and the female operculum is much more narrowly rounded apically in L. lanemeloi (figs. 110, 133). L. espinolai which occurs in the same mountains is larger, has a lighter colour and the angles of pronotum more rounded (figs. 104, 124).

\section{Limnocoris decarloi $\mathrm{sp} . \mathrm{n}$}

(figs. 113-116, 122, 165-166)

[Limnocoris sattleri De Carlo, 1966: 113 (partim, paratypes from RS). misidentification]

Material examined. - Holotype, brachypterous male, BRAZIL: RS, Cipo, 10.IX-8.XII.1960, leg. Ribeiro (ZSMC). Paratypes $5 \hat{0} 5 q$ same data as holotype: $2 \hat{0}$

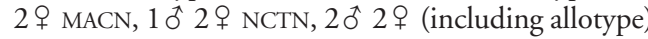




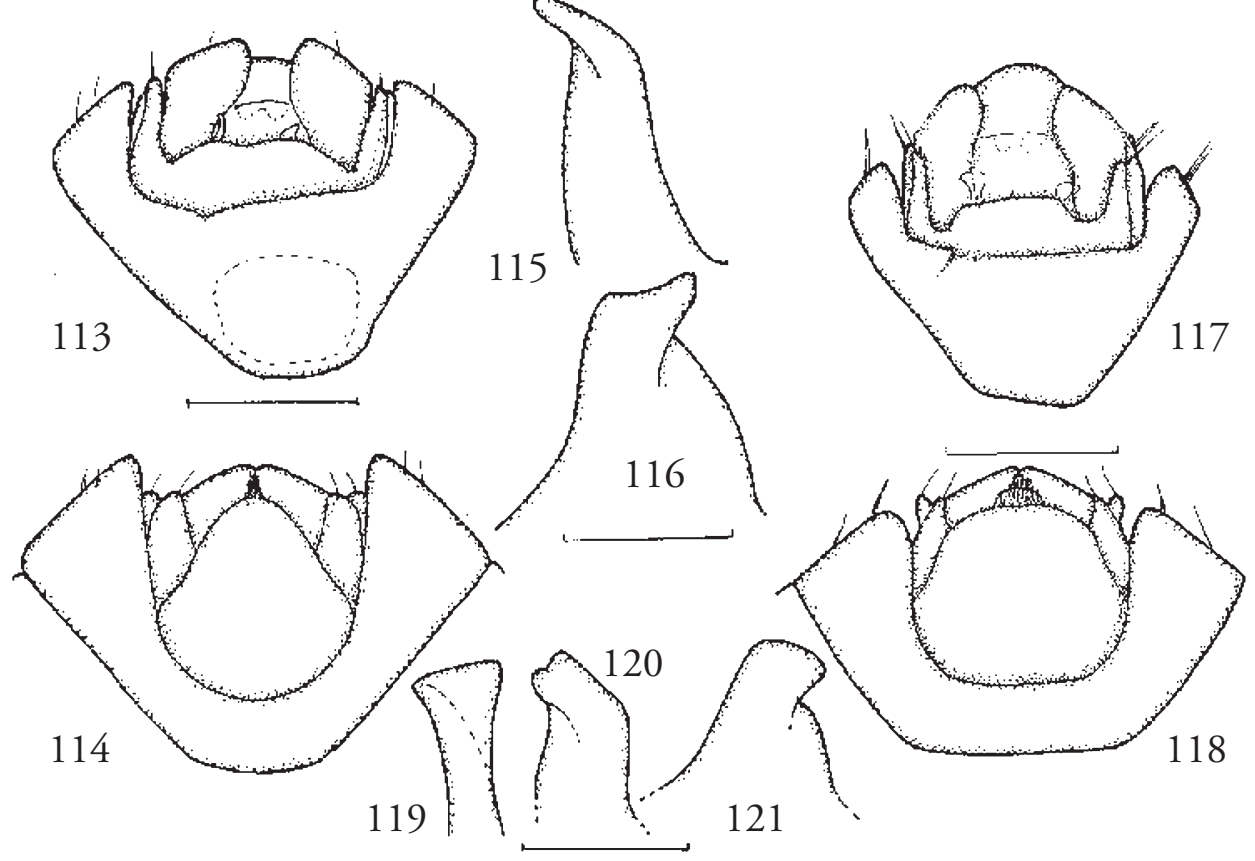

Figs. 113-116. Limnocoris decarloi paratypes. - 113, male, apex of abdomen, dorsal view; 114, female, apex of abdomen, ventral view; 115, right pseudoparamere; 116, left pseudoparamere. Scales 113, $1141 \mathrm{~mm}, 115,1160.25 \mathrm{~mm}$.

Figs. 117-121. Limnocoris espinolai paratypes. - 117, male, apex of abdomen, dorsal view; 118, female, apex of abdomen, ventral view; 119, 120, right pseudoparamere 119, medial view, 120, dorsal view; 121, left pseudoparamere. Scales 117,1181 $\mathrm{mm}, 119-1210.25 \mathrm{~mm}$.

ZSMC; L(agoa) Vermelha, Rio Santa Rita, 28²0’S $51^{\circ} 18^{\prime} \mathrm{W}, 800 \mathrm{~m}, \mathrm{IV} .1959,1 \mathrm{o}^{\text {` }}$; RS, Pulador, streamlet, $28^{\circ} 15^{\prime} \mathrm{S} 52^{\circ} 40^{\prime} \mathrm{W}, 650 \mathrm{~m}$, XI.1959, $20^{\circ} 1$ \% ; RS, Arr. Arapua, $30^{\circ} 52^{\prime} \mathrm{S} 53^{\circ} 00^{\prime} \mathrm{W}, 120 \mathrm{~m}, \mathrm{XI} .1964,10^{\circ}$ - SC, Bocaina, Rio Piurras, $27^{\circ} 48^{\prime} \mathrm{S} 49^{\circ} 55^{\prime} \mathrm{W}, 700 \mathrm{~m}$, XII.1962, $10^{\Uparrow}$ (MPLA). All brachypterous, leg. F. Plaumann, NCTN unless otherwise indicated.

Additional specimens: BRAZIL, PR, Bocaiuva, brook, $25^{\circ} 08^{\prime} \mathrm{S} 49^{\circ} 04^{\prime} \mathrm{W}, \mathrm{XII} .1963$, leg. F. Plaumann, 7 ○ $^{\circ}$ $3+$ (CASC).

Remarks. - The specimens from MACN, 19 from NCTN and the specimens from ZSMC bear paratype labels of $L$. sattleri De Carlo. Of these the 201 o with red labels in ZSMC are not paratypes of $L$. sattleri, since these specimens were not sent over to De Carlo by Weber. They were labelled paratype after the description was published. The specimens from Paraná have not been included in the type series, since they are larger (mean length ot 9.3, +9.4 ; width ot 6.91, o 7.13) and isolated, from the populations of RS.

\section{Description}

Brachypterous form (based on dry pinned speci- mens). - Generally a medium sized, dorso-ventrally somewhat bulging, broadly oval species, colour dull medium brown with lighter lateral margins. Dimensions. Length of 8.1-8.2-8.3 क 8.3-8.4-8.6 \{HT 8.1\}, width of 6.2-6.2-6.3 $\{6.22\}$ o $6.1-6.4-6.5$, anterior width of vertex ô $1.83-1.90-1.97\{1.83\}$ q 1.88 1.90-1.92, width of pronotum 0 5.40-5.50-5.52 $\{5.40\}$ 9 5.40-5.58-5.75, median length of pronotum ot 1.66-1.68-1.71 \{1.67\} o $1.73-1.75-1.78$, lateral length of pronotum ơ 2.41-2.47-2.55 \{2.41\} ㅇ 2.302.41-2.50, median length of head+pronotum ô 2.822.91-3.01 \{2.82\} ㅇ 2.85-2.95-3.00.

Colour. - Interoculus, lateral parts of pronotum, anterior part of scutellum embolium and connexiva light to orange brown. Disk of pronotum, apex of scutellum and hemielytra in most specimens dull greyish medium brown, due to confluence of ill defined dark markings. Interoculus with vague, irregular dots, eyes grey-brown, connexival segments with variable dark patches anteriorly, from absent to covering anterior third of segment. Venter and legs orange brown, central parts of thorax and abdomen, darker, greyish brown. 
Structural characteristics. - Anterior margin of head slightly projecting in relation to the curvature of pronotum. Head distinctly declining anteriorly, anterior width of vertex 1.4 times the synthlipsis (1.90/1.37); length of head subequal to median length of pronotum (1.70/1.72); length of an eye over twice its width (1.32/0.60); anteclypeus projecting 0.100.13 anteriorly of labrum. Lateral margins of labrum very slightly converging in basal half, converging to a very obtuse tip in apical half, its basal width 1.4 times the median length $(0.53 / 0.42)$. Pronotum distinctly convex dorsally, lateral angles acutely rounded, 0.2 anteriorly of posterior margin, lateral margin weakly serrate, about 35 teeth $/ \mathrm{mm}$; maximal width slightly over twice anterior width $(5.54 / 2.67)$ and 2.3 times the lateral length (5.54/2.44). Scutellum less than twice as wide at base as its median length (2.37/1.30) and 1.4 times as long as hemielytral commissure (1.30/0.91). Hemielytra leaving a broad (0.7-1.0 wide) strip of abdomen exposed, inner two thirds of this area wrinkled. Embolium laterally slightly convex, posterolateral lateral angle obtuse, ill defined (fig. 122), its lateral margin indistinctly serrate in proximal half with about 35 teeth $/ \mathrm{mm}$, width across embolium larger than maximal width across connexiva $(6.30 / 6.05)$, claval suture absent, right membrane strongly reduced, coriaceous but apically thinner than proximal part of hemielytron, narrowly rounded, leaving most of left membrane exposed, membranal suture absent. Left membrane somewhat more strongly reduced than right membrane, coriaceous, narrowly rounded apically; narrow inner strip of left hemielytron, covered by right hemielytron, membranaceous. The hemielytra end in two separate points. Hind wings strongly reduced, reaching posterior margin of first abdominal tergite. Covered part of abdomen waxy medium rufous brown. Connexival segments distinctly indented, the margins of connexival segments at their bases originating 0.05-0.10 inward compared with posterolateral angle of preceding segment, last segment obtusely angulate posteriorly. Segment 4 serrate, about 26-27 teeth $/ \mathrm{mm}$. Dorsal granulations small, set in small pits. Prosternal carina distinctly to strongly slanting posteriorly, anteriorly distinctly bifid. Mesosternal carina (figs. 165, 166), strongly elevated, well developed, posterior part distinctly sloping abruptly ending in a vertical edge, without teeth, central part wide with a widely oval, shallow fossa, anterior part strongly sloping, with a hardly developed tooth at anterior edge of fossa and a distinct anterior tooth. Metasternal carina well developed ventral fossa indicated only, covering central third of metaxiphus. Pubescence of venter well developed but short and not very distinct except for median area. Fore femur distinctly less than twice as long as wide (2.02/1.14). Middle femur nearly four and a half times as long as wide $(2.11 / 0.48)$ and about
1.3 times as long as middle tibia (2.11/1.58). Hind femur over 5 times as long as wide $(2.86 / 0.51)$ and about as long as hind tibia (2.86/2.89).

Male. - Genital segments as in fig. 113, proximal projection of right lobe of tergite 6 not differentiated. Pseudoparameres as in figs. 115, 116.

Female. - Genital operculum (fig. 114) lateral margin straight to slightly concave, apex broadly rounded, only slightly wider than long (1.2/1.1).

Macropterous form unknown.

\section{Etymology}

Decarloi: a name in genitive. This species is dedicated to Prof. José De Carlo who laid the foundation for our knowledge of several nepomorphan families in southern South America.

\section{Distribution}

Brazil: RS, SC, PR.

\section{Comparative notes}

The series containing the holotype was originally included as paratypes in L. sattleri, which is now considered to be a synonym of $L$. nigropunctatus. $L$. decarloi differs from L. nigropunctatus in being slightly smaller on average, having a more dorsoventrally bulging body shape, a more strongly sloping prosternal carina, a more strongly developed mesosternal carina, posterolateral angle of embolium poorly defined and fore femur more stoutly built. For differences with other species of the L. insignis-group, see the key.

\section{Limnocoris espinolai $\mathrm{sp} . \mathrm{n}$.}

(figs. 117-121, 123-124, 167-168)

Material examined. - Holotype brachypterous female (DPIC): BRAZIL, MG, Serra da Caraça, Santa Bárbara, 12 Oct. 1972, leg. H. Espinola. Paratypes, same

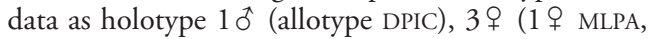
2 + NCTN); same locality as holotype, upstream of small waterfall, 29.XI.1997, leg. A. L. de Melo, $10^{\star}$ 1 ㅇ․ $11 \mathrm{vV}$ (NCTN).

\section{Description}

Brachypterous form (based on dry pinned specimens). - Generally a medium sized, dark brown, oval species.

Dimensions: length of 8.35-8.42 + 8.2-8.3-8.6 \{HT 8.62\}, width ô 5.9-6.0 क 6.0-6.2-6.4 \{6.35\}, anterior width of vertex ô 1.64-1.73 9 1.69-1.74-1.82 $\{1.78\}$, width of pronotum $\delta$ 5.20-5.28 $q$ 5.125.27-5.37 $\{5.37\}$, median length of pronotum $\delta$ 1.48-1.50 $+1.40-1.45-1.48\{1.42\}$, lateral length of pronotum of 2.30-2.31 $+2.28-2.35-2.40\{2.38\}$, median length of head+pronotum ô 2.67-2.80 o 2.65-2.73-2.80 $\{2.80\}$. 


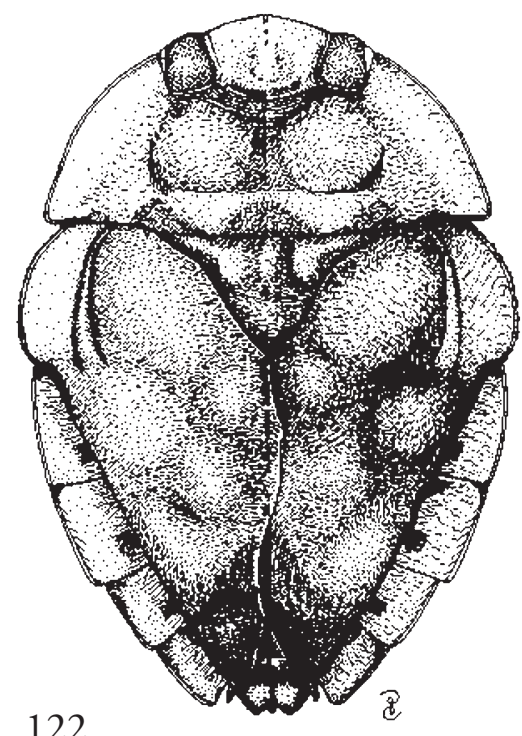

123
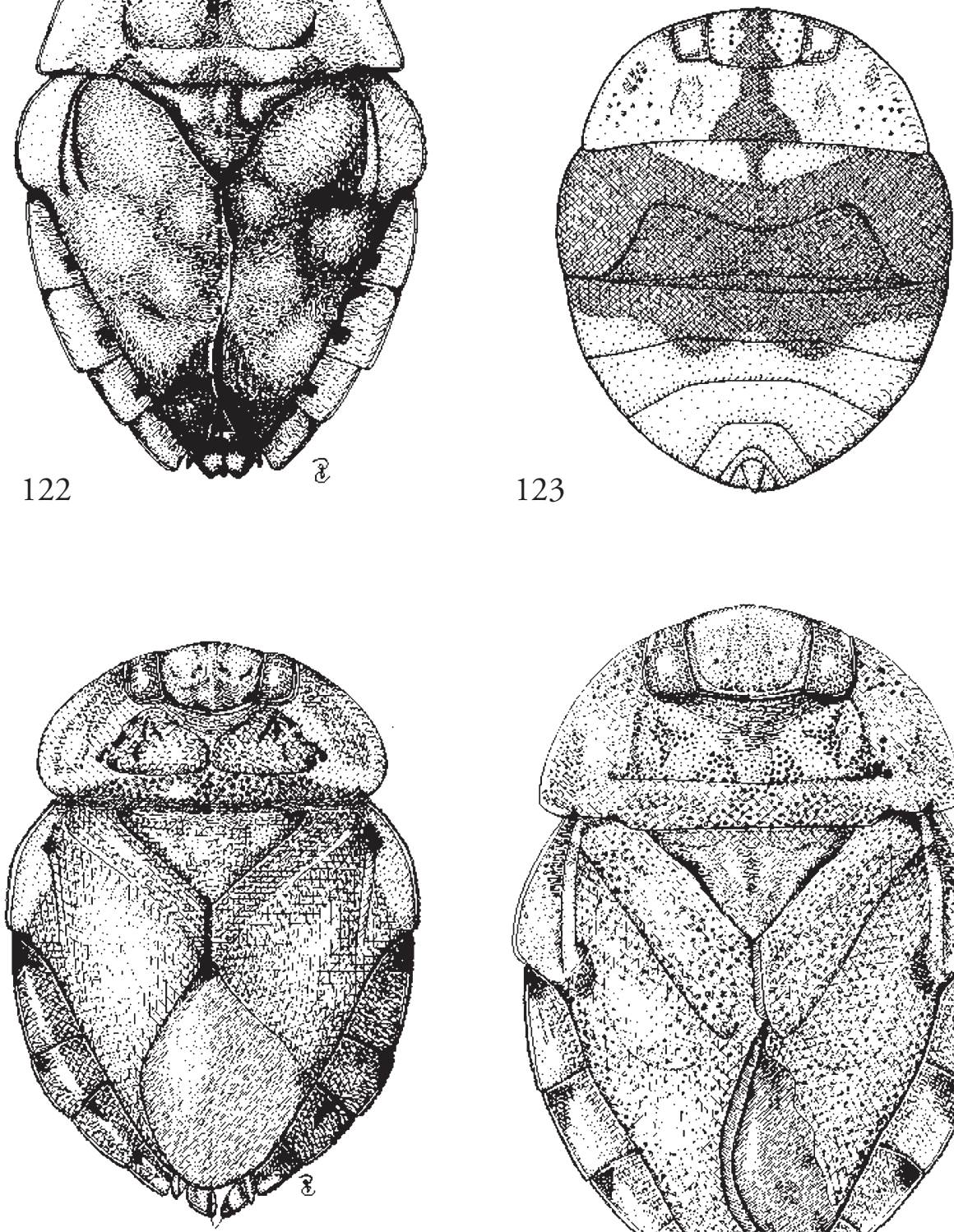

124

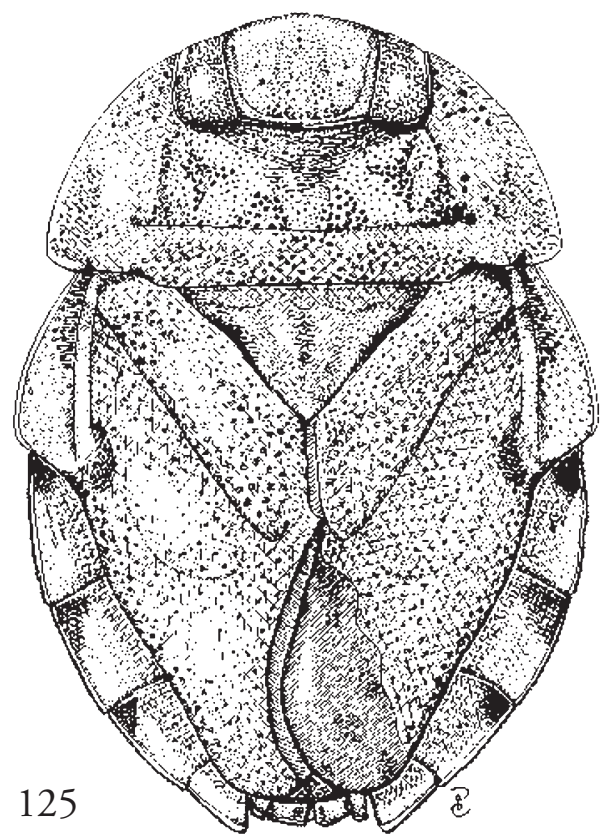

Figs. 122-125. Habitus of Limnocoris. - 122, L. decarloi paratype, brachypterous female, body length $8.5 \mathrm{~mm}$; 123 , L. espinolai larva V, body length $7.0 \mathrm{~mm} ; 124$, L. espinolai holotype, brachypterous female, body length $8.8 \mathrm{~mm} ; 125, \mathrm{~L}$. intermedius holotype, brachypterous female, body length $9.8 \mathrm{~mm}$. 
Colour. - Dorsally dark brown, lateral parts of head and most of pronotum light brown, irregular patches on, scutellum, most of embolium and apical part of corium also slightly lighter. Most of membrane blackish. Lateral margin of connexival segments dorsally yellowish brown, anterior two thirds infuscated; medianly connexiva and dorsum of abdomen dull light brown. Venter of head, lateral part of prosternum and fore legs sordid yellow, remainder of venter and legs light to medium brown.

Structural characteristics. - Anterior margin of head following the curvature of pronotum but slightly projecting relative to anterior angles of pronotum. Median mark of interoculus ill defined, broad posteriorly, arrowhead-shaped in anterior half (figs. 123, 124). Anterior width of vertex 1.1 times the synthlipsis (1.71/1.54); length of head subequal to median length of pronotum (1.42/1.46); length of an eye twice its width (1.16/0.54); anteclypeus projecting 0.12 anteriorly of labrum. Lateral margins of labrum slightly convergent basally, smoothly rounded in apical quarter, its basal width one and a third times the median length $(0.4 / 0.3)$. Pronotum with lateral angles broadly rounded, maximal width about 0.5 removed from posterior margin, central area distinctly elevated, lateral margin indistinctly serrate, about 22 teeth $/ \mathrm{mm}$; maximal width twice anterior width $(5.27 / 2.65)$ and 2.25 times the lateral length (5.27/2.34). Scutellum more than twice as wide at base as its median length (2.87/1.25) and less than twice as long as hemielytral commissure (1.25/0.75). Dorsal granulations lying on top of surface covering the dorsal surface except for most of exposed part of dorsum of abdomen, finer and more densely placed on right membrane. Hemielytra leaving a broad (0.7-0.9 wide) strip of abdomen exposed, inner three fourth of this area dull brown, wrinkled. Embolium with lateral margin only slightly convex, slightly diverging posteriorly, posterolateral lateral angles obtuse, ill defined (fig. 124), its lateral margin serrate, about 22 teeth $/ \mathrm{mm}$, width across embolium distinctly larger than maximal width across connexiva (6.1/5.8), claval suture absent, right membrane coriaceous but thin and flexible, broadly rounded, covering left membrane, membranal suture absent, however, membrane clearly delimited because of darker colour and smoother texture. Left membrane well developed, membranaceous, smoky brown. Hind wings strongly reduced, reaching base of second abdominal tergite. Covered part of abdomen waxy medium rufous brown. Connexival segments not indented forming a continuous lateral margin of abdomen, last segment obtusely angulate posteriorly. Connexival segment 4 distinctly serrate with about 18 serration $/ \mathrm{mm}$. Prosternal carina very gradually slanting posteriorly, low and weakly bifid anteriorly. Mesosternal carina (figs. 167, 168), relatively small, posterior part gradually sloping, central part relatively large with a shallow, anteriorly distinctly widening fossa, anterior part short, strongly sloping, anterior tooth only weakly developed. Metasternal carina distinct, occupying central quarter of metaxiphus, with an elongate rhomboid fossa. Pubescence of venter poorly developed. Fore femur slightly less than twice as long as wide (2.16/1.18). Middle femur slightly over five and a half times as long as wide $(2.16 / 0.37)$ and 1.5 times as long as middle tibia (2.16/1.48). Hind femur 6.8 times as long as wide (2.91/0.43) and slightly longer than hind tibia (2.91/2.86).

Male. - Genital segments as in fig. 117, proximal projection of right lobe of tergite 6 short and blunt, ill defined. pseudoparameres as in figs. 119-121.

Female. - Genital operculum (fig. 118) lateral margin slightly sinuate, apex truncately rounded.

Macropterous form unknown.

Larva V. - Length 7.2, width (across wing-pads) 5.88 , anterior width of vertex 1.50 , width of pronotum 5.25, median length of pronotum 1.00, lateral length of pronotum 1.81, synthlipsis 1.40 , median length of head+pronotum 2.03. Colour, dorsally dirty yellow to light brown, head pattern as in adult, mesoalinotum, exposed part of metanotum, base of abdomen up to tergite 3 dark brown with purplish tinge (fig. 123). Abdominal tergite 3 laterally dark in basal half only, median part entirely dark. Ventrally, prosternum and legs mostly yellowish, a transverse dark band corresponding to the dorsal dark pattern, abdominal venter medially brown laterally dirty yellowish with small dark patches anteriorly on each segment. Lateral margins of connexiva distinctly serrate, about 20 teeth $/ \mathrm{mm}$ on segment 4 .

\section{Etymology}

Espinolai, name in the genitive. This species is named in honour of Prof. Dr. H. N. Espinola for his interest in aquatic Heteroptera, which resulted in a small but important collection from MG.

\section{Distribution}

Only known from the type series from Brazil, MG.

\section{Comparative notes}

L. espinolai belongs to the L.insignis-group. It is similar to $L$. porphyros, differing from this species in having a much less pronounced purple hue, being larger and slightly more slender on average, the fossa of the mesosternal carina is larger (figs. 168, 192) and the lateral margins of pronotum and embolium are less distinctly serrate. See also under $L$. caraceae.

The larva $V$ has a similar colour pattern as the larva of $L$. saphis and unlike the known larvae of other species. It is unfortunate that the number of species of which the larva $\mathrm{V}$ is known is small, because we con- 

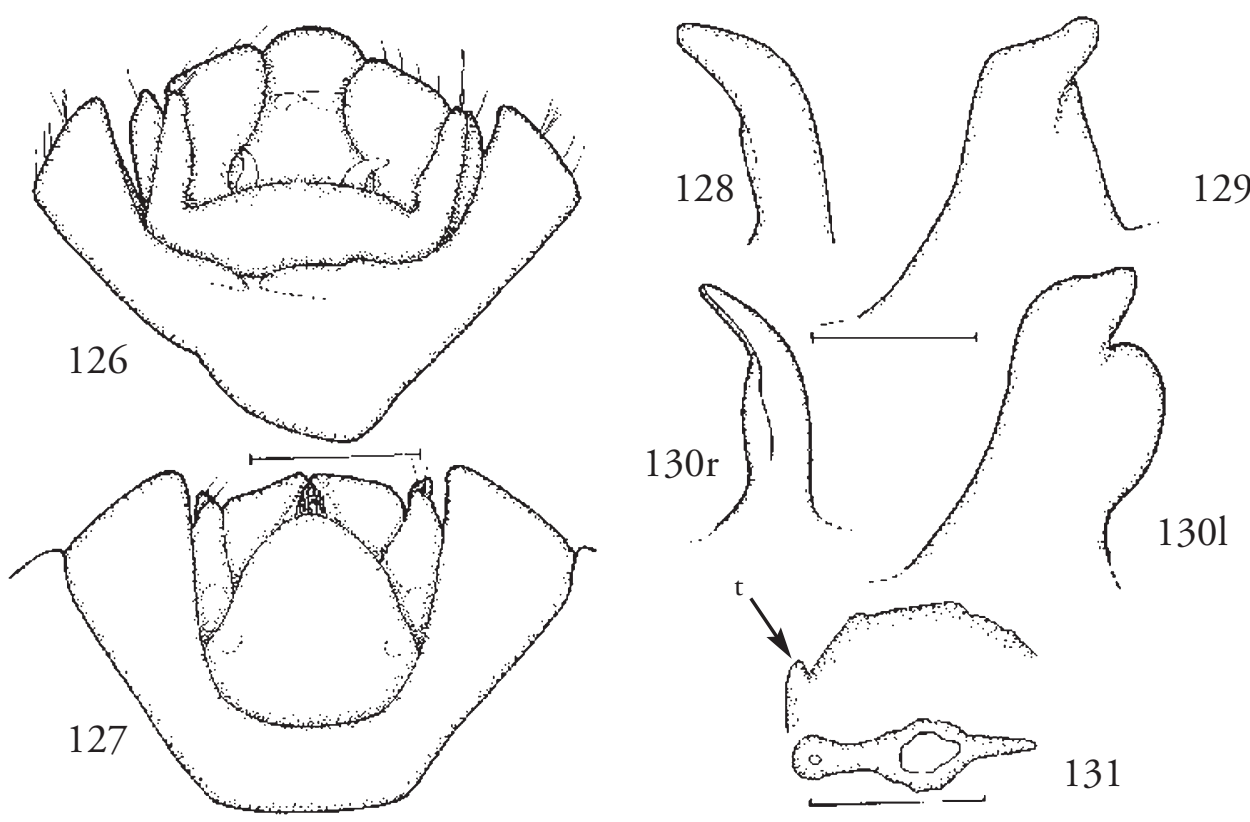

Figs. 126-129. Limnocoris intermedius paratypes. - 126, male apex of abdomen, dorsal view; 127, female, apex of abdomen, ventral view; 128, right pseudoparamere; 129 , left pseudoparamere.

Figs. 130, 131. Limnocoris lanemeloi paratype male. - 130, pseudoparameres, r right, 1 left; 131, mesosternal carina, upper: lateral view, lower: ventral view, t anterior tooth. Scales 126, 127, $1311 \mathrm{~mm}, 128-1300.25 \mathrm{~mm}$.

sider this characteristic as possibly important for an analysis of species groups.

\section{Limnocoris intermedius sp. $\mathrm{n}$.}

(figs. 125-129, 173-174)

Type material. - Holotype brachypterous female (NCTN): BRASIL, PR, Bocaiuva, V.1964, Rio Capivari, $25^{\circ} 15^{\prime} \mathrm{S}, 49^{\circ} 07 \mathrm{~W}, 1000 \mathrm{~m}$ asl., F. Plaumann. - Paratypes, same data as holotype, $1 \delta^{\dagger}$; Bocaiuva, brook, $25^{\circ} 06^{\prime} \mathrm{S}, 49^{\circ} 04^{\prime} \mathrm{W}, 1000 \mathrm{~m}$ asl. 19 ; Serra do Mar, V.1964, Rio Pinhal, $25^{\circ} 13^{\prime} \mathrm{S} 49^{\circ} 00^{\prime} \mathrm{W}, 850 \mathrm{~m}$ asl. 2 우 (1ㅇ MLPA); Serra do Mar, Rio Bonito, $25^{\circ} 14^{\prime} \mathrm{S}$ $48^{\circ} 56^{\prime} \mathrm{W}, 800 \mathrm{~m}, \mathrm{~V} .1964$, leg. F. Plaumann, $10^{\text {o }}$ (allotype). All brachypterous and in NCTN unless otherwise specified.

Remarks. - One male paratype is damaged by dermestids on the right side of head and pronotum, so some measurements have been taken only once. The holotype will be deposited in RMNH.

\section{Description}

Brachypterous form (based on dry pinned specimens). - Generally a medium sized, broadly ovate, slightly bulging dorsoventrally, medium brown species with distinctly reduced hemielytra. Dimen- sions: length of 9.4-9.6 $+9.2-9.5-9.8$ स HT 9.80\}, width 0 7.12-7.32 9 7.00-7.10-7.22 \{7.22\}, anterior width of vertex ot 2.20 \% $1.93-2.08-2.20\{2.20\}$, width of pronotum $\delta$ 6.36-6.79 $+6.20-6.36-6.62$ $\{6.62\}$, median length pronotum ô $1.88-1.92$ o 1.82-1.88-2.00 $\{2.00\}$, lateral length of pronotum $\delta$ 2.75-2.75 $+2.67-2.77-2.82\{2.79\}$, median length of head+pronotum ô 3.33 \& 3.29-3.33-3.37 $\{3.33\}$.

Colour. - Medium brown, head and pronotum light brown with disk of pronotum medium brown, eyes brown to blackish, interoculus with small, little contrasting, brown dots arranged in two spots posteriorly, more diffuse anteriorly. Embolium, exposed part of abdomen and anterior margins of abdominal segments infuscated. Ventrally head, thorax and legs yellowish, abdomen castaneous.

Structural characteristics. - Anterior margin of head following the curvature of pronotum and eyes. Anterior width of vertex 1.4 times the synthlipsis (2.11/1.52); length of head subequal to shorter than median length of pronotum (1.91/1.90 in $\delta 1.87 /$ 1.79 in 9$)$; length of an eye over twice its width (1.49/ 0.67 ); anteclypeus projecting 0.1-0.2 anteriorly of labrum. Lateral margins of labrum virtually parallel in basal half, converging to an acutely rounded tip in apical half, its basal width 1.2 times the median length 
(0.61/0.50). Pronotum with lateral angles acutely rounded, nearly at same level as its posterior margin, central area hardly elevated, lateral margin indistinctly serrate, about 32 teeth $/ \mathrm{mm}$; maximal width over twice anterior width (6.36/3.04) and 2.3 times the lateral length $(6.44 / 2.75)$. Scutellum twice as wide at base as its median length (2.94/1.43) and 1.3 times as long as claval commissure (1.43/1.13). Hemielytra leaving a broad (0.8-0.9 wide) strip of abdomen exposed, inner three fourth of this area wrinkled. Embolium with posterior half of lateral margin nearly straight and slightly diverging posteriorly relative to body axis; posterior distinctly curving inward, posterolateral lateral angle reasonably well defined (fig. 125), its lateral margin weakly serrate, about 32 teeth $/ \mathrm{mm}$, width across embolium larger than maximal width across connexiva (7.1/6.9), claval suture absent, right membrane coriaceous, strongly reduced, narrowly rounded, covering narrow, membraneous, velvety brown to blackish median strip of left hemielytron, leaving tip of left membrane exposed, membranal suture absent, however, the membrane is clearly delimited because of smoother texture compared to corium. Left membrane partly exposed, more strongly reduced and apically more narrowly pointed (than right membrane); hemielytra just reaching or very slightly surpassing the hind margin of last abdominal tergite. Hind wings vestigial. Covered part of abdomen waxy yellowish to light rufous brown. Connexival segments slightly indented, anterolateral edges of connexival segments 0.1 more medially than posterolateral angle of preceding segment, last segment obtusely angulate posteriorly. Segment 4 serrate with about 25 teeth $/ \mathrm{mm}$. Dorsal granulations indistinct, set in small pits which form a reticulate pattern, apparently absent on most of the membranal areas. Prosternal carina well developed, slanting posteriorly, anteriorly broadly bidentate. Mesosternal carina (figs. 173, 174), strongly elevated, posterior part about half as long as central part, strongly slanting, central part compact (about 0.6 long, 0.5 wide) with a shallow nearly circular to somewhat heart-shaped fossa, anterior part about as long as central part, strongly slanting, with a well developed tooth at anterior edge of fossa, anterior tooth also well developed. Metasternal carina low but with a broad, thin walled shallow fossa, occupying central third of metaxiphus. Ventral abdominal pubescence dense with two pairs of small bare patches on each segment. Fore femur distinctly less than twice as long as wide (2.24/1.34). Middle femur 4.3 times as long as wide $(2.46 / 0.57)$ and 1.3 times as long as middle tibia $(2.46 / 1.88)$. Hind femur six times as long as wide (3.05/0.49) and shorter than hind tibia (3.32/3.44).

Male. - Genital segments as in fig. 126, right lobe of tergite with a vestigial proximal projection. Right pseudoparamere slender (fig. 128).
Female. - Genital operculum (fig. 127), greatest width subequal to median length (1.2/1.2), lateral margins distinctly convex anteriorly, gradually tapering with virtually straight lateral margins to broadly rounded apex posteriorly.

Macropterous form unknown.

\section{Etymology}

Intermedius (Latin adjective: intermediate), because its size is intermediate between $L$. abbreviatus and L. rotundatus which are of similar general form.

\section{Distribution}

Brazil: PR.

\section{Comparative notes}

L. intermedius belongs to the L. insignis-group. The mesosternal carina is similar to that of L. lanemeloi which has a similar overall shape but is distinctly smaller (maximal length 8.8 compared to minimum length 9.2 in L. intermedius), has the hind femur as long as to very slightly longer than tibia and the female operculum slightly shorter than wide. L. abbreviatus La Rivers from RJ and SC is larger (length 10.3) and has a narrow mesosternal carina (fig. 11), L. rotundatus De Carlo from PR (length 8.5) is smaller.

\section{Limnocoris lanemeloi sp. n.}

(figs. 130-133, 141, 175-176)

Material examined. - Holotype, brachypterous male (DPIC): BRAZIL: MG, São Roque de Minas, Rio do Peixe, 27.III.1996, 20¹4’35” S/ 46²2'13”W, leg. N. Nieser \& A.Pelli, N9636. Mountain stream in gorge with trees, $4-10 \mathrm{~m}$ wide, up to $0.7 \mathrm{~m}$ deep, v.c. very variable, rapids (Cryphocricos), riffles (Ambrysus, Limnocoris lanemeloi \& L. pusillus), quiet parts (with Limnocoris maculiceps at margins), water clear to turbid (depending on distance from waste outlets) and somewhat eutrophied (algal growth), bottom small boulders to sand with gravel or sometimes at edges sand only, mostly shaded but with sunny patches. Edges with overhanging vegetation and leaf litter. Paratypes (adults only), same data as holotype $160^{\star}$ 22 ㅇ $1 \mathrm{lvV}$ distributed as follows: DPIC $10^{\mathrm{t}} 2$ 우 (including allotype), 1 t 19 JTPC, 10 t 2 ㅇ PCMG, 1 t 1 우 RMNH, 10 to 1 ? ZMAN, 1 ㅇ ZSMC. Additional paratypes: same locality as holotype, 7.XI.1997, leg. Nieser $\&$ Pelli, N9636a, 60 89 brach., 1 macr., lvV. Serra da Canastra, tributary of Rio S. Francisco, just upstream of Casca d'Anta waterfall, 5.XI.1997, small stream, $2-5 \mathrm{~m}$ wide, ca. $0.5 \mathrm{~m}$ deep, gravelly bottom at sample site, leg. N. Nieser, N9718, $20^{\star}$. At park station 'Pé da Cascata, Casca d'Anta', 6.XI.1997, leg. N. Nieser, N9722. River in gallery forest, about $20-30 \mathrm{~m}$ wide with small islands (which after rain are under wa- 

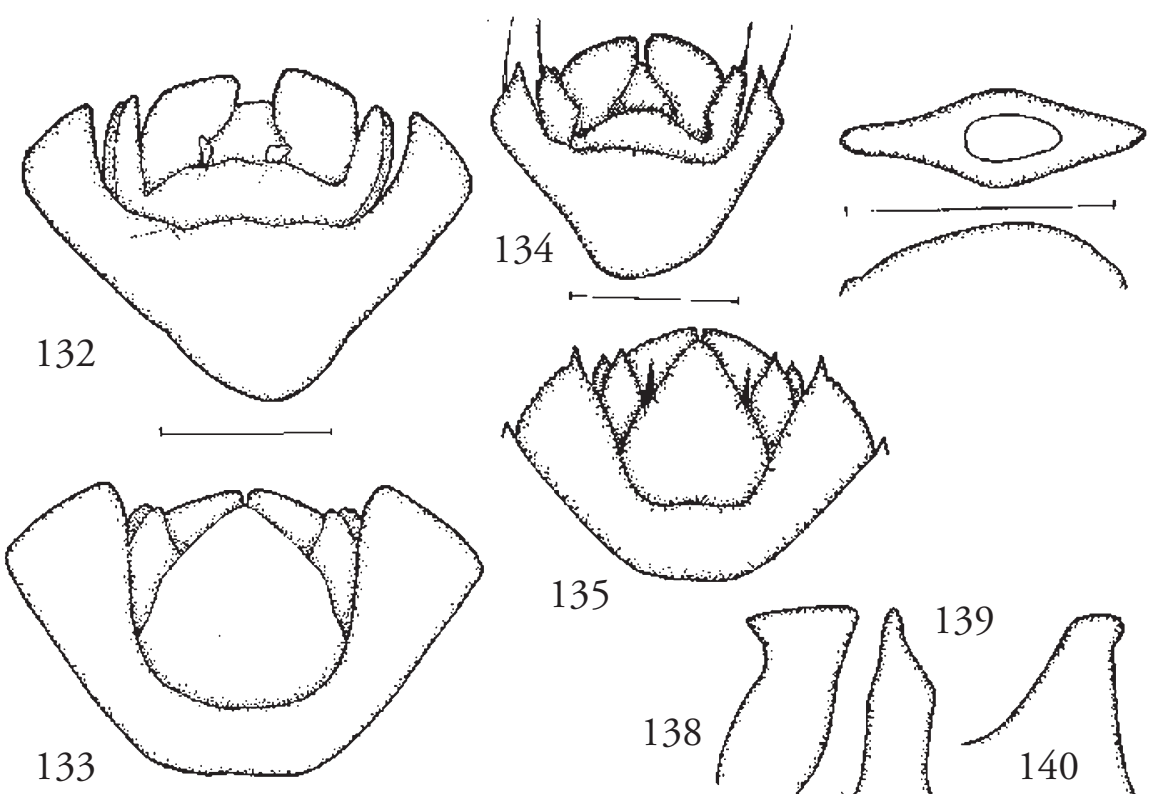

Figs. 132, 133. Limnocoris lanemeloi paratypes. - 132, male, apex of abdomen dorsal view; 133, female, apex of abdomen, ventral view.

Figs. 134-140. Limnocoris machrisi. - 134, male holotype, apex of abdomen, dorsal view; 135, female paratype, apex of abdomen, ventral view; 136-140, holotype, 136, 137, mesosternal carina, anterior side to the left, 136, ventral view, 137, lateral view; 138, 139, right pseudoparamere, 138, medial view, 139, dorsal view; 140, left pseudoparamere. Scales $132-1371$ $\mathrm{mm}, 138-1400.25 \mathrm{~mm}$.

ter) gravel, stones, boulders, Limnocoris from small stretch with rather fine gravel and little current, depth variable up to over $1 \mathrm{~m}$. Water clear, light brown. 20 2 , , 7lvV, 2lvIII; Rio do Peixe $\pm 5 \mathrm{~km}$ upstream of S. Roque, at camping site, 7.XI.1997, leg. A. Pelli, N9724. River bed very broad (probably artificially as result of search for minerals. The (probably) original bed mostly shaded with well developed marginal vegetation (Limnocoris), secondary gully mostly exposed to sun, bare margins except for shrubs and trees, bottom pebbles, $1 \hat{0}$ (PCMG). Rio Aguari at S. João Batista, open field (used as parking lot), 11.XI.1997, leg. A. Pelli, N9731. Small stream, 2-4m wide, shallow, exposed to sunshine, clear hyaline water flowing over pebbles, $204 q$ brach. Rio Aguari $\pm 300 \mathrm{~m}$ downstream of base of waterfall, 11.XI.1997, leg. N. Nieser, N9732B 200-400m. Limnocoris at edge with gravel and sand, not between larger stones, $2 q$ brach., 1 i macr., 3lvV. Brachypterous and NCTN unless otherwise indicated.

\section{Description}

Brachypterous form (based on (mostly alcohol) specimens from N9636). - Generally a medium sized, very broadly ovate, medium brown species with distinctly reduced hemielytra. Dimensions: length 0 8.2-8.4-8.6 \{HT 8.39\} क 8.2-8.5-8.8, width ô 6.426.55-6.69 \{6.61\} 9 6.40-6.48-6.65, anterior width of vertex ot $1.83-1.85-1.89\{1.81\}$ o $1.80-1.84-1.95$, width of pronotum 0 5.75-5.84-5.95 \{5.82\} +5.63 5.79-5.98, median length pronotum of 1.68-1.70$1.73\{1.71\}$ $1.60-1.69-1.80$, lateral length of pronotum ô 2.50-2.55-2.65 $\{2.50\}$ क $2.42-2.48$ 2.55 , median length of head+pronotum 0 2.882.95-3.09\{2.93\} क 2.80-2.91-3.08.

Colour. - Head and pronotum light brown, eyes brown to blackish, interoculus with small brown dots arranged in two spots posteriorly, more diffuse anteriorly, central disk and posterior margin of pronotum medium brown. Hemielytra medium brown, embolium exposed part of abdomen and, in most specimens, scutellum light brown, anterior margins of connexival segments infuscated, indistinct in some specimens. Lateral parts of venter and legs yellowish, central part of venter light castaneous with a variable greyish tone. Anterior margin following the curvature of pronotum and eyes. Median mark of interoculus ill defined hardly visible in some specimens.

Structural characteristics. - Anterior margin of head following the curvature of pronotum and eyes. Anteri- 
or width of vertex 1.4 times the synthlipsis (1.85/ 1.30); length of head shorter than median length of pronotum (1.56/1.70); length of an eye twice its width (1.32/0.67); anteclypeus projecting about 0.2 anteriorly of labrum. Labrum slightly converging apically in basal half, converging to an acutely rounded tip in apical half, its basal width only slightly larger than the median length $(0.50 / 0.45)$. Pronotum with lateral angles acutely rounded, at same level as its posterior margin, central area hardly elevated, lateral margin weakly serrate, about 32 teeth $/ \mathrm{mm}$; maximal width twice anterior width $(5.82 / 2.83)$ and 2.3 times the lateral length $(5.82 / 2.52)$. Scutellum twice as wide at base as its median length (2.64/1.28) and 1.3 times as long as claval commissure (1.28/0.95). Hemielytra leaving a broad (0.7-0.9 wide) strip of abdomen exposed, inner three fourth of this area light brown, wrinkled. Embolium with posterior half of lateral margin nearly straight and slightly diverging posteriorly gradually curving inward, posterolateral lateral angle ill defined (fig. 141), its lateral margin weakly serrate, about 32 teeth $/ \mathrm{mm}$, width across embolium larger than maximal width across connexiva (6.5/6.3), claval suture absent, right membrane coriaceous, strongly reduced, narrowly rounded, covering narrow, membraneous, velvety brown to blackish median strip of left hemielytron, membranal suture absent, however, the membrane is clearly delimitated because of smoother texture compared to corium. Left membrane partly exposed, more strongly reduced and apically more narrowly pointed; hemielytra just reaching or very slightly surpassing the hind margin of last abdominal tergite. Hind wings vestigial, reaching halfway the first abdominal tergite. Covered part of abdomen waxy yellowish to light rufous brown. Connexival segments slightly indented, anterolateral edges of connexival segments $0.05-0.10$ more medially than posterolateral angle of preceding segment, last segment obtusely angulate posteriorly. Segment 4 serrate with about 27 teeth/mm. Dorsal granulations set in small pits which form a reticulate pattern, except on most of the membranal areas. Prosternal carina well developed, only slightly slanting posteriorly to nearly parallel with ventral surface of prosternum, anteriorly with a small subapical indentation and a broadly rounded tip. Mesosternal carina (fig. 131,175, 176), strongly elevated, posterior part short, strongly slanting, central part short and broad (about 0.5 long, 0.4 wide) with a shallow nearly circular fossa, anterior part about as long as central part, strongly slanting, with small tooth at anterior edge of fossa, anterior tooth well developed. Metasternal carina well developed with a relatively broad shallow fossa, occupying central third of metaxiphus. Ventral abdominal pubescence well developed. Fore femur distinctly less than twice as long as wide (2.08/1.18). Middle femur five times as long as wide $(2.26 / 0.45)$ and 1.4 times as long as middle tibia
(2.26/1.66). Hind femur six times as long as wide (3.05/0.49) and about as long as hind tibia (3.05/3.00).

Male. - Genital segments as in fig. 132, posterior margin of abdominal tergite 6 with three faintly indicated broad lobes right lobe of tergite 6 with a vestigial proximal projection. Right pseudoparamere slender (fig. 130r).

Female. - Genital operculum (fig. 133), greatest width only slightly larger than median length (1.2/1.1), lateral margins slightly convex to sinuate, distinctly converging posteriorly over most of their length, apex broadly rounded.

Macropterous form (based on two females). - As brachypterous form except for being relatively slightly more slender and modifications connected with macropterism. Dimensions: length 8.6-9.0, width 6.31-6.50, anterior width of vertex 1.79-1.82, width of pronotum 5.50-5.84, median length of pronotum 1.82-1.95, lateral length of pronotum 2.53-2.85, median length of head+pronotum 2.90-3.30, basal width of scutellum 2.92-3.20, median length of scutellum 1.50 , more than twice the length of claval commissure $(1.50 / 0.58)$. Colour somewhat darker than brachypterous specimens. Right membrane blackish with pale mottling, left membrane and hind wings smoky blackish. Posterolateral angles of pronotum rounded, about 0.7 anteriorly of posterior margin. Scutellum more strongly developed than in brachypterous form and claval commissure shorter (see above). Membranes and wings fully developed, right membrane overlapping left membrane. A broad lateral strip (0.60.7) of abdomen not covered by hemielytra, inner part of exposed strip distinctly wrinkled.

Larva V. - Dimensions length 7.5, width 6.2, anterior width of vertex 1.61 , synthlipsis 1.29 , width of pronotum 5.46, median length of pronotum 1.04, lateral length of pronotum 2.01, median length of head+pronotum 2.36. Colour yellowish to light brown dorsally with a broad lighter margin laterally, marked with rather widely spaced medium brown dots which on abdomen are partly arranged in a double row medially of the lighter lateral margin, on dry specimens the dots are poorly contrasting in the darker areas. Interocular mark indistinct to absent. Posterolateral angles of pronotum sharp, somewhat posteriorly of the level of the hind margin medially. Lateral margin of connexiva serrate with 25 teeth/mm. Central part of mesosternal carina strongly elevated, apically with a sharp point directed slightly backward.

\section{Etymology}

Lanemeloi, name in genitive case. Dedicated to Prof. Dr. A. Lane de Melo, DPIC, UFMG for his interest in and stimulation of the study of aquatic bugs of Minas Gerais. 

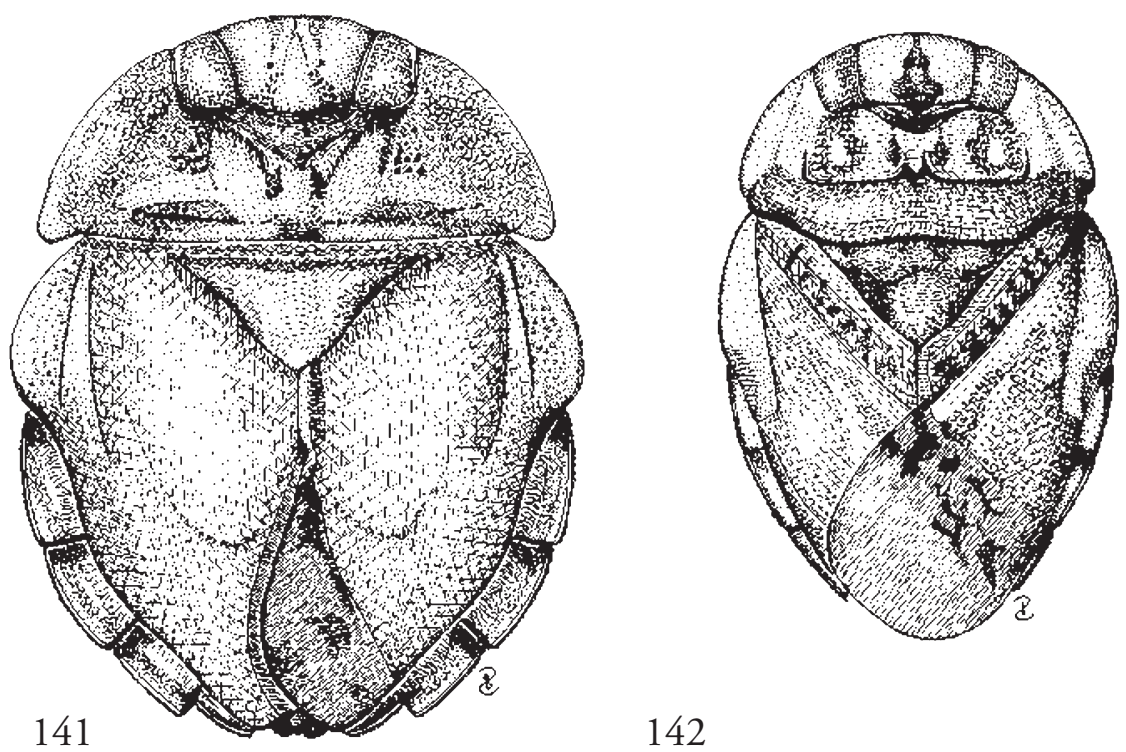

142

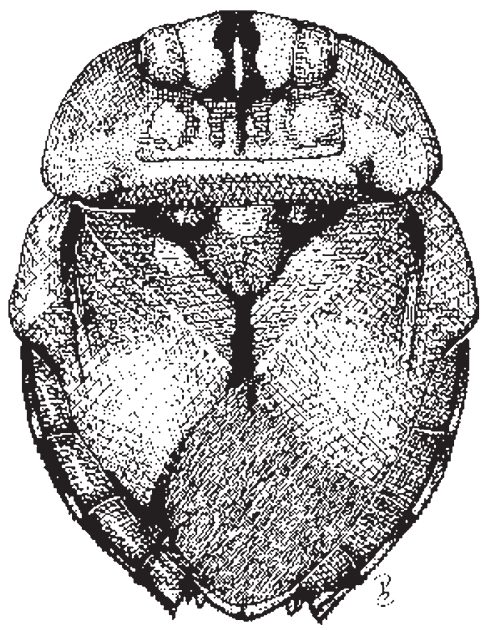

143

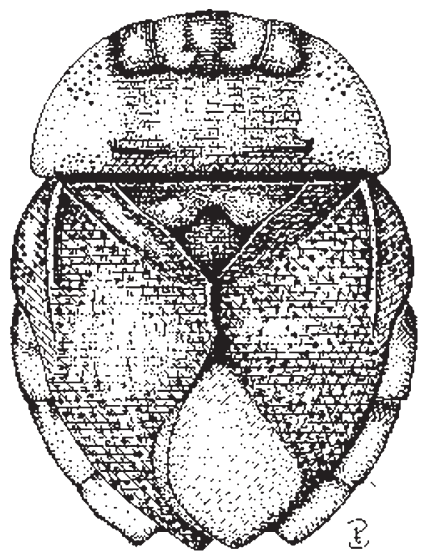

144

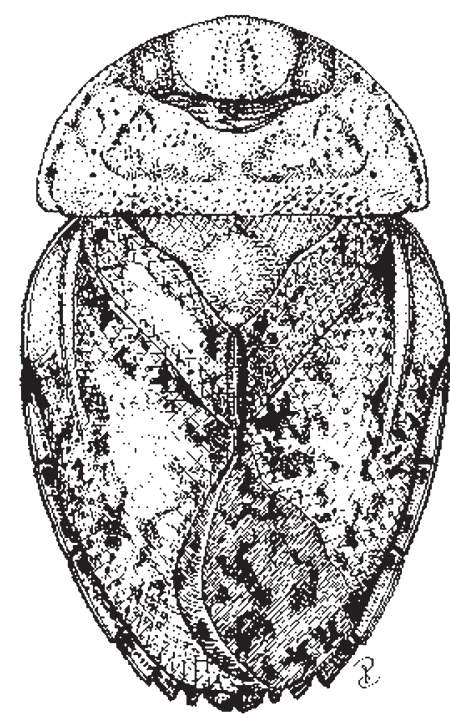

145

Figs. 141-145. Habitus of Limnocoris. - 141, L. lanemeloi paratype, brachypterous male, body length 8.4 mm; 142, L. machrisis holotype, macropterous male, body length $7.5 \mathrm{~mm} ; 143$, L. porphyros paratype, brachypterous male, body length $7.7 \mathrm{~mm}$; 144, L. saphis paratype, brachypterous male, body length $6.8 \mathrm{~mm}$; 145, L. subpauper holotype, brachypterous female, body length $8.2 \mathrm{~mm}$. 


\section{Distribution}

Brazil: MG. Habitat, apparently this species has a preference for more or less exposed parts of streams with a gravelly bottom.

\section{Comparative notes}

L. lanemeloi belongs to the insignis-group and differs from L. submontandoni, which occurs in the same area, and L. nigropunctatus, reported from Minas Gerais, by the mesosternal carina, which in L. submontandoni and L. nigropunctatus has a relatively much narrower central part. Furthermore L. submontandoni has in the brachypterous form the posterolateral angles of pronotum more acute, the posterior margin of embolium curving more abruptly inward and the serration of connexiva less distinct (figs. 1, 141). In L. nigropunctatus, which is very similar, males have the median lobe of posterior margin of abdominal tergite 6 not faintly trilobate and the right pseudoparamere less slender (figs. 59, 61, 62; 130r, 132). The female has the genital operculum more truncate apically (figs. 60, 133). For differences with other species, see the key.

\section{Limnocoris machrisi sp. $\mathrm{n}$.}

(figs. 134-140, 142)

Type material. - Holotype macropterous male (LACM), BRAZIL: GO, Veadeiros, 1.V.1956. Paratypes, 4 ㅇ same locality as holotype 27.IV-1.V.1956 (2우 including allotype LACM, 19 JTPC, 19 NCTN). All macropterous.

\section{Description}

Macropterous form (based on dry pinned specimens). - Generally a rather small, elongate oval, light to medium brown species. Dimensions: length $\delta$ 7.42 \% 7.29-7.50, width of $4.92+4.93-5.0$, anterior width of vertex $\$ 1.36+1.39-1.40$, width of pronotum $\hat{0} 4.30$ \% $4.27-4.30$, median length of pronotum $\$ 1.69$ \& 1.64-1.70, lateral length of pronotum $\delta 2.00$ क $2.00-2.08$, median length of head+pronotum ô 2.63 ㅇ 2.60-2.68.

Colour. - Dorsally head and pronotum yellowish, eyes dark brown to blackish. Interoculus with a well defined median brown mark consisting of a semicircular posterior and a triangular anterior part, disk of pronotum mottled with brown. Scutellum and hemielytra medium brown mottled with yellow, embolium largely yellow. Exposed part of connexiva yellowish, anterior part of segments light brown. Venter yellowish to light brown, legs yellowish.

Structural characteristics. - Anterior margin of head following the curvature of pronotum and eyes. Anterior width of vertex 1.2 times the synthlipsis (1.38/
1.11); length of head distinctly shorter than median length of pronotum (1.31/1.70); length of an eye less than twice its width (1.00/0.58); anteclypeus projecting 0.06-0.10 anteriorly of labrum. Labrum parallelsided in basal half, converging to a very obtuse tip in apical half, its basal width 1.3 times the median length (0.51/0.40). Pronotum with lateral angles ill defined, broadly rounded, maximal width $0.5-0.7$ removed from median part of posterior margin, central area not elevated, lateral margin smooth; maximal width 1.7 times anterior width (4.29/2.46) and 2.1 times the lateral length (4.29/2.04). Scutellum 2.3 times as wide at base as its median length (2.65/1.15) and 2.1 times as long as claval commissure (1.15/0.54). Hemielytra leaving a narrow (0.2-0.3 wide) smooth strip of abdomen exposed. Embolium with lateral margin smooth to very faintly serrate, virtually straight, diverging posteriorly. Posterior part smoothly curved, posterolateral lateral angle poorly defined (fig. 142). Width across embolium distinctly larger than maximal width across connexiva (4.9/4.5), claval suture and nodal furrow distinct, right membrane coriaceous, broadly rounded, covering left membrane, membranal suture absent, except for being thinner of the same texture as corium. Left membrane well developed, membranaceous, velvety brown. Hind wings well developed. Connexival segments not indented forming a continuous lateral margin of abdomen, segments five and six with spinose posterior angles. Margin of connexiva distinctly serrate, at segment 4 with 20 teeth $/ \mathrm{mm}$. Granulations very fine, pale, sunk into the dorsal surface. Prosternal carina hardly slanting posteriorly, with a distinctly bifid knob anteriorly. Mesosternal carina (fig. 136, 137), well developed, posterior sloping part about one fourth of its total length, central part narrow with a shallow fossa about one third of its total length, anterior part strongly sloping, anterior tooth only weakly developed. Pubescence of venter consisting of a dense layer of very short hairs with sparse long ones superimposed. Fore femur about twice as long as wide (1.75/0.91). Middle femur nearly six times as long as wide $(1.81 / 0.31)$ and 1.6 times as long as middle tibia (1.81/1.15). Hind femur 6.0 times as long as wide $(2.40 / 0.40)$ and longer than hind tibia (2.40/2.17).

Male. - Genital segments as in fig. 134, right lobe of tergite with a vestigial proximal projection. Right pseudoparamere slender with widened tip in inner view (fig. 138).

Female. - Genital operculum (fig. 135) lateral margin straight to slightly concave with a pair of tufts of long hairs about midway, apex narrowly rounded.

Brachypterous form unknown. 


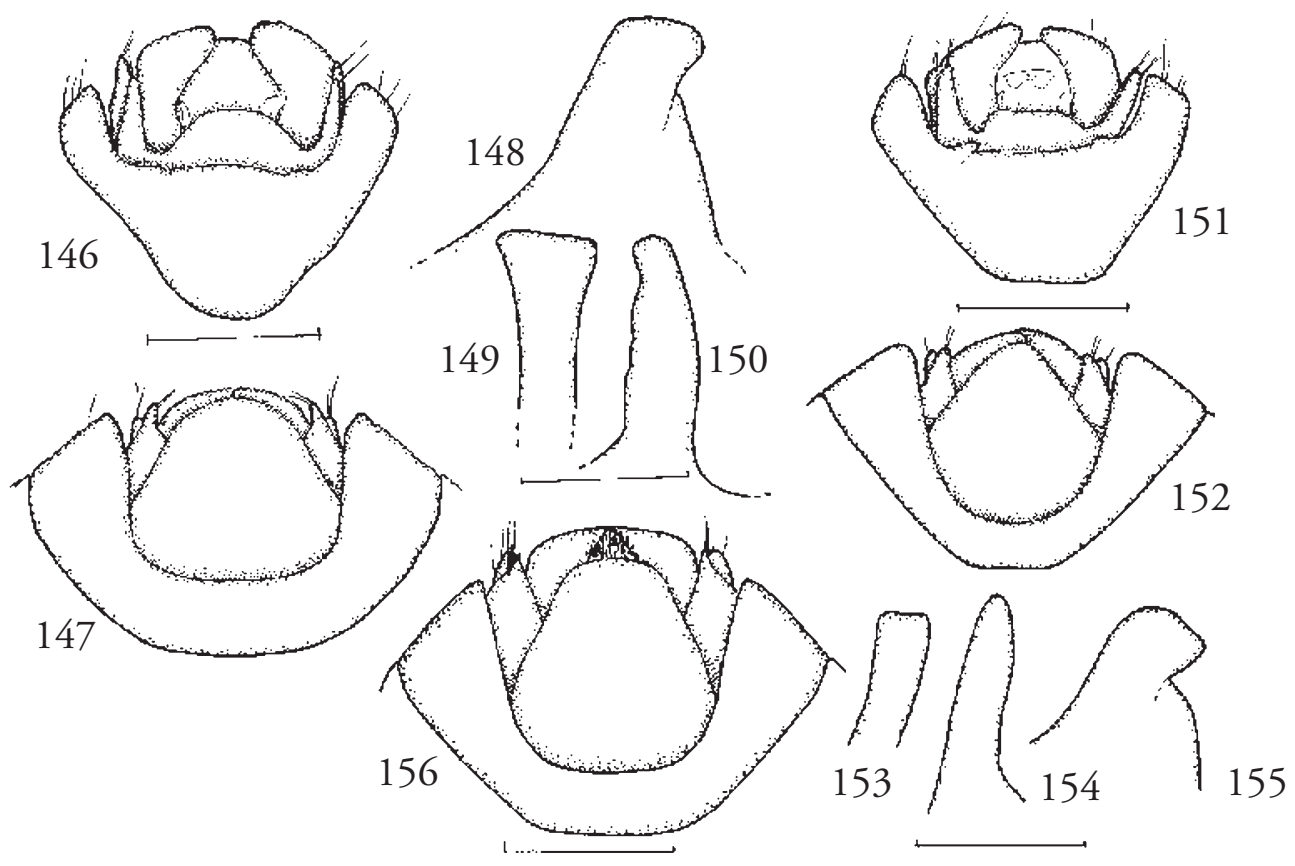

Figs. 146-150. Limnocoris porphyros paratypes. - 146, male, apex of abdomen dorsal view; 147, female, apex of abdomen, ventral view; 148, left pseudoparamere; 149, 150, right pseudoparamere, 149, medial view, 150, dorsal view. Scales 146 , 147 $1 \mathrm{~mm}, 148-1500.25 \mathrm{~mm}$.

Figs. 151-155. Limnocoris saphis paratypes. - 151, male, apex of abdomen, dorsal view; 152, female, apex of abdomen, ventral view; 153, 154, right pseudoparamere, 153, medial view, 154, dorsal view; 155, left pseudoparamere. Scales 151,152 $1 \mathrm{~mm}, 153-1550.25 \mathrm{~mm}$.

Fig. 156. Limnocoris subpauper holotype female, apex of abdomen, ventral view, scale $1 \mathrm{~mm}$.

\section{Etymology}

Named after the Machris family who financed the expedition during which this species was collected (Truxal 1957).

\section{Distribution}

Brazil: Goiás.

\section{Comparative notes}

L. machrisi belongs to the L. maculiceps-group, it is similar in general shape, size and colour to $L$. bruchi De Carlo from the Rio Xingu basin, this has the posterolateral angles of connexiva spinose from segment 4 posteriorly and a larger fossa on the mesosternal carina. Its elongate shape compared with a rather small size sets it apart from other species in the area under consideration.

\section{Limnocoris porphyros sp. $\mathbf{n}$.}

(figs. 143, 146-150, 191-192)

Type material. - Holotype brachypterous male (DPIC), BRAZIL: MG, Bacia do Rio Doce, Ribeirão Indaía, 1100m, VIII.1993, leg. L. Rocha. Paratypes $90^{\widehat{0}}$ 5 ㅇ same data as holotype distributed as follows: 1 ㅇ (allotype) DPIC, 10 JTPC, $3 \delta^{\star} 3$ ㅇ NCTN, 10 NHMW, 101 tक MLPA, 10 ZMAN. Additional paratypes: Bacia do Rio Doce, $\pm 1100 \mathrm{~m}, 27$. VIII.1991, leg. L. Rocha,

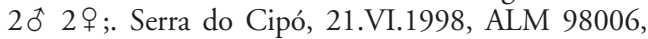
leg. A. Lane de Melo, 1 đ 2 ㅇ, 1 lvV, 2 lvIV (DPIC, $1 \uparrow, 1 \mathrm{lvV}$ NCTN). All brachypterous.

\section{Description}

Brachypterous form (based mainly on alcohol specimens). - Generally a small to medium sized, dark brown with a pair of lighter spots on hemielytra, broadly oval species. Dimensions: length ot 7.6-7.88.0 \{HT 7.80\} क् 7.70-8.0-8.4, width ô 5.7-5.8-5.9 
$\{5.78\}$ ? 5.8-5.8-5.9, anterior width of vertex $\sigma^{t}$ $1.58-1.65-1.72\{1.61\}$ o $1.70-1.72-1.77$, width of pronotum ot 4.93-5.03-5.12 \{5.12\} क 5.11-5.165.20 , median length of pronotum o $1.38-1.39-1.40$ $\{1.38\}$ o $1.42-1.44-1.47$, lateral length of pronotum of 2.05-2.18-2.30 \{2.30\} ㅇ $2.30-2.32-2.33$, median length of head+pronotum ot 2.48-2.63-2.75 $\{2.71\}$ o 2.55-2.63-2.74.

Colour. - Dorsally medium to dark brown with a purplish hue apical part of corium lighter. Median part of head, disk of pronotum extending laterally to a variable extent, scutellum, basal third of hemielytra except lateral two-thirds to three-quarters of embolium medium to dark brown with a purplish hue. Membrane dark brown with indistinct blackish mottling. Lateral third of interoculus, lateral margin of pronotum anterolateral two-thirds to three-quarters of embolium and apical half of corium light to medium brown. Lateral margin of connexival segments dorsally dark with apical third light brown; medianly connexiva and dorsum of abdomen dull grey pruinose. Venter of head, lateral part of prosternum and legs light to medium brown, remainder of venter greyish pruinose.

Structural characteristics. - Anterior margin of head following the curvature of pronotum and eyes, not projecting. Median mark of interoculus well defined, broad posteriorly, slightly narrowing and expanding again between eyes, narrow anteriorly (fig. 143). Anterior width of vertex 1.1 times the synthlipsis (1.7/1.5); length of head slightly longer than median length of pronotum (1.48/1.41); length of an eye twice its width (1.07/0.54); anteclypeus projecting $0.15-0.20$ anteriorly of labrum. Labrum parallel-sided in basal half, converging to a very obtuse tip in apical half, its basal width one and a half times the median length $(0.45 / 0.31)$. Pronotum with lateral angles obtusely rounded, maximal width 0.5 removed from posterior margin, central area distinctly elevated, lateral margin distinctly serrate, about 25 teeth $/ \mathrm{mm}$; maximal width nearly twice anterior width (5.14/2.64) and 2.2 times the lateral length $(5.14 / 2.31)$. Scutellum twice as wide at base as its median length $(2.65 / 1.29)$ and twice as long as claval commissure (1.29/0.62). Hemielytra leaving a broad ( 0.7 wide) strip of abdomen exposed, inner three fourth of this area dull grey, wrinkled. Embolium with lateral margin only slightly convex pointing laterad up to obtuse posterolateral lateral angle (fig. 143), its lateral margin distinctly serrate, about 20 teeth/mm, width across embolium distinctly larger than maximal width across connexiva (5.8/5.5), claval suture absent, right membrane coriaceous, broadly rounded, covering left membrane, membranal suture absent, however, in all but one specimens membrane clearly delimitated because of darker colour. Left membrane well developed, membranaceous, velvety brown. Hind wings strongly reduced, reaching base of abdomen. Covered part of abdomen waxy medium rufous brown. Connexival segments not indented forming a continuous lateral margin of abdomen, last segment obtusely angulate posteriorly. Margin of connexiva serrate, at segment 4 with 19 teeth $/ \mathrm{mm}$. Granulations on top of dorsal surface. Prosternal carina very gradually slanting posteriorly, low and weakly bifid anteriorly. Mesosternal carina (figs. 191, 192), relatively small, posterior sloping part small, central part narrow with a shallow fossa, anterior part strongly sloping, anterior tooth only weakly developed. Pubescence of venter poorly developed. Fore femur about twice as long as wide (2.15/1.10). Middle femur nearly six times as long as wide $(2.01 / 0.34)$ and 1.4 times as long as middle tibia (2.01/1.41). Hind femur 6.7 times as long as wide (2.73/0.41) and as long as hind tibia $(2.73 / 2.72)$.

Male. - Genital segments as in fig. 146, proximal projection of right lobe of tergite 6 not differentiated. Right pseudoparamere slender with widened tip in inner view (fig. 149).

Female. - Genital operculum (fig. 147) lateral margin straight to slightly concave, apex broadly rounded.

Macropterous form unknown.

Larva V. - Length 7.3, width (across wing-pads) 5.82 , anterior width of vertex 1.60 , width of pronotum 5.40, median length of pronotum 1.01, lateral length of pronotum 1.92, synthlipsis 1.47 , median length of head+pronotum 2.22 . Colour, dorsally dirty yellow to light brown, head pattern as in adult, mesoalinotum, exposed part of metanotum, base of abdomen up to tergite 3 dark brown with purplish tinge. Abdominal tergite 3 laterally dark in basal half only, median part entirely dark. Lateral part of pronotum with some dark dots, light part of abdomen without such dots. Ventrally, prosternum and legs mostly yellowish, a transverse dark band corresponding to the dorsal dark pattern, abdominal venter medially brown laterally dirty yellowish with small dark patches anteriorly on each segment. Posterolateral angles of pronotum acute, on the same level as posterior margin. Mesosternal carina with a well developed central part with a shallow but distinct rather narrow fossa. Lateral margins of connexiva distinctly serrate, about 16 teeth $/ \mathrm{mm}$ on segment 4 .

\section{Etymology}

Porphyros, Greek adjective meaning purple, referring to the general colour of the species.

\section{Distribution}

Brazil: MG.

\section{Comparative notes}

L.porphyros belongs to the L.insignis-group and is 
very similar to $L$. espinolai sp. n., see under that species. The colour pattern with the light spots on apical half of corium is characteristic. Structural differences with species of roughly the same size and hemielytral structure are: embolium much more angular and maximal width of pronotum more posteriorly in L. acutalis. L. submontandoni and L. insignis both have the lateral angles of pronotum produced more posteriorly and more sharply defined. See also under L. asper.

Lane de Melo (personal communication) has reared $L$. porphyros and states that the larva has the same colour pattern as the larva of L. espinola.

\section{Limnocoris saphis sp. n.}

(figs. 144, 151-155, 197-198)

Type material. - Holotype brachypterous female (DPIC): BRAZIL: MG, Serra da Canastra, Córrego at the entrance at the west (Sacramento) side, 12.XI.1997, N9736. Stream in well developed gallery forest, water clear colourless, hyaline, pools (some over $1 \mathrm{~m}$ deep) connected by trickles of water, width on average $1 \mathrm{~m}$, depth on average $0.3-0.5 \mathrm{~m}$. Bottom sandy, at most places with leaf litter, leg. N. Nieser. Paratypes, same data as holotype $201 \%$, brach. (including allotype $\widehat{o}$ NCTN). Additional specimens $1 \mathrm{lvV}, 1 \mathrm{lvIV}$ (NCTN).

\section{Description}

Brachypterous form (based on alcohol specimens). - Generally a small, dark, broadly oval species with distinct light patches laterally on interoculus and pronotum. Dimensions (the holotype is the smaller female): length of 6.3-6.8 क 6.7-6.9, width of 4.75.0 क 4.9-5.0, anterior width of vertex ot 1.47-1.48 क 1.40-1.50, width of pronotum ô 4.28-4.42 क 4.28-4.41, median length of pronotum 0 1.30-1.31 क 1.29-1.30, lateral length of pronotum ô 1.91-1.97 o 1.85-1.94, median length of head+pronotum $\delta$ 2.38-2.40 क 2.37-2.42.

Colour. - Dorsally dark brown with a purplish hue especially on hemielytra, eyes blackish. Lateral third of interoculus and part of pronotum laterally of eyes yellow, demarcation between yellow and brown area sharp, especially on pronotum. Most of membrane and apical two thirds of connexival segments lighter than hemielytra. Right membrane concolorous with corium or slightly darker, left membrane velvety dark brown to blackish. Venter of head, pronotum laterally, fore legs, tibiae and tarsi yellowish, middle and hind femurs light brown, remainder of venter variegated pruinose grey and brownish with sparse, very short, golden pilosity, longer near midline on abdominal venter and genital segments.

Structural characteristics. - Anterior margin of head following the curvature of pronotum and eyes, not projecting. Anterior width of vertex 1.1 times the synthlipsis (1.44/1.29); length of head subequal to median length of pronotum (1.29/1.30); length of an eye 1.7 times its width $(0.93 / 0.54)$; anteclypeus projecting 0.08-0.10 anteriorly of labrum. Labrum with straight, slightly converging distally, lateral margins in basal half, obtusely rounded in apical half, its basal width 1.4 times the median length $(0.40 / 0.29)$. Pronotum with lateral angles obtusely rounded, maximal width 0.25 removed from posterior margin, central area distinctly elevated, lateral margin weakly serrate, not visible in dorsal view, about 30 teeth $/ \mathrm{mm}$; maximal width 1.9 times the anterior width (4.37/2.34) and 2.3 times the lateral length (4.37/1.90). Scutellum 1.9 times as wide at base as its median length $(2.29 / 1.19)$ and 1.7 times as long as claval commissure (1.19/0.69). Hemielytra leaving a 0.3-0.4 wide strip of connexiva exposed, of the same texture as pronotum and corium. Embolium with lateral margin softly convex, posterolateral angle obtuse (fig. 144), its lateral margin indistinctly serrate with about 17 teeth $/ \mathrm{mm}$, width across embolium larger than maximal width across connexiva (4.96/4.88), claval suture absent, right membrane coriaceous, smoother (due to finer granules) than corium, broadly rounded, covering left membrane, membranal suture absent. Left membrane reduced, its inner margin parallel to longitudinal body axis, membranaceous. Hind wings strongly reduced, reaching second visible abdominal tergite. Covered part of abdomen waxy light rufous brown. Connexival segments not indented, forming a continuous lateral margin of abdomen, last segment posteriorly obtusely angulate in male, narrowly truncate in females. lateral serration of connexiva distinct, segment 4 with 19 teeth $/ \mathrm{mm}$. Granulations on top of dorsal surface. Prosternal carina hardly slanting posteriorly, low and weakly bifid anteriorly. Mesosternal carina characteristic (figs. 197, 198), posteriorly distinctly sloping, central part small with a shallow fossa but strongly elevated and slightly sloping posteriorly; anterior part strongly sloping, nearly vertical, anterior tooth only weakly developed. Pubescence of venter poorly developed. Fore femur slightly less than twice as long as wide (1.86/0.97). Middle femur 5.3 times as long as wide (1.75/0.33) and about 1.4 times as long as middle tibia $(1.75 / 1.26)$. Hind femur about 6 times as long as wide $(2.32 / 0.39)$ and as long as hind tibia $(2.32 / 2.32)$.

Male. - Genital segments as in fig. 151, right lobe of tergite 6 with a small but distinct proximal projection. Right pseudoparamere slender (figs. 153, 154).

Female. - Genital operculum (fig. 152) lateral margins nearly straight, apex rounded.

Macropterous form unknown.

Larva V. - Length 5.9, width (across wing-pads) 
4.78 , anterior width of vertex 1.28 , width of pronotum 4.29, median length of pronotum 0.92 , lateral length of pronotum 1.64, synthlipsis 1.22 , median length of head+pronotum 1.91. The colour pattern, especially the strikingly dark pteronotum is different from other larvae seen so far except $L$. porphyros and L. espinolai see under that species for comment.

\section{Etymology}

Saphis (Greek adjective), meaning distinct, referring to the distinctly delimited colour pattern on head and pronotum.

\section{Distribution \\ Brazil: MG.}

\section{Comparative notes}

L. saphis belongs to the maculiceps-group. The colour pattern of head+pronotum and the mesosternal carina, with its small but strongly elevated central part giving it a pointed appearance, are characteristic.

\section{Limnocoris subpauper sp. n.}

(figs. 145, 156, 201-202)

Type material. - Holotype brachypterous female (NCTN): BRAZIL: SP, Serra do Descanço, IV. 1964, leg. F. Plaumann. Paratypes, BRAZIL, PR, Serra do Mar, Rio do Cervo, $25^{\circ} 14^{\prime} \mathrm{S} 49^{\circ} 01 \mathrm{~W}, 1200 \mathrm{~m}$, XII.1963, leg. F. Plaumann, 29 brach. (NCTN).

Remark. - The holotype will be transferred to RMNH.

\section{Description}

Brachypterous form (based on dry pinned females). - Generally a medium sized, flat, medium brown elongate oval species with slightly reduced hemielytra in brachypterous form. Dimensions, the holotype is the largest $q$ : length $q$ 7.9-8.1-8.2, width $q 5.32$ 5.36-5.43, anterior width of vertex $q$ 1.75-1.761.76, width of pronotum 9 4.79-4.84-4.90, median length pronotum + 1.48-1.49-1.50, lateral length of pronotum $\&$ 2.11-2.15-2.20, median length of head+pronotum 2.60-2.65-2.72.

Colour medium brown with indistinct dark mottling most noticeably on right membrane, interocular dots forming only an indefinite pattern, consisting of a double row of regular darker points wide apart enclosing a subcircular area posteriorly, anteriorly subparallel enclosing a narrower strip. Connexival segments yellowish, slightly infuscated anteriorly. Legs yellowish, abdominal venter shiny due to dense pilosity.

Structural characteristics. - Anterior margin of vertex following the curvature of pronotum and eyes, not protruding. Anterior width of vertex 1.2 times the synthlipsis (1.76/1.45), length of head subequal to the median length of pronotum (1.52/1.49), length of an eye over twice its width (1.21/0.54). Anteclypeus projecting 0.11-0.13 anteriorly of labrum. Lateral margins of labrum nearly parallel in basal part, apical half triangular with an acutely rounded tip, basal width larger than median length $(0.53 / 0.40)$. Pronotum with distinct, rounded posterolateral angles, which are at a level very slightly anteriorly of posterior margin (0.1-0.2), its maximal width less than twice the anterior width $(4.84 / 2.54)$ and 2.3 times the lateral length (4.84/2.15), lateral margin evenly convex, serrate ventrally, about 27 teeth $/ \mathrm{mm}$. Granulations on dorsum of body fine, lying in small pits. Scutellum over twice as wide at base than its median length (2.35/1.10) and of subequal length as claval commissure (1.10/1.12). Hemielytra leaving a narrow strip of connexiva $(0.25$ 0.30 wide) exposed. Embolium weakly convex, margins posterolaterally nearly straight and parallel, curving gradually inward posteriorly, posterolateral angle indistinct (fig. 145), lateral margin weakly serrate, approximately 20 teeth $/ \mathrm{mm}$; maximal width across embolium only slightly larger than maximal width across connexiva (5.36/5.23). Claval suture and right membranal suture absent, right membrane coriaceous, reduced, broadly rounded, right hemielytron covering a median strip of left hemielytron. Lateral and apical part of left membrane coriaceous, bluntly pointed, not covered by right hemielytron, inner strip of hemielytron covered by right hemielytron membranaceous, dark velvety brown to blackish, sutured off by the difference in structure between coriaceous and membranaceous part. Hind wings vestigial. Dorsum of abdomen velvety yellowish brown. Connexival segments hardly indented, forming a nearly smooth outer edge of abdomen, posterolateral angle of last connexival segment bluntly rounded. Connexiva laterally distinctly serrate, segment 4 with about 25 teeth/mm. Prosternal carina distinctly elevated, sloping posteriorly and bifid anteriorly. Mesosternal carina with a comparatively small but well developed elevated widened part with a distinct broadly oval to rhomboid fossa (figs. 201, 202) which is placed rather posteriorly due to the very short distinctly sloping posterior part, posteriorly abruptly vertical; anterior part as long as widened part $(0.5 / 0.5)$ distinctly sloping to an indistinct anterior tooth which tops a vertical edge. Mesosternal fossa with small teeth anteriorly and posteriorly, moreover the lateral margins are sinuated as to suggest a low and blunt lateral tooth on each. Metasternal carina moderately developed consisting of a tubercle with a ventral fossa on central quarter of metaxiphus. Abdominal venter with dense golden yellow pilosity leaving only the serrate rim of connexiva exposed, but not extending onto meta- and meso-sternum. Fore femur 1.7 times as long as wide 
(2.07/1.25). Middle femur 4.3 times as long as wide $(1.95 / 0.45)$ and 1.3 times longer than middle tibia $(1.95 / 1.50)$. Hind femur 5.4 times as long as wide $(2.67 / 0.49)$ and slightly shorter than hind tibia (2.67/2.85). Female genital operculum about as long as wide (1.2/1.2), greatest width about basal third, apical part gradually tapering toward a truncate apex (fig. 156).

Male and macropterous form unknown.

\section{Etymology}

Subpauper, Latin compound adjective: sub (under) and pauper (poor), referring to the similarity in shape but smaller size compared to L. pauper.

\section{Distribution}

Brazil: PR, SP, only known by the type series.

\section{Comparative notes}

L. subpauper belongs to the L.maculiceps-group. Structurally, $L$. pauper and $L$. subpauper are nearly identical, although the posterolateral angles of the pronotum are somewhat more acute and pointing slightly more posteriorly in L. subpauper. The main difference is, however, the distinct difference in size; length in L. pauper +9 9.4-10.1, in L. subpauper $q$ 7.9-8.2 etc. As long as no intermediate specimens are found, we prefer to treat these as separate taxa.

\section{Checklist of species of Limnocoris Stål}

With indication of distribution and type depository.

We give a few notes at the end of the checklist. Species mentioned in the notes have been marked with an ${ }^{*}$ in the list. For depositories and abbreviations see introduction.

$$
\begin{aligned}
& \text { Limnocoris Stål, } 1860 \\
& \text { Borborocoris Stål, } 1861 \\
& \text { Usingerina La Rivers, } 1950 \\
& \text { Sattleriella De Carlo, } 1966 \\
& \\
& \text { abbreviatus La Rivers, } 1974 \\
& \text { montandoni la Rivers, } 1974 \\
& \text { Brazil: RJ, SC - HT: CASC. } \\
& \text { abrasum Nieser e.a., 1993 } \\
& \text { Colombia: Valle - HT: NCTN. } \\
& \text { aculabrum La Rivers, 1973 } \\
& \text { Brazil: SC - HT: CASC. } \\
& \text { acutalis La Rivers, 1974 } \\
& \text { Brazil - HT: ZMHB. } \\
& \text { alcorni La Rivers, 1976. } \\
& \text { Guatemala - HT: CASC. } \\
& \text { angulatus Nieser et al., } 1993 \\
& \text { Colombia: Valle - HT: NCTN. } \\
& \text { asper sp. n. }
\end{aligned}
$$

Brazil: MG - HT: DPIC. aymarana Poisson, 1954

Peru: South Peru - types lost ?

bergrothi Montandon, 1898*

Venezuela - HT: ? MZHF.

birabeni De Carlo, 1967

Brazil: PA - HT: ZSMC.

borellii Montandon, 1897

profundus Stål (nec Say), 1862

stali Montandon 1897

manco-capaci Poisson, 1954

Argentina: Salta; Bolivia; Peru: S. Peru-ST: BMNH, MITZ.

bouvieri Montandon 1898

Colombia: Bogota - HT: MNHN.

brailovskyi La Rivers, 1976

Mexico: Jalisco - HT: UNAM.

brasiliensis De Carlo, 1941

bergi De Carlo, 1941

Brazil: RJ, MG - HT: QBUM.

brauni De Carlo, 1966

Peru - HT: ZSMC.

bruchi De Carlo, 1967

Brazil: MT - HT: ZSMC.

burmeisteri De Carlo, 1967*

bachmanni De Carlo 1967

Brazil: AM, PA; Surinam - HT: ZSMC.

calii Nieser e.a., 1993

Colombia: Valle - HT: RMNH.

caraceae sp. n.

Brazil: MG - HT: NCTN.

carcharus La Rivers, 1976

Venezuela: Caracas - HT: ZMHB.

decarloisp. n.

Brazil: SC, RS - HT: ZSMC.

distanti Montandon, 1911

Mesoamerica: 'Manaure' - ST: BMNH.

dubiosus Montandon, 1898*

Chile; ? Venezuela; ? Martinique - HT: MNHN.

espinolaisp. n.

Brazil: MG - HT: DPIC.

exogkoma Manzano e.a. 1995

Colombia: Valle - HT: RMNH.

fittkaui fittkaui De Carlo, 1967

fittkaui De Carlo, 1967

fittkaui fittkaui Nieser, 1975

Brazil: AM - HT: ZSMC.

fittkaui surinamensis Nieser, 1975

Surinam - HT: UMUN.

gracilis Nieser e.a., 1993

Colombia: Valle - HT: NCTN.

hintoni La Rivers, 1970

Mexico: Mexico, Puebla, Guadalajara - HT: CASC.

illiesi De Carlo, 1967

Brazil: AM, MG - HT: ZSMC.

inornatus Montandon, 1898 
Guatemala - HT: ZMUH.

insignis Stål, 1897

ubleri Montandon, 1910

admontandoni La Rivers, 1974

Brazil: RJ, SP, PR, SC, RS - HT: NHRS.

insularis Champion, 1901

Honduras - HT: BMNH.

intermedius sp. $\mathrm{n}$.

Brazil: PR - HT: NCTN.

lanemeloisp. $\mathrm{n}$.

Brazil: MG - HT: DPIC.

laucki La Rivers, 1970

Mexico: Nayarit - HT: CASC.

lutzi La Rivers, 1957

USA: Texas, Guadalupe River - HT: LCPU, AT: CASC.

machrisisp. n.

Brazil: GO - HT: LACM.

maculatus De Carlo, 1951

Colombia: R. Bocon - HT: MACN.

maculiceps Montandon, 1897

Brazil: MT, MG - LT: MNHN.

malkini La Rivers, 1974

Colombia: Magdalena - HT: AMNH.

melloleitaoi De Carlo, 1951

Brazil: PR - HT: DZUP.

menkei La Rivers, 1962

Venezuela - HT: LACM.

minutus De Carlo, 1951

Argentina: Corrientes; Paraguay, Rio Paraguay HT: MACN.

moapensis (La Rivers, 1950, Usingerina)

USA: Nevada - HT: CASC.

nigropunctatus Montandon, 1909

sattleri De Carlo, 1966

Brazil: MG, RJ, SP, PR, SC - HT: UZMH.

obscurus Montandon, 1898

Colombia: Abejoral - HT: MNHN.

ochraeus Montandon, 1898

Colombia - HT: MNHN.

ovatulus Montandon, 1897

Argentina: Salta, Catamarca; Bolivia: Tarija - LT: BMNH.

pallescens (Stål, 1861, Borborocoris)

Venezuela, Colombia - HT: NHRS.

panamensis La Rivers, 1970

Panama - HT: CASC.

pauper Montandon, 1897

plaumanni La Rivers, 1973

Brazil: SP, PR, RS, 'Cumbase' - HT: BMNH.

pectoralis Montandon, 1897

peruvianus Melin, 1930*

Argentina: Salta, Jujuy; Bolivia: La Paz; Peru - LT:

NHMW.

porphyros sp. n.

Brazil: MG - HT: DPIC. profundus (Say, 1832, Naucoris)

Mexico - HT: USNM.

pulchellus La Rivers, 1974

Colombia: Sra. Nevada - HT: AMNH.

pusillus Montandon 1897

mansosotoi De Carlo 1951

vianai De Carlo 1967

Argentina: Northeast Argentina; Brazil: South

Brazil; Bolivia: East Bolivia; Colombia: Meta - LT:

BMNH.

pygmaeus La Rivers, 1956

Mexico: Guerrero - HT: SEMC.

rivalis Melin, 1930

Peru - ST: NHRS.

robustus Roback \& Nieser, 1974

Colombia: Meta. - HT: ANSP.

rotundatus De Carlo, 1951

Brazil: PR - HT: DZUP.

saphis sp. n.

Brazil: MG - HT: DPIC.

signoreti Montandon, 1897

Mexico - ST: NHMW, BMNH.

siolii (De Carlo, 1966, Sattleriella)

Brazil: SP - HT: ZSMC.

solenoides La Rivers, 1970

Mexico: Oaxaca - HT: AMNH.

stangei La Rivers, 1976

Mexico: Nayarit - HT: LACM.

submontandoni La Rivers, 1974

Brazil: SP, MG - HT: CASC.

subpauper sp. n.

Brazil: PR, SP - HT: NCTN.

trilobatus Nieser e.a., 1993

Colombia: Valle - HT: RMNH.

virescens Montandon, 1897

Costa Rica - HT: BMNH.

volxemi (Lethierry, 1877, Borborocoris)*

Origin unknown - ST: ??

woytkowskii La Rivers, 1970

Peru: Huanuco - HT: CASC.

De Carlo (1967) reports a number of holotypes to be kept in INPA, Manaus. They do not occur in the list of types by Adis e.a. (1985) who only mention some paratypes of these species. Dr. E.-G. Burmeister (in litt.) confirmed that these holotypes are in ZSMC as reported in the list below.

\section{Limnocoris bergrothi Montandon}

Remark: The HT was reported to be in Bergroth collection, MZHF but according to Jansson (1987) is missing. 


\section{Limnocoris burmeisteri De Carlo}

Limnocoris burmeisteri De Carlo, 1967: 197-198.

Limnocoris bachmanni De Carlo, 1967: 198-199. Syn. n.

We studied type material, including the holotypes of L. bachmanni and L. burmeisteri. There are some minute differences in curvature of embolium e.d. but sternal carinae, apex of male abdomen and female genital operculum are identical. L. burmeisteri is the senior synonym because of page priority.

\section{Limnocoris dubiosus Montandon}

Limnocoris dubiosus Montandon, 1898: 422-423.

Remark: Montandon (1898) mentions Chile as first locality. In view of present knowledge of distribution patterns it is doubtful that the specimens from Venezuela and especially Martinique would belong to the same species.

\section{Limnocoris malkini La Rivers}

Limnocoris malkini La Rivers, 1974: 8-9.

Limnocoris pulchellus La Rivers 1974: 9-10.

We studied 101 iq paratype of both species from CASC. They are quite similar and structurally also very similar to L. pallescens (Stål) which, however, is $1 \mathrm{~mm}$ smaller (Length malkini/pulchellus $9.2 \mathrm{~mm}$, pallescens 7.8-8.1 mm.). Because of the distance between localities they are not synonymized, in spite of the fact that the $q$ genital operculum is not different, contrary to the statement by La Rivers (1974).

\section{Limnocoris peruvianus Melin}

Limnocoris peruvianus Melin, 1930: 194-196.

Remark: For the synonymy, see discussion under L. pectoralis in the text.

\section{Limnocoris volxemi (Lethierry)}

Borborocoris volxemi Lethierry, 1877: 41.

Remark: The identity and origin of this species is unclear. It was described from Portugal which, in view of the fact that the description fits a species of Limnocoris, is an error. The fauna of Portugal as far as naucoroids are concerned contains only the genera Aphelocheirus, Naucoris and perhaps Ilyocoris (Nieser e.a. 1994). The size and mentioning of the deeply excavated mesosternal carina reminds of $L$. pectoralis.

\section{RESUMEN}

Revisión de las especies del género Limnocoris Stål del área Sudeste de Bolivia, Sureste y Sur del Brasil, Paraguay, Uruguay y Norte de la Argentina, con clave de identificación de especies. Se describen diez especies: $L$. asper, L. caraceae, $L$. decarloi, L. espinolai, L. intermedius, L. lanemeloi, L. machrisi,
L. porphyros, L. saphis y L. subpauper, todas del sur de Brasil. Se designan lectotipos de cuatro especies: L. maculiceps Mont., L. ovatulus Mont., L. pectoralis Mont. and L. pusillus Mont. Se establecen las siguientes sinonimias nuevas entre []: L. borellii Mont. [L. manco-capasi Poiss., L. stali Mont.]; L. burmeisteri De C. [L. bachmanni De C.]; L. insignis Stål [ $L$. uhleri Mont., L. admontandoni La R.] L. nigropunctatus Mont. [L. sattleri La R.]; L. pauper Mont. [L. plaumanni La R.]; L. pusillus Mont. [L. mansosotoi De C., L. vianai De C.]. Se anexa una lista de todas las especies del género Limnocoris con sinonimias y ubicación de los holotipos.

Palabras clave. - Naucoridae, Limnocoris, especies nuevas, designación de lectotipos, sinonimias nuevas, Argentina, Sur del Brasil, clave, catálogo.

\section{RESUMO}

Revisão das espécies do gênero Limnocoris Stål que occorrem na região Sudeste da Bolivia, Sudeste e Sul do Brasil, Paraguai, Uruguai e Argentina, com chave de identificação das espécies dessa área. São descritas dez espécies novas: $L$. asper, L. caraceae, L. decarloi, L. espinolai, L. intermedius, $L$. lanemeloi, L. machrisi, L. porphyros, L. saphis and L. subpauper todas do sul do Brasil. Se designam lectotipos de quatro especies: L. maculiceps Mont., L. ovatulus Mont., L. pectoralis Mont. and L. pusillus Mont.

As siguintes sinonímias são estabelecidas, sinomímias jovens entre []: L. borellii Mont. [L. manco-capasi Poiss., L. stali Mont.]; L. insignis Stål [L. uhleri Mont., L. admontandoni La R.]; L. nigropunctatus Mont. [L. sattleri La R.]; L. pauper Mont. [L. plaumanni La R.]; L. pusillus Mont. [L. mansosotoi De C., L. vianai De C.]. Também é anexada uma lista de todas as espécies do gênero Limnocoris.

Palavras chave. - Naucoridae, Limnocoris, espécies novas, sinonimias novas, Argentina, Sul do Brasil, chave, catalogação.

\section{REFERENCES}

Adis, J., Junk, W. J. \& Penny, N. D., 1985. Material zoológico depositado nas coleções sistemáticas de entomologia do INPA, resultante do 'projecto INPA/Max-Planck (Convênio CNPq/MPG). - Acta Amazonica 15: 481-504.

Arnett, R.H., Samuelson, G.A. \& Nishida, G.M., 1993. The Insect and Spider Collections of the World (Ed. 2). - Flora \& Fauna Handbooks 11: i-vi, 1-310.

Champion, G. C., 1901. Rhynchota Hemiptera-Heteroptera 2. Biologia Centrali Americana: 1-416, pls. 1-22.

De Carlo, J.A., 1941. Descripción de dos especies nuevas del género Limnocoris Stal. - Revista de la Sociedad Entomológica Argentina 11: 37-41.

De Carlo, J.A., 1951. Género Limnocoris Stal (Hem. Naucor.). - Misiones de Estudios de Patologia Regional Argentina 22: 41-51.

De Carlo, J.A., 1954. Alotipo de Limnocoris bergi y L. brasiliensis. - Revista de la Sociedad Entomológica Argentina 17: 13-14.

De Carlo, J.A., 1966. Un nuevo género y nuevas especies de las subfamilias Limnocorinae y Ambrysinae (Hemiptera, Naucoridae). - Revista de la Sociedad Entomológica Argentina 28: 111-117.

De Carlo J.A., 1967. Una nueva especie del género Ranatra y nuevas especies de Naucoridae. - Amazoniana 1: 189-200. ICZN (International Commission on Zoological Nomeclature), 1999. International Code of Zoological Nomencla- 
ture. 4th Edition. International Trust for Zoological Nomenclature, London. xxix+306 pp.

Jansson, A., 1987. Lists of the insect types in the Zoological Museum, University of Helsinki. 1. Heteroptera: Nepomorpha. - Acta Entomologica Fennica 48: 1-9.

La Rivers, I., 1950. A new naucorid genus and species from Nevada. (Hemiptera). - Annals of the Entomological Society of America 43: 368-373.

La Rivers, I., 1956. A new Limnocoris from Mexico (Hemiptera, Naucoridae). - Proceedings of the Entomological Society of Washington 58: 92-94.

La Rivers, I., 1957. A Limnocoris for the United States (Hemiptera: Naucoridae). - Pan-pacific Entomologist 33: 71-75.

La Rivers, I., 1962. A new Limnocoris from Venezuela. Proceedings of the Entomological Society of Washington 64: 195-196.

La Rivers, I., 1970. New species of Limnocoris from Latin America (Hemiptea, Naucoridae). - Biological Society of Nevada Occasional Papers 23: 1-10.

La Rivers, I., 1971. Catalogue of taxa described in the family Naucoridae (Hemiptera). - Biological Society of Nevada Memoirs 2: 65-99.

La Rivers, I., 1973. Two new species of Limnocoris from Brazil (Hemiptera, Naucoridae). - Biological Society of Nevada Occasional Papers 35: 1-7.

La Rivers, I., 1974. Catalogue of taxa described in the family Naucoridae (Hemiptera) Supplement 1. Biological Society of Nevada Occasional Papers 38: 1-17.

La Rivers, I., 1976. Catalogue of taxa described in the family Naucoridae (Hemiptera) Supplement 2. Biological Society of Nevada Occasional Papers 41: 1-17.

La Rivers, I. \& Nieser, N., 1972. The Ambrysus of Surinam with the description of a new species, A. bifidus (Hemiptera, Naucoridae). - Biological Society of Nevada Occasional Papers 29: 1-8.

Lethierry, L., 1877. Relevé des Hémiptères recueillis en Portugal et en Espagne par M. C. van Volxem en Mai et Juin 1871. - Annales de la Société Entomolgique de Belgique 20: 40-43.

Lopez Ruf, M. L., 1991. El genero Cryphocricos en la Argentina (Hemiptera-Limnocoridae). - Revista de la Sociedad Entomológica Argentina 49: 103-120.

Lopez Ruf, M. L., 1993. Descripción de ninfas de Limnocoris ovatulus Montandon (Heteroptera: Limnocoridae). - Revista de la Sociedad Entomologica Argentina 52: 17-20.

Manzano, M. del R., Nieser, N. \& Caicedo, G., 1995. Lista preliminar de Heterópteros acuáticos en la Isla Gorgona y Llanura del Pacífico. - Biblioteca José Jeronimo Triana 11: 47-72.

Melin, D., 1930. Hemiptera from South and Central America I. - Zoologiska Bidrag fran Uppsala 12: 151-198.

Montandon, A.L., 1897. Hemiptera Cryptocerata. Revision de le S. Fam. 'Limnocorinae'. - Bollettino del Musei di Zoologia et Anatomia Comparata della R. Università di Torino 12 (297): 1-8.

Montandon, A.L., 1898. Hemiptera Cryptocerata. Fam. Naucoridae. - Sous-fam. Limnocorinae. - Verhandlungen der Zoologisch-Botanischen Gesellschaft in Wien 48: 414-425.

Montandon, A.L., 1909. Naucoridae descriptions d'espèces nouvelles. - Bulletin de la Société de Sciences de Bucarest 18: 43-61.

Montandon, A.L., 1910. Trois espèces nouvelles de la famille Naucoridae. - Bulletin de la Société de Sciences de Bucarest 19: 438-444.

Montandon, A.L., 1911. Deux espèces nouvelles de la fam. Naucoridae (Hem.). - Bulletin de la Société de Sciences de Bucarest 19 (1910): 1268-1271.

Nieser, N., 1975. The water bugs (Heteroptera: Nepomorpha) of the Guyana Region. - Studies on the Fauna of Suriname and the other guyanas 16: 1-308, 24 pls.

Nieser, N., Baena, M., Martinez-Aviles, J. \& Millán, A., 1994. Claves para la identificación de los heterópteros acuáticos (Nepomorpha \& Gerromorpha) de la Península Ibérica. - Asociación Española de Limnologia, Claves de Identificación 5: 1-112.

Nieser, N., Gonzáles, R. \& Eichelkraut, K., 1993. Nuevas especies de Naucoridae Fallen, (Heteroptera: Nepomorpha). - Boletín del Museo de Entomología de la Universidad de la Valle 1: 1-11.

Nieser, N. \& Lane de Melo, A., 1997. Os heterópteros aquáticos de Minas Gerais. - Editora UFMG, Belo Horizonte, MG, Brazil: 1-180.

Nieser, N., \& Lane de Melo, A., 1999. Limnocoris bergi De Carlo, a new junior synonym of L. brasiliensis De Carlo (Heteroptera, Naucoridae). - Revista Brasileira de Zoologia 16: 1235-1236.

Nieser, N., Pelli, A. \& Lane de Melo, A.L. de, 1999. Two new Ambrysinae (Heteroptera: Naucoridae) from Minas Gerais (Brazil). - Acta Societatis Zoologicae Bohemicae 63: 157-163.

Poisson, R. A., 1954. Hydrocoridae (Heteropt.). - in: E. Titschack (Ed.) Beiträge zur Fauna Perus 4: 63-80.

Polhemus, J.T., 1994. Stridulatory mechanisms in aquatic and semiaquatic Heteroptera. - Journal of the New York Entomological Society 102: 270-274.

Roback, S.S. \& Nieser, N., 1974. Aquatic Hemiptera (Heteroptera) from the Llanos of Colombia. - Proceedings of the Academy of Natural Sciences of Philadelphia 126: 29-49.

Say, T., 1832. Descriptions of new species of Heteropterous Hemiptera of North America. - New Harmony, Indiana: 1-39.

Signoret, V., 1850. Description d'un genre nouveau de l'ordre des Hémiptères-Hétéroptères, et de la section des $\mathrm{Hy}$ drocoryses. - Revue et Magasin de Zoologie Pure et Appliquée 2: 289-291.

Sites, R.W., 1991. Egg ultrastructure and descriptions of nymphs of Pelocoris poeyi (Guérin Méneville) (Hemiptera: Naucoridae). - Journal of the New York Entomological Society 99: 622-629.

Sites, R.W. \& Nichols,B.J., 1990. Life history and descriptions of immature stages of Ambrysus lunatus lunatus (Hemiptera: Naucoridae). - Annals of the Entomological Society of America 83: 800-808.

Sites, R.W. \& Willig, M.R., 1991. Microhabitat associations of three sympatric species of Naucoridae (Insecta: Hemiptera). - Environmental Entomology 20: 127-134.

Sites, R.W. \& Willig, M.R., 1994. Efficacy of mensural characters in discriminating among species of Naucoridae (Insecta: Hemiptera): Multivariate approaches and ontogenetic perspectives. - Annals of the Entomological Society of America 87: 803-814.

Stål, C., 1860. Bidrag till Rio Janeiro-Trakens HemipterFauna. - Kungliga Svenska Vetenskapsakademiens Handlingar 2(7) (1858): 1-84.

Stål, C., 1861. Nova methodus familias quasdam Hemipterorum disponendi. - Ofversigt af Kungliga Svenska Vetenskapsakademiens Förhandlingar 18: 195-212. 
Stål, C., 1862. Hemiptera mexicana enumeravit speciesque novas descriptsit. - Stettiner Entomologische Zeitung 23: 437-462.

Stål, C., 1876. Enumeratio Hemipterorum 5. - Kungliga Svenska Vetenskapsakademiens Handlingar 14: 1-162.

Thorpe, W.H. \& Crisp, D.J., 1947. Studies on plastron respiration I-III. - Journal of Experimental Biology 24: $227-$ 269, 270-303, 310-328.

Truxal, F.S., 1957. The Machris brazilian expedition. Entomology. General and systematics of Notonectidae. - Los Angeles County Museum Contributions in Science 12: 3-23.

Usinger, R.L., 1947. Classification of the Cryphocricinae (Hemiptera: Naucoridae). - Annals of the Entomological Society of America 40: 329-343.

Received: 13 November 2000

Accepted: 27 March 2001

\section{INDEX}

abbreviatus La Rivers, 1974 . . 267-269, 270, 276, 309, 318 abrasum Nieser et al., 1993. . . . . . . . . . . . . 318 aculabrum La Rivers, 1973 . . . . . . . . . . . 269-270, 283,318 acutalis La Rivers, 1974 . . . . . . . . . . 270, 272, 316, 318 admontandoni La Rivers, 1974 . . . . . . . . . . . 279, 319

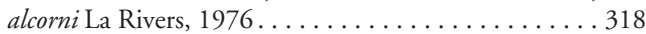
angulatus Nieser et al., 1993 . . . . . . . . . . . 293, 318 asper sp. n. . . . . . . . . 300, 301-302, 318, 327 aymarana Poisson, $1954 \ldots \ldots \ldots \ldots \ldots \ldots \ldots 318$ bachmanni De Carlo 1967 . . . . . . . . . . . . . . 318, 319 bergi De Carlo, $1941 \ldots \ldots \ldots \ldots \ldots \ldots \ldots \ldots$. . . . 275, 318 bergrothi Montandon, 1898 . . . . . . . . . . . 318, 319 birabeni De Carlo, 1967 . . . . . . . . . . . . . . . . . 318 Borborocoris Stål, $1861 \ldots \ldots \ldots$. . . . . . . 265, 318 borellii Montandon, $1897 \ldots$. . . . . 270, 273-275, 318, 323 bouvieri Montandon $1898 \ldots \ldots \ldots \ldots \ldots \ldots \ldots \ldots$ brailovskyi La Rivers, 1976 . . . . . . . . . . . . . . . 318 brasiliensis De Carlo, 1941 . . 270, 274, 275-276, 284, 318 brauni De Carlo, 1966 . . . . . . . . . . . . . . 318 bruchi De Carlo, 1967 ................ 314, 318 burmeisteri De Carlo, 1967* . . . . . . . . . . 318, 320 calii Nieser et al., $1993 \ldots \ldots \ldots \ldots \ldots \ldots \ldots \ldots 318$ caraceae sp. n. ......... 300, 302-304, 308, 318, 323

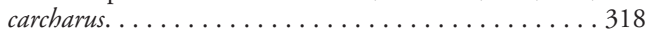
decarloi sp. n. ........ 287, 303-305, 306, 318, 324 distanti Montandon, $1911 \ldots \ldots \ldots \ldots \ldots \ldots \ldots$ dubiosus Montandon, 1898* . . . . . . . . . 318, 320 espinolai sp. n.. . . . . . . 303, 3-4, 305-308, 316-318, 324 exogkoma Manzano et al. 1995 . . . . . . . . . . . . . 318 fittkaui De Carlo, 1967 . . . . . . . . . . . . . . . 318 gracilis Nieser et al., 1993 . . . . . . . . . . . . . . . . . 318 hintoni La Rivers, 1970 . . . . . . . . . . . . . . . . . 318 illiesi De Carlo, 1967 . . . . . . . . 276, 277-279, 318, 324 inornatus Montandon, 1898. . . . . . . . . . . 318

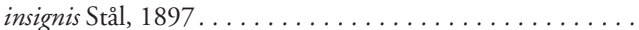
$265,276,278,279-281,316,319,324$ insularis Champion, $1901 \ldots \ldots \ldots \ldots \ldots$ intermedius sp. n.............. . 308-309, 319, 325 lanemeloi sp. n. . . . . . . . . . . . 303, 309-313, 319, 325 laucki La Rivers, 1970 . . . . . . . . . . . . . . . . . 319 Limnocoris Stål, 1860 . . . . . . . . . . . . . 265-266, 319 lutzi La Rivers, 1957 . . . . . . . . . . . . . . . . . . 319 machrisi sp. n. .......... 310, 312, 313-314, 319 maculatus De Carlo, 1951 . . . . . . . . . . . . . . . . 319 maculiceps Montandon, 1897 . . . . . . . . . . . . . .

. . . . . . . 264, 271-272, 278, 280, 319, 325 malkini La Rivers, $1974 \ldots . . \ldots \ldots \ldots . . . .319,320$ mancocapaci Poisson, 1954 . . . . . . . . 273, 275, 318 mansosotoi De Carlo 1951 . . . . . . . . . . . . 293, 319 melloleitaoi De Carlo, 1951 . . 280, 283-284, 291, 319, 325 menkei La Rivers, 1962. . . . . . . . . . . . . . . . . . . . 319 minutus De Carlo, 1951 . . . . . . . 277, 284-285, 319, 326 moapensis (La Rivers 1950) . . . . . . . . . . . . 265, 319 montandoni la Rivers, 1974 . . . . . . . . . . . . 267, 318

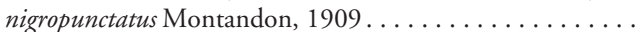
... 285-287, 288, 297, 301, 303, 305, 313, 319, 326 obscurus Montandon, 1898 . . . . . . . . . . . . . . . . 319 ochraeus Montandon, 1898 . . . . . . . . . . . . . 319 ovatulus Montandon, 1897 . . . . . . 286, 287-289, 319, 326 pallescens (Stål 1861) . . . . . . . . . . . . . . 265, 319 panamensis La Rivers, 1970 . . . . . . . . . . . . . . . . . . . . . . . . . pauper Montandon, 1897 $276,284,288,298-291,318,319,326$ pectoralis Montandon, 1897 . 289, 290, 291-293, 319, 320 peruvianus Melin, 1930 . . . . . . . . . . . . 291, 319, 320 plaumanni La Rivers, 1973 . . . . . . . . . . . . 289, 319 porphyros sp. n. . . . . 302, 308, 314-316, 317, 319, 327 profundus (Say, 1832) . . . . . . . . . . . . . . . . 319 profundus Stål, $1862 \ldots \ldots \ldots \ldots \ldots \ldots$. . . . . . . . . 318 pulchellus La Rivers, 1974 . . . . . . . . . . . . . . . . 319, 320 pusillus Montandon $1897 \ldots \ldots \ldots \ldots \ldots$. . . . . . . . . _. . . . 277, 285, 288, 292, 293-295, 319, 327 pygmaeus La Rivers, 1956 . . . . . . . . . . . . . . . . . . 319 rivalis Melin, 1930 . . . . . . . . . . . . . . . . . . . . 319 robustus Roback \& Nieser, 1974 . . . . . . . . . . . 274, 319 rotundatus De Carlo, 1951 . . 295-297, 300, 309, 319, 327 saphis sp. n. . . . . . . . . . . . 308, 316-317, 319, 328 sattleri De Carlo, $1966 \ldots \ldots \ldots \ldots$. . . 285, 304, 305, 319 Sattleriella De Carlo, 1966 . . . . . . . . . . . . . . . 265, 318 signoreti Montandon, 1897. . . . . . . . . . . . . . . . . . . 319 siolii (De Carlo 1966) . . . . . . . . . . 265, 297-298, 319 solenoides La Rivers, 1970 . . . . . . . . . . . . . . . . . . 319 stali Montandon, $1897 \ldots \ldots \ldots$. . . . . . . . 273, 318 stangei. . . . . . . . . . . . . . . . . . . . 319 submontandoni La Rivers, 1974 . . . . . . . . . . . . . . . . . . . . . . 264, 269, 298-301, 316, 319, 328 subpauper sp. n...... 276, 284, 291, 317-318, 319, 328 surinamensis Nieser, $1975 \ldots \ldots \ldots \ldots \ldots \ldots$. . . . . . . 318 trilobatus Nieser et al., 1993 . . . . . . . . . . . . . . . . . 319 uhleri Montandon, 1910 . . . . . . . . . . 279, 281, 319 Usingerina la Rivers, $1950 \ldots \ldots \ldots \ldots$. . . . . 265, 318 vianai De Carlo $1967 \ldots$. . . . . . . . . . . . . . . . . . . . 319 virescens Montandon, 1897. . . . . . . . . . . . . . 319 volxemi (Lethierry 1877) . . . . . . . . . . . . . . . 319, 320 woytkowskii La Rivers, 1970 . . . . . . . . . . . 319 

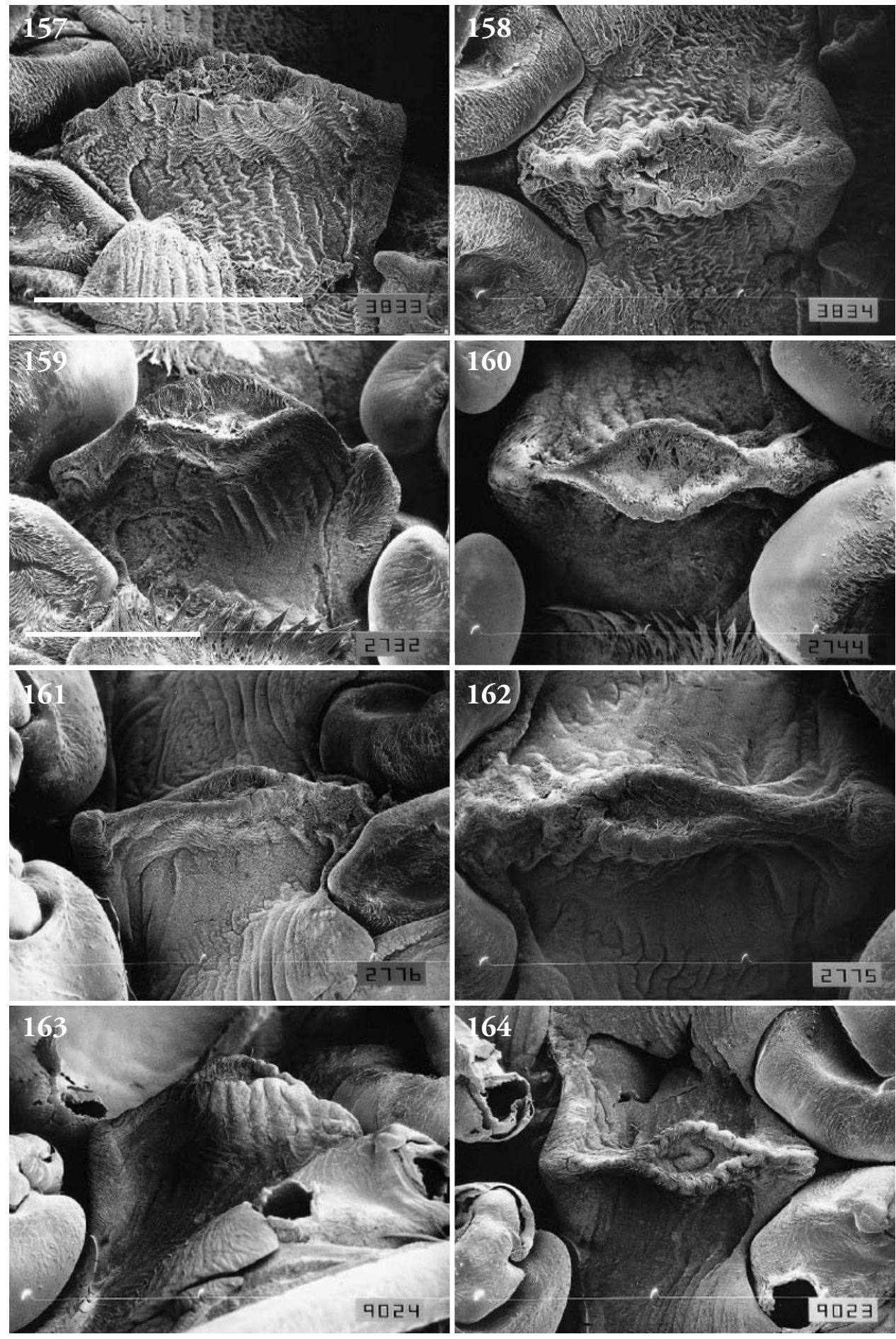

Captions: see page 328 

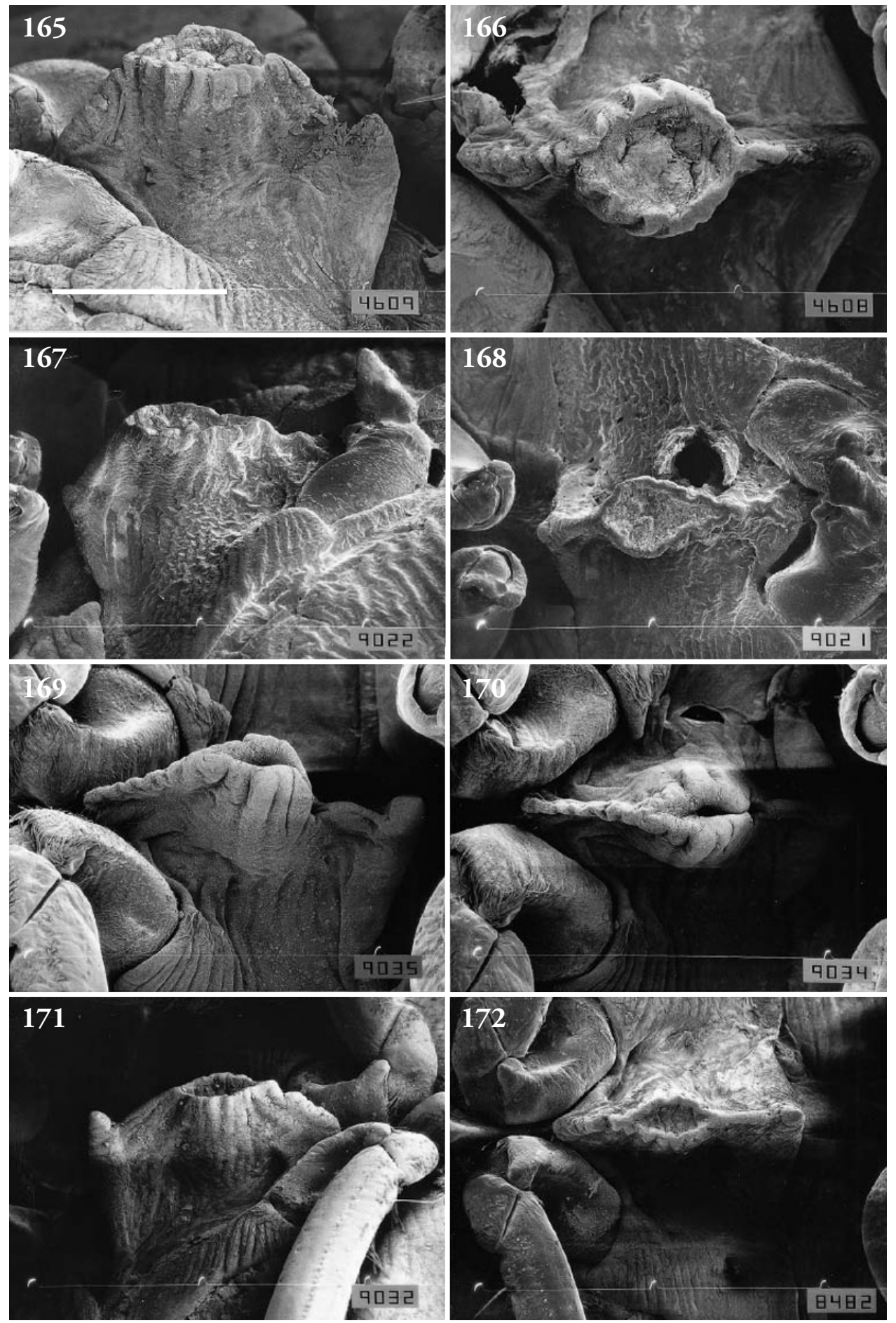

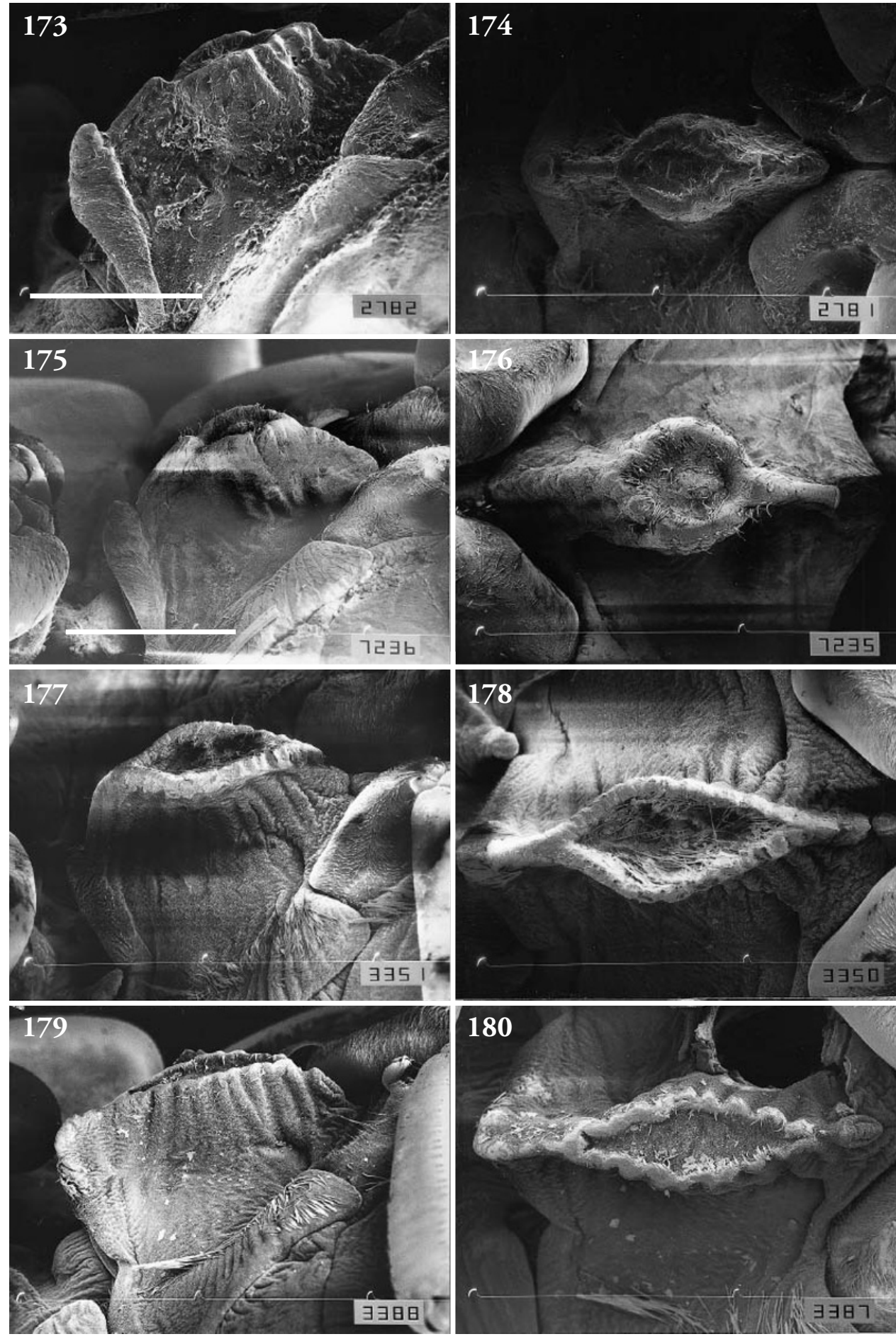

Captions: see page 328 

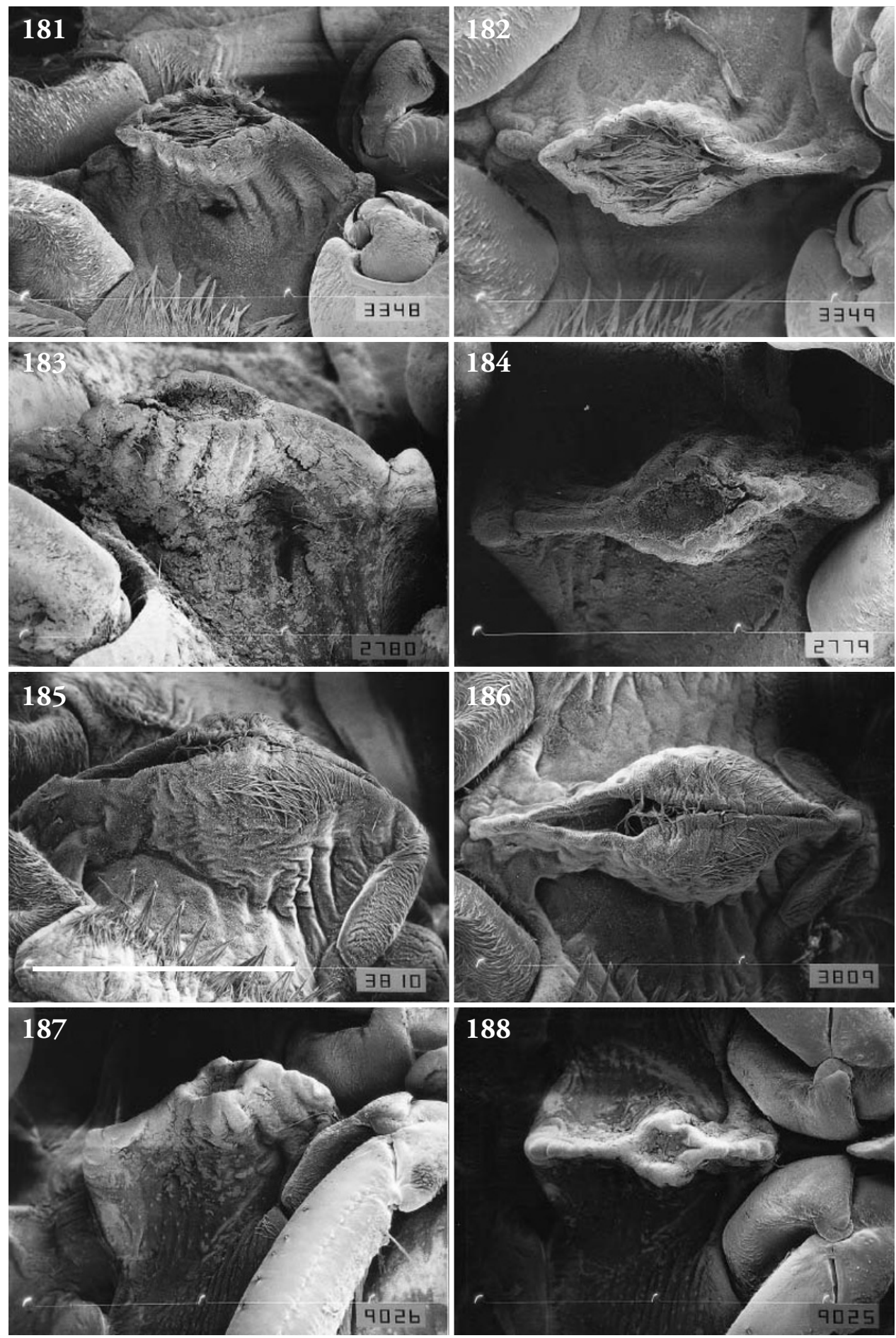

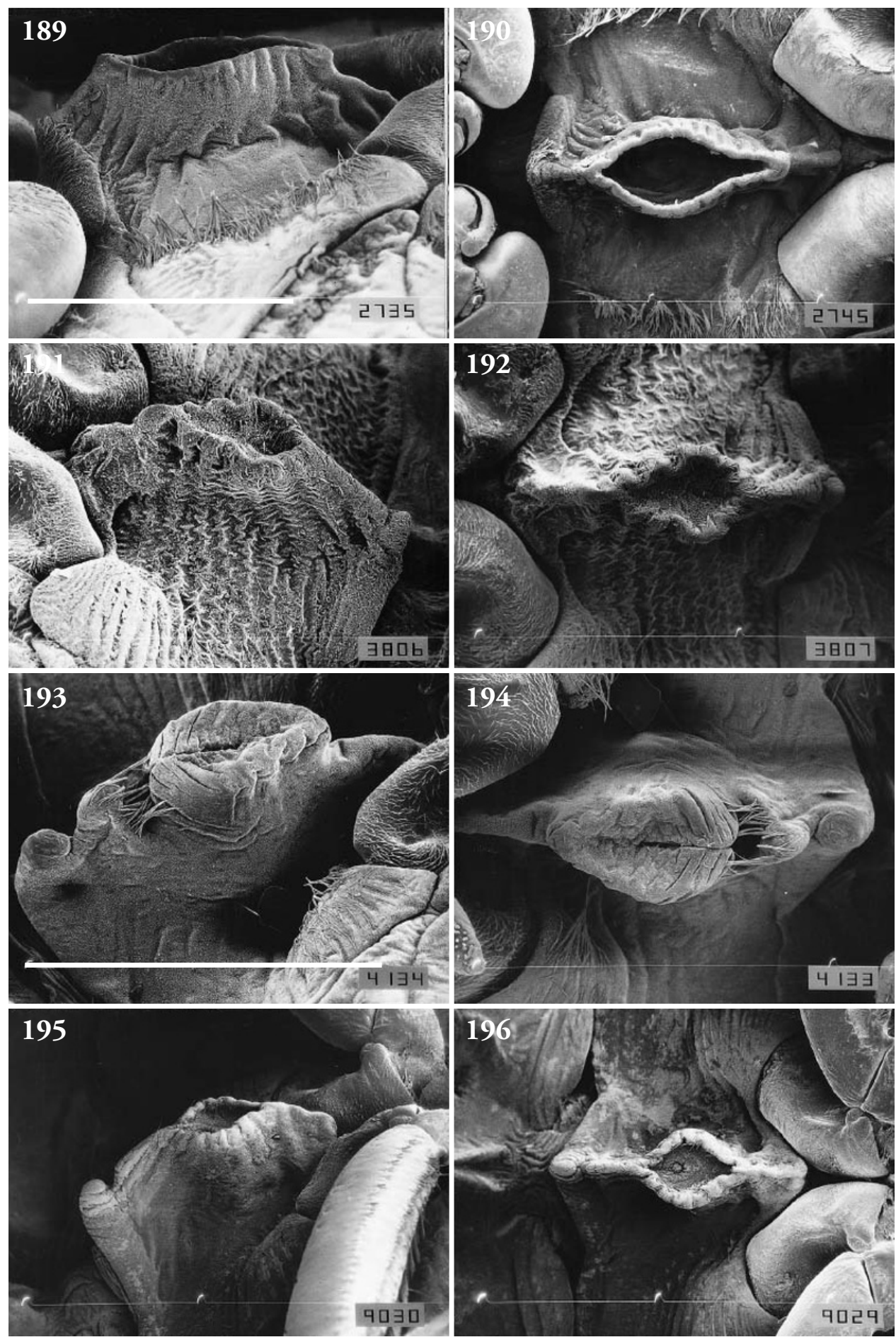

Captions: see page 328 

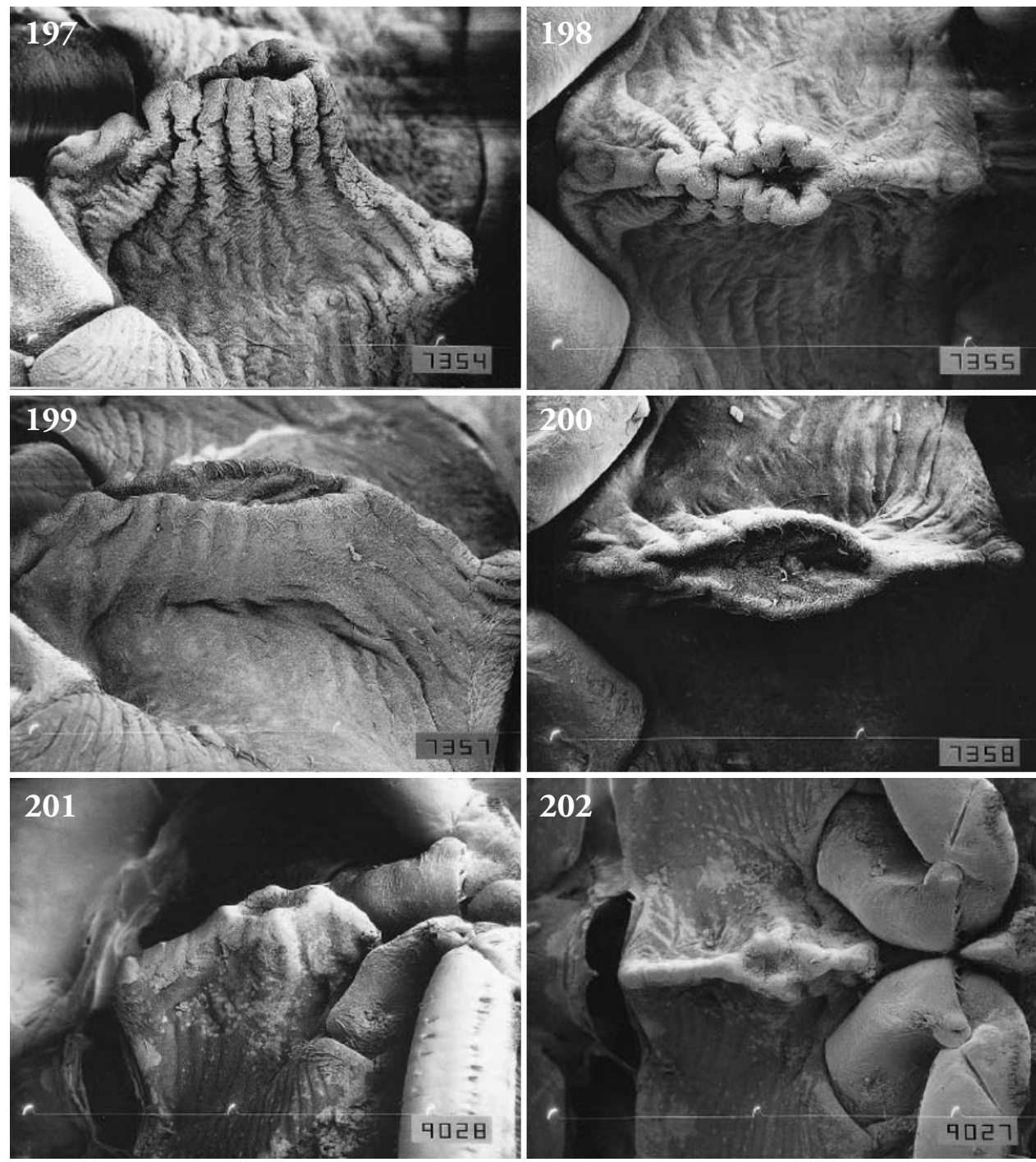

Figs. 157-202. Metasternal carina of Limnocoris species, anterior side to the left unless otherwise indicated; scales (between two 'teeth' on the photograph) $1 \mathrm{~mm}$. Left photographs lateral view, right ventral view.

157-158. L. asper, anterior side to the right.

159-160. L. borellii, anterior side to the right.

161-162. L. brasiliensis. - 161, anterior side to the left; 162 , anterior side to the right.

163-164. L. caraceae.

165-166. L. decarloi. - 165, anterior side to the right; 166 , anterior side to the left.

167-168. L. espinolai.

169-170. L. illiesi, anterior side to the right.

171-172. L. insignis. - 171, anterior side to the left; 172 , anterior side to the right.

175-176. L. lanemeloi.

177-178. L. maculiceps, anterior side to the right.

179-180. L. melloleitaoi, anterior side to the right.

181-182. L. minutus, anterior side to the right.

183-184. L. nigropunctatus. - 183, anterior side to the right;

184 , anterior side to the left.

185-186. L. ovatulus, anterior side to the right.

187-188. L. pauper.

189-190. L. pectoralis.

191-192. L. porphyros.

193-194. L. pusillus. - 193, anterior side to the left; 194, anterior side to the right.

195-196. L. rotundatus

197-198. L. saphis, anterior side to the right.

199-200. L. submontandoni, anterior side to the right.

201-202. L. subpauper. 